\title{
5 XViri sacris faciundis, Matronae, Pueri, Puellae. Eine prosopografische Analyse der Acta saecularia Severiana
}

\author{
von François Chausson
}

Eine vollständige Prosopografie der Männer, Frauen und Kinder, deren Namen im commentarium der severischen Säkularspiele von $204 \mathrm{n}$. Chr. in verschiedenen Erwähnungen erscheinen, würde die Dimensionen dieser Studie sprengen. Dieses Kapitel enthält deshalb allgemeine und technische Überlegungen, die für die Erstellung des Textes herangezogen wurden. Daneben liefert es eine aktualisierte Liste der beteiligten Personen und kommentiert neue Lesarten. Giovanni Battista Pighi hatte in seiner Ausgabe bereits eine recht genaue Berechnung der Personennamen vorgenommen, auf die die Untersuchungen von Bärbel Schnegg und François Chausson regelmäßig zurückgegriffen haben. Die neue Edition des severischen commentarium bot die Gelegenheit, einen Versuch zu unternehmen, die Position jedes einzelnen Namens der Listen zu analysieren, um jeder erhaltenen oder fehlenden Nomenklatur einen Platz in der Inschrift zuzuweisen. Für die Erwähnung der Namen bei den einzelnen Personenbezeichnungen wird versucht, die verwendeten Regeln deutlich zu machen. Der durchschnittliche Platz, den jede Nomenklatur einnimmt, wird berechnet. Daneben wird ein Rahmen für den Verlauf der Namenslisten festgelegt, der die Grundlage für alle weiteren prosopografischen Arbeiten bilden könnte.

\section{I Die historiografische Tradition}

Jede Annäherung an die im commentarium von 204 n. Chr. enthaltenen Personenlisten muss auf einer langen historiografischen Tradition beruhen. Die Entdeckungen von I 890 führten im folgenden Jahrzehnt zu prosopografischen Studien von Theodor Mommsen (I89I und I892) und Christian Hülsen (I902) sowie zu Mitteilungen in der I897-I 898 veröffentlichten Prosopographia Imperii Romani. Die Funde neuer Fragmente aus dem Jahr 1930 lieferten weitere Passagen aus diesen Listen, womit sich die Kenntnisse über die Personen, deren Namen im Dokument enthalten waren, erheblich erweiterten. Diese Entdeckungen wurden von Pietro Romanelli (193 I), Christian Hülsen (1932), Jean Gagé (1932) und Ernst Diehl (1934) kurz darauf kommentiert. In den gleichen Jahren sorgten langfristige redaktionelle Projekte, wie die Realencyclopädie und die zweite Edition der Prosopographia Imperii Romani ab 1933, für eine regelmäßige Erweiterung der prosopografischen Kenntnisse. ${ }^{1}$ Daraus konnte Pighi bis zum fasciculum von 1936

I Zur Geschichte der Veröffentlichung der PIR² von 1933 bis 2015 siehe Eck (2017), I-94. 
zitieren, das den Buchstaben C enthielt; der Buchstabe D erschien erst I943, nach Erscheinen von Pighis Buch. Zur selben Zeit boten die Monografien von Pierre Lambrechts über den Senat einen guten Zugang zur Klärung prosopografischer Fragen. $^{2}$

Die Edition von Pighi aus dem Jahr i94I ist der wichtigste Ausgangspunkt aller neuen Arbeiten. Sie enthält zwei Kapitel zur Prosopografie mit den Titeln »Prosopographia ludorum septimorum« (S. 238-263) und »Prosopographia complementum«(S. 264-268). Diese stützen sich auf die neu veröffentlichten Mitteilungen in den oben genannten Nachschlagewerken. Pighi arbeitete an dem gesamten Dokument mit den 1930 entdeckten Fragmenten und konnte einen neuen Verlauf der Aufzeichnungen für die Personenlisten vorschlagen. Wie bereits gesagt wurde, bleiben seine Berechnungen im Allgemeinen solide und gültig und sollten als Grundlage für weitere Arbeiten dienen.

Seit Pighi hat kein Autor mehr eine vollständige Studie der Listen durchgeführt. In seiner Monografie über den Senatorenstand im 3. Jahrhundert beschäftigte sich Guido Barbieri jedoch in umfassender Weise mit allen Personen und schuf einen Überblick über die senatorischen Familien des 2. und 3. Jahrhunderts, ${ }^{3}$ wobei er auf onomastische Parallelen zurückgreifen konnte. ${ }^{4}$ Seit der Veröffentlichung dieser grundlegenden Arbeiten stellen die weitere Veröffentlichung der Realencyclopädie mit den prosopografischen Beiträgen von Werner Eck in dem 1974 erschienenen Supplement XIV und der Abschluss der zweiten Ausgabe der Prosopographia Imperii Romani im Jahr $20 \mathrm{I} s$ beachtliche Aktualisierungen dar. Es ist bedauerlich, dass der kompilatorische Ansatz der PIR ${ }^{2}$ bisweilen einen veralteten Zustand von Namen und Aufzeichnungen wiedergibt.' Eckpfeiler bilden die Ergebnisse des Kolloquiums »Epigrafia e ordine senatorio «, ${ }^{6}$ angereichert mit Monografien zu regionalen Prosopografien, zum Beispiel A. Caballos Rufino über spanische Senatoren, ${ }^{7}$ Y. Burnand über Senatoren gallischer Herkunft ${ }^{8}$ und G. Camodeca über Senatoren kampanischer Herkunft. ${ }^{9}$ Die Prosopografie der Matronen aus dem Senatoren- und Ritterstand muss auf der Arbeit von M.-Th. Raepsaet-

2 Lambrechts (1937).

3 Barbieri (1952).

4 Barbieri wurde erweitert durch die Studie von Jacques (I986).

5 I999 erscheint in PIR² R I66 Puella Nr. 6 als [Ru]fia Vesti[na] Maxi[ma]. Bereits I952 hat G. Barbieri ihr Gentilicium als [A]lfia gelesen, siehe (Albo 635 p. I 37: "[A]lfia (non [Ru]fia Vesti[na] Maxi[ma]) - la lettura è stata controllata sull'originale«). Dieses Ergebnis hat Antonio Caballos Rufino (1990) mit der Aufnahme des Namens in den Katalog der Mitglieder der Familie der Alfii bestätigt.

6 Epigrafia e ordine senatorio, I-II, Tituli 4-5, Roma (1982) i984; M. L. Caldelli, G. L. Gregori (edd.), Epigrafia e ordine senatorio, 30 anni dopo, Tituli Io, Roma 2014.

7 Caballos Rufino (199I).

8 Burnand (2005).

9 Camodeca (2008). 
Charlier, ${ }^{10}$ die einige der während der Säkularspiele anwesenden Matronen behandelte, und A. Alvarez Melero ${ }^{\text {II }}$ basieren. Schließlich hat die finnische Schule für Onomastik solide Arbeitsmittel zur Verfügung gestellt, insbesondere das onomastische Repertorium von Heiki Solin und Olli Salomies. ${ }^{\text {I2 }}$

Neben diesen grundlegenden Werken gibt es Artikel und vereinzelte Studien von G. Alföldy, G. Camodeca, M. Christol, W. Eck, O. Salomies, die seit der Arbeit von Pighi und Barbieri neue Informationen über Personen und ihre Familien liefern. Es wurden alle Anstrengungen unternommen, um für diese Untersuchung einen möglichst umfassenden Informationsstand zu erhalten. Dennoch ist es möglich, dass entlegene bibliografische Daten über eine bestimmte Person entgangen sein können. Die hier vorgestellten Ergebnisse sind der Auftakt zu einer umfassenderen Studie über die an den severischen Säkularspielen beteiligten Personen und ihre Beziehungen.

\subsection{Die verwendeten Abkürzungen}

Da es sich um ein regelmäßiges Zitieren von Personen handelt, die hauptsächlich $\mathrm{zu}$ sechs Gruppen gehören, werden folgende Abkürzungen verwendet, um diese Gruppen zu bezeichnen, die so selbsterklärend wie möglich gewählt wurden:

$\begin{array}{ll}\text { XVvir(i) sacris faciundis } & \text { XVvir(i) } \\ \text { Virgines Vestales } & \text { VV } \\ \text { Paar aus dem Senatorenstand: } & \\ \text { senatorische Matrone } & \text { MatrSen } \\ \text { Ehemann einer MatrSen } & \text { MaritSen } \\ \text { Paar aus dem Ritterstand: } & \\ \text { ritterliche Matrone } & \text { MatrEq } \\ \text { Ehemann einer MatrEq } & \text { MaritEq } \\ \text { Mädchen } & \text { Puella } \\ \text { Knabe } & \text { Puer } \\ \text { Knabe am lusus Troiae } & \text { PuerLus }\end{array}$

\subsection{Die Position der Personennamen auf dem Stein und ihr Erhaltungszustand}

Die Verteilung der Namen der Personengruppen auf dem Stein ist in allen Fällen unterschiedlich. Die XVviri sind im gesamten Dokument erwähnt, da ihre Teilnahme an den vorbereitenden Sitzungen und Handlungen vor den Spielen und an

Io Raepsaet-Charlier (1987) und (2016).

I I Alvarez Melero (2018).

I 2 Solin, Salomies (I994). 
den Riten der Spiele selbst aufgezeichnet ist. Nur in den Zeilen 65-68 werden alle Mitglieder des Kollegiums in einer vollständigen Liste genannt.

Die beiden Vestalinnen erscheinen nur zweimal im Rahmen ihrer Anwesenheit an Riten. ${ }^{13}$

Im Gegensatz zur augusteischen gibt die severische Inschrift nicht nur die Anzahl der Matronen, Pueri und Puellae, sondern auch deren Namen an, das heißt die Namen der 109 Matronen, gefolgt von den Namen ihrer Ehemänner im Genitiv, außerdem die Namen der 27 Pueri, der 27 Puellae und der 40 bis 50 Pueri, die an den Reiterspielen des lusus Troiae teilnahmen. ${ }^{14}$ Neben den XVviri und den beiden Vestalinnen waren etwa 200 bis 2 I0 Frauen und Kinder an den Ritualen beteiligt. Wenn wir die Namen der kaiserlichen Familie, die 20 XVviri, die beiden Vestalinnen, die rog Ehemänner, die dem Namen ihrer Frauen folgen, und ein paar Mimen, die an den ludi honorarii auftraten, hinzufügen, können wir davon ausgehen, dass der Stein insgesamt die Namen von fast 360 Menschen trug.

Es überrascht nicht, dass sich die Listen der Matronen und Ehemänner (Z. I $88-$ 205), der Pueri (Z. 26I-263), der Puellae (Z. 263-266), der Pueri der Reiterspiele beim lusus Troiae (Z. 307-317) im unteren Teil des großen Marmorblocks auf Augenhöhe befunden haben. Diese Listen waren gut lesbar und wahrscheinlich sogar der Betrachtung ausgesetzt. Man sollte nicht davon ausgehen, dass der Stein sich in einem Teil des Heiligtums befunden hat, der normalerweise geschlossen und nur am Ende eines saeculum wieder geöffnet wurde. Ein Beweis dafür ist die Rasur des Namens von Geta, die gegen Ende des Jahres 21 I oder Anfang 2 I 2 durchgeführt werden musste: Es ist schwer vorstellbar, dass das Heiligtum trotz verbindlicher religiöser Gebote geöffnet wurde, nur um diese Rasur durchzuführen. Deswegen ist davon auszugehen, dass dieser große Block im oberen Teil des Heiligtums stand, wahrscheinlich unter einem Säulengang, denn einige gut gemeißelte Buchstaben zeigen keine Spuren von Schäden durch Witterungseinflüsse.

Das Erscheinen von Listen mit Matronen und Kindern im unteren Bereich des Blocks bedeutet, dass sie zugänglich waren. Wenn es sich um eine severische Innovation handelt, zielt sie darauf ab, die Teilnahme von Mitgliedern wichtiger Familien an den Riten zu zeigen. Sieben Jahre nach dem Ende des zweiten Bürgerkriegs und den anschließenden Proskriptionen war es für die severische Macht nicht ohne Interesse, den politischen Konsens um die kaiserliche Familie bei der Durchführung staatlicher Riten zu dokumentieren. So wie das gesamte Dokument die Erinnerung an die ludi saeculares erhalten sollte, erlaubte es den großen senatorischen Familien, für künftige Generationen sichtbar zu sein.

I 3 Act. Sev. I 2 I/I 22 sacrum hostiae praecidaneae; Act. Sev. I $84 /$ I 85 supplicatio der I IO Matronen.

I $4 \mathrm{Da}$ eine Inschrift der ludi saeculares unter Domitian (88 n. Chr.) nicht vorliegt, ist nicht klar, ob die Nennung aller Beteiligten erst in severischer oder bereits in flavischer Zeit eingeführt wurde. 
Die Listen befinden sich in sehr unterschiedlichem Zustand:

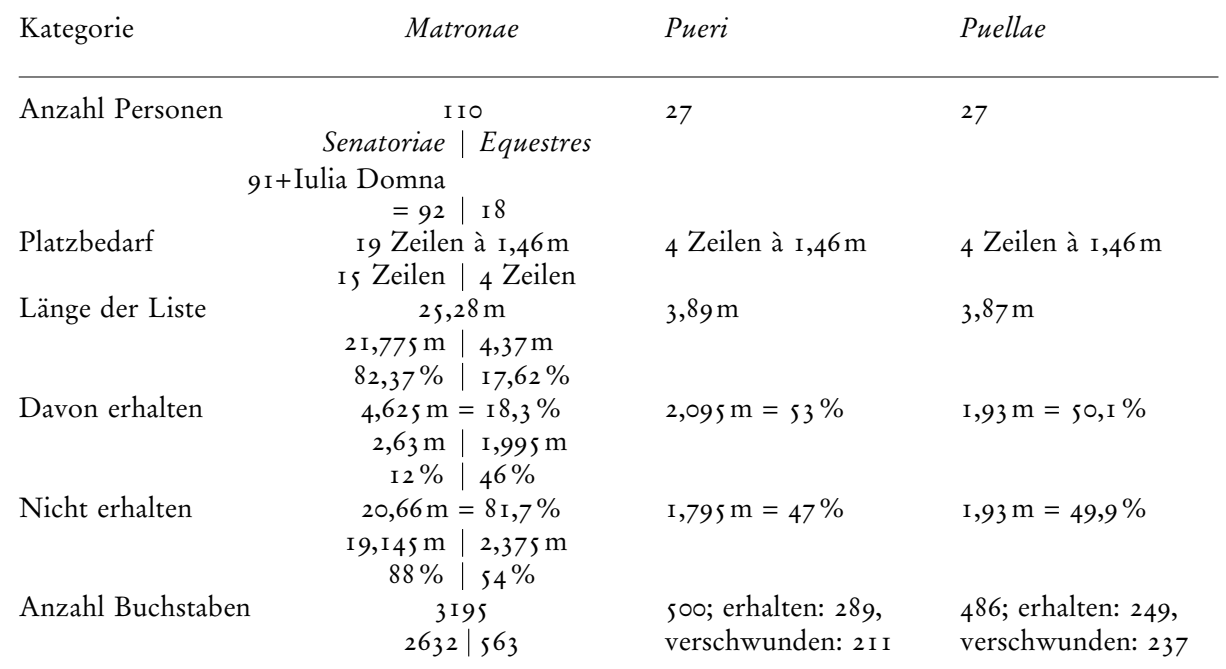

Die längste Liste war die der senatorischen Matronen und ihrer Ehemänner; sie umfasste is Zeilen oder ein Band von Namen über fast $22 \mathrm{~m}$ Länge. Diese Liste wurde von den Hammerschlägen der Kalkbrenner schwer getroffen. Es sind nur Fragmente über eine Länge von 2,63 m oder etwa I $2 \%$ erhalten, die nicht zusammenhängen. Das ist bedauerlich: Wir würden mit der erhaltenen Liste über die Namen eines Sechstels der Senatoren des Jahres 204 verfügen. Bei den Matronen aus dem Ritterstand ist der Zustand der Fragmente zufriedenstellender: Die Liste von 4,37 m Länge lief über 4 Zeilen und davon sind etwa $2 \mathrm{~m}$ oder $46 \%$ erhalten. Dies verbessert die Rekonstruktion der Namen der Matronen und ihrer Ehemänner wesentlich. Glücklicherweise erlaubt das erhaltene Wort [E]questres (Z. 202) eine klare Unterscheidung zwischen den Matronen der beiden Stände; Anfang und Ende der beiden Listen sind dadurch erkennbar.

Die Liste der 27 Pueri, die das carmen saeculare sangen, ist am besten erhalten. Sie wurde auf einer Länge von fast 3,90 $\mathrm{m}$ über 4 Zeilen verfasst. Mehr als $2 \mathrm{~m}$ sind erhalten, das heißt $53 \%$. Bei ähnlichem Zustand der Fragmente ist fast über die Hälfte der Beschriftung mit Namen der Puellae des carmen saeculare verfügbar: 3,87 m verteilt über 4 Zeilen; davon sind I,93 m erhalten oder 50,I \%. Der Anfang der Liste der Pueri ist unzweifelhaft rekonstruierbar; das Ende ist eindeutig durch ein vacat markiert, anschließend wird durch das Wort Puellae (Z. 263) der Übergang zur Aufzählung der Mädchen eingeleitet, deren Liste ebenfalls mit einem vacat (Z. 266) abgeschlossen ist. 25 Pueri gehören dem Senatorenstand an, die beiden letzten sind wahrscheinlich ritterlicher Herkunft: Nr. 26 hat den equus publicus erhalten, und Nr. 27 ist wahrscheinlich der Sohn eines römischen Ritters. Alle Mädchen scheinen dem Senatorenstand angehört zu haben. 
Was die am lusus Troiae teilnehmenden Pueri betrifft, so wurden ihre Namen am Ende der Inschrift auf der rechten Seite des Marmorblocks eingetragen, unterhalb davon sind keine weiteren Gravuren erkennbar. Mit ihrer Aufzählung endete also das severische commentarium. Die Anordnung dieser Liste unterscheidet sich von den vorherigen. Die Listen auf der Vorderseite des Blocks sind in gedrängten Buchstaben geschrieben, wodurch das Anliegen des Steinmetzen deutlich wird, so viel Text wie möglich auf der Vorderseite des Blocks unterzubringen. Dort war die größte Sichtbarkeit garantiert. Da er ohnehin auf die rechte Seite des Blocks für das Ende des inschriftlichen Textes ausweichen musste, konnte er den reichlich verfügbaren Platz nutzen, um die Liste der Pueri des lusus Troiae weitläufiger zu gravieren. Jeder Namensnennung geht ein vacat voraus; das ermöglicht, die $\mathrm{Na}$ men mühelos voneinander abzutrennen. Vielleicht war eine echte ordinatio beabsichtigt, die mit den Namen der Pueri ihre Anordnung im Reiterspiel widerspiegeln sollte.

Dennoch ist diese letzte Liste diejenige, deren Begrenzung am schwierigsten zu definieren ist. Sie scheint mit Z. $307 \mathrm{zu}$ beginnen, in der die Buchstaben [ $\cdots$ S]ATYRVS DO $[\cdots]$ wahrscheinlich zum Namen eines Puer gehören. Es ist aber nicht sicher, ob die ersten in dieser Zeile lesbaren Buchstaben $E M I$ nicht ebenfalls zu einem Namen gehören, z. B. [A]emi[lius], [A]emi[lianus]. In der letzten lesbaren Zeile 317 steht als letztes Element der Liste: Licini[us $\cdot 10 \cdot$ e]q(uitis) R(omani) fil(ius). Dies ist der letzte Name eines Puer, der mit Sicherheit gelesen werden kann. Der Buchstabe $C[\cdots]$, der folgt, kann entweder der Anfang des Namens eines anderen Puer oder der erste Buchstabe eines abschließenden Verbs oder eines anderen Wortes sein. Außerdem ist es schwierig zu bestimmen, wo sich die beiden erhaltenen Fragmente in Bezug auf den linken und rechten Rand der Steinseite befinden. Es ist daher unmöglich, über die Anzahl der fehlenden Buchstaben auf beiden Seiten und über die Position der Fragmente in der Breite der Seite zu spekulieren. Sicher ist, dass diese Fragmente das Ende des Gesamttextes trugen. So wie es aussieht, liefern diese beiden untersten beschriebenen Fragmente die Namen von mindestens 29 Pueri; die Lücken sind aber so groß, dass davon ausgegangen werden kann, dass sie mindestens 40 , wenn nicht sogar 50 Pueri insgesamt enthielten. Es ist wahrscheinlich, dass einige der Pueri, die das carmen saeculare gesungen haben, auch an dem lusus Troiae teilgenommen haben, wie z. B. Puer Nr. 23 Baebius Marcellinus (Z. 263), der höchstwahrscheinlich PuerLus Nr. 26 Bae$\left[\cdot{ }^{12} \cdot\right]$ us (Z. 316$)$ ähnlich ist; aber man sollte nicht annehmen, dass alle Pueri an beiden Vorführungen teilgenommen haben. Deswegen kann die Liste der singenden Pueri nicht zur Rekonstruktion der Liste der reitenden Pueri verwendet werden, wie Pighi es getan hat.

Von den 312 Personen, die in den Listen der Matronen, Ehemänner und Kinder enthalten sind - ohne die 40 Pueri des lusus Troiae -, weisen nur die Namensnennungen von $\mathrm{I}_{42}$ Personen Spuren auf, die mehr oder weniger verwertbar sind. Bei manchen handelt es sich nur um einen oder zwei Buchstaben. So sind 48 
senatorische Matronen und Ehemänner erkennbar, von I 82 sind das etwas mehr als ein Viertel; 24 ritterliche Matronen und Ehemänner, von 36 zwei Drittel; 23 Pueri, von 27 eine gute Mehrheit; 8 Puellae, von 27 zwei Drittel; 29 Pueri des lusus Troiae, von mindestens 40 etwa zwei Drittel. Damit sind die Grenzen der prosopografischen Untersuchung gesteckt, insbesondere für die Paare senatorischen Ranges.

Es stellt sich die Frage nach der Verbindung der Personen untereinander auf den verschiedenen Listen. Die XVviri und die Vestalinnen nehmen aufgrund ihrer priesterlichen Befugnis an den Riten teil. Die Kriterien für die Auswahl der Matronen können nicht ohne Weiteres festgelegt werden, aber wir wissen, dass mindestens eine von ihnen (MatrSen Nr. I) die Ehefrau eines XVvir und gleichzeitig die Mutter der Puella Nr. I war. Eine andere (MatrSen Nr. 8) ist zweifellos die Ehefrau eines anderen $X$ Vvir. Es ist durchaus möglich, dass andere Frauen von XVviri anwesend waren. Die 27 Pueri und 27 Puellae des carmen saeculare waren patrimi et matrimi, und es ist anzunehmen, dass auch ihre Mütter unter den Io9 Matronen waren. Leider gibt es für die 4I mehr oder weniger erhaltenen Pueriund Puellae-Sänger nur 48 senatorische Matronen und Ehemänner, was die $\mathrm{Zu}$ ordnung statistisch verringert.

\subsection{Die verschiedenen Personengruppen}

Die große Zahl von Personen macht es sinnvoll, sie in Listen einzuteilen und zu nummerieren. Die Nummerierung entspricht in der Regel der Reihenfolge des Erscheinens in der Inschrift. So wird die erste Matrone aus dem Senatorenstand auf der Liste als MatrSen Nr. I, ihr Mann als MaritSen Nr. I usw. bezeichnet.

Die Autopsie des Steins führte zu neuen Lesarten: Manchmal war es möglich, noch einige Buchstaben zu entschlüsseln, manchmal nicht einmal mehr die von Pighi angegebenen Buchstaben zu erkennen. In anderen Fällen wurden neue Interpretationen vorgeschlagen, die auf bereits von Pighi gelesenen Buchstaben beruhen. Schlussendlich gibt es nicht viele Änderungen bei den Namensnennungen; einige von ihnen wurden schon früher vorgeschlagen. Die Anzahl der Abweichungen in der Nomenklatur von Personen sind bei den XVviri eine; bei den MatrSen I ; bei den MatrEq 7; den Pueri 6; den Puellae ı, davon 7 von Chausson, 3 von Solin, Degrassi und Barbieri; bei den PuerLus I 3 .

Die neuen Ergänzungen oder Interpretationen sind fett gedruckt, um die Abweichungen von den von Pighi vorgeschlagenen Namen zu verdeutlichen. Gegebenenfalls ist dazu der Name des Autors, der eine neue Textkonstitution bereits vorgeschlagen hatte, in Klammern und Kursivschrift angegeben, z. B. (Solin). Pighis abweichende Lesarten oder Interpretationen werden in einer gesonderten Spalte der Liste angegeben, sodass der Leser die Änderungen dieser Edition schnell erfassen kann. 


\section{a. XVviri sacris faciundis}

Die Konturen des Kollegiums bleiben unsicher. ${ }^{\text {is }}$ Sicher ist, dass es trotz seines Namens mehr als fünfzehn Mitglieder hatte, auch ohne die kaiserliche Familie. Wie Bärbel Schnegg im Sachkommentar zu Z. 64-7I betont, ist in den Zeilen 65-68 die vollständige Liste der Mitglieder des Kollegiums aufgeführt, während in der Fortsetzung des Dokuments die Namen der XVviri in verschiedenen kleineren Gruppen erscheinen, je nachdem, welche Aufgaben sie erfüllten, für die sie durch das Los bestimmt waren. Diese Listen scheinen keiner Hierarchie des cursus honorum zu entsprechen, das heißt nach der Reihenfolge der ausgeführten Senatsfunktionen. Es ist nicht ausgeschlossen, dass diese Gesamtliste des Kollegiums aufgrund des Eintrittsdatums in das Kollegium erstellt wurde, also nach dem Anciennitätsprinzip. ${ }^{16}$ Dies war bereits bei Aufzählung der XVviri im augusteischen commentarium (Act. Aug. I66-I68) der Fall.

Unseres Wissens hatte das Kollegium 20 Mitglieder, abgesehen von Septimius Severus, Caracalla und Geta. Plautianus wird mehrmals im commentarium erwähnt. Sollte man also davon ausgehen, dass er in das Kollegium der XVviri aufgenommen war? Er wurde $197 \mathrm{n}$. Chr. vir clarissimus, gehörte in Zusammenhang mit der Heirat seiner Tochter Plautilla mit Caracalla im Jahr 202 n. Chr. zu den Patriziern; er war in das Kollegium der pontifices aufgenommen worden. ${ }^{77}$ Die Zugehörigkeit zu einem der vier großen Priesterkollegien erlaubt es einem Einzelnen grundsätzlich nicht, in ein anderes einzutreten; wenn Plautianus bereits pontifex ist, wäre es für ihn schwierig, auch XVvir sacris faciundis zu sein. Seine Stellung im Protokoll des Kaiserhauses ist jedoch außergewöhnlich, wie der Ausdruck pontifex nobilissimus bezeugt. Deshalb kann nicht ausgeschlossen werden, dass Plautianus als XVvir im Kommentar neben den Mitgliedern der kaiserlichen Familie erscheint und nicht nur als enger Verwandter des Kaisers und Stütze der Herrschaft präsent ist. In den Zeilen 223, 228f., 230, 253, 266, 282 ist er wahrscheinlich in die kaiserliche Gruppe innerhalb des Kollegiums der XVviri eingeschlossen, was wohl auch bei Lücken in Z. I79 und I 83 der Fall ist. Überraschend wäre, wenn er zusammen mit den Mitgliedern der kaiserlichen Familie, die in ihrer Funktion als $X$ Vviri erscheinen, aufträte und selbst nicht Teil des Kollegiums der XVviri gewesen wäre, zumal nach seinem Titel mehrmals (Z. 223, 229, 230, 253, 266, 282) der Ausdruck et ceteri XVviri folgt, der ihn mit Septimius Severus, Caracalla und Geta in das Kollegium einschließt. Man kann daher Schu-

is Zu den XVviri im Hohen Kaiserreich siehe Schumacher (1973) und (1978), ebenso Rüpke (2005).

I6 Die Reihenfolge der Teillisten, die manchmal durch Auslosung bestimmt wird, steht oft im Widerspruch zur Ausgangsliste, die die einzige ist, die einer Hierarchie zu gehorchen scheint.

I7 CIL VI I074 (ILS 456), wo Plautianus sogar als pontifex nobilissimus erwähnt ist. Zur Chronologie der Ehrungen, die Plautianus erhalten hat, siehe Christol (2007) 2 1 7-236. 
macher ${ }^{18}$ zustimmen, dass Plautianus wie der Kaiser und seine beiden Söhne eines der überzähligen Priesterämter innehatte, die der kaiserlichen Familie zukamen und nach dem Tod des Inhabers erloschen. Diese Priesterschaft und die Einbindung von Plautianus in die Zeremonien der Säkularfeier als Mitglied des organisierenden Priesterkollegiums zeigen die protokollarische Stellung, die er erworben hatte. ${ }^{19}$

Eine der Errungenschaften der neuen Edition ist es, als bisher unbekanntes Mitglied des Kollegiums Calpurnius Maximus hinzufügen zu können. Dieser hatte im Rahmen der Vorbereitung der ludi saeculares (Z.25) die rituellen Vorgaben aus einem Handbuch der Priesterschaft vorgelesen. Er muss wohl als MaritSen Nr. 8 [Cal]|purnius [Maxi]mus der MatrSen Nr. 8 Rufria [· I2 ·] identifiziert werden. ${ }^{20}$

In der Liste der Zeilen 65-68 fehlen einige XVviri, deren Namen in den großen Lücken ( \pm 30 Buchstaben) gestanden haben müssen. Diese Lücken können die Namen zweier Männer enthalten haben. Eine Liste mit den Namen der entsprechend nummerierten Personennamen kann erstellt werden, während unten die sieben im weiteren Text der Inschrift belegten XVviri aufgeführt sind. Diese sieben Namen von XVviri können eventuell zur Wiederherstellung der vollständigen Liste herangezogen werden, aber wir geben uns vorläufig damit zufrieden, ihnen eine ungefähre Stelle in der Hierarchie des Kollegiums zuzuweisen. Ihre unsichere Position innerhalb der Hierarchie wird durch einen Asterisk (*) gekennzeichnet.

Liste der XVviri sacris faciundis

Nr. Nomenklatur der Gesamtliste

Zeile Weitere Erwähnung Abweichende Form

\begin{tabular}{lll}
\hline I & {$[\cdot 29 \cdot]$} & 65 \\
2 & {$[\cdot 29 \cdot]$} & 65 \\
3 & {$[\cdot 29 \cdot$ Nonius Arri-]|us M[ucianus } & $65 \mathrm{f} . \quad 69,86,207,272$
\end{tabular}

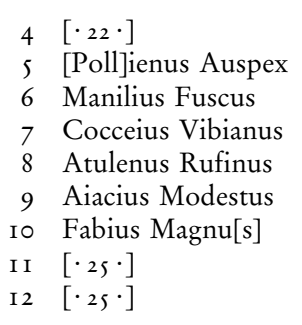

$\begin{array}{ll}66 & \\ 66 & 8 \mathrm{I} \\ 66 & 6,208 \\ 66 & 7 \mathrm{I} \\ 66 & 5 \mathrm{I} \\ 66 & 86, \mathrm{I} 83,207,27 \mathrm{I} \\ 66 & \mathrm{I} 83 \\ 66 & \\ 66 & \end{array}$

Nonius Mucianus (69), Nonius Arriu[s] Mucianus [. $5 \cdot]$ (207), Nonius Arri[us Mucia]nus (272)

I8 Schumacher (1973) 98, 36, i65f.

I9 John Scheid hat sich freundlicherweise bereit erklärt, diese Fragen im Detail mit uns zu diskutieren. Ihm sei hier gedankt.

$20 \mathrm{PIR}^{2} \mathrm{C} 277$. 
I $3[\cdot 25 \cdot$ Iulius Pompeius $] \mid$ Rusonianus $66 \mathrm{f} . \quad 6 \mathrm{I}, 87 \mathrm{f}$., I $42 \mathrm{f}$., $\mathrm{m}$ [ag. collegi]
I 4

Is Cassius Pius Marcellinus quaestor desig.

I6 Vlpius Soter cos. desig.

I7 Venidius Rufus [curat.] albei [Tiber.]

I $8[\cdot 29 \cdot]$

I9 $[\cdot 29 \cdot]$

$20[\cdot 29 \cdot$ Fulvius $] \mid \mathrm{Gra}[\mathrm{n}]$ ianus q. Augg.
$6750,27 \mathrm{I}$

$6789,207,271,300$

678 I, 90, I 44, 255

$67 \quad 208,269$

67

67

67 f. $\quad 70,87,208,269$
Pompeius Rusonianus (6I), $\left[\cdot{ }^{\prime}{ }_{33} \cdot\right.$ Iulius $] \mid$ Pompeius Ru$s[\cdots]$ (87f.), [' ros. Iulius Pom- $] \mid$ peius Rus $[\cdots]$ ( ${ }^{4} 2 \mathrm{f}$.), [Iulius] Pompeius Rusonia$\mathrm{nu}$ [s (207), P[ompeius] $\mathrm{Ru}-$ sonianus magist[er] (270)

$[\cdot 24 \cdot$ Antius $] \mid$ Crescens Calpurnianus (49f.), [Antiu]s Crescens Calpurnianus (27I)

F[ulvius] Fuscus (70), [· I 25 . Fulvius] | [Fuscus] Gran[ianus q. Augg.] (86f.), Fulvius Granianus q. Augg. (208), Fulvius Fusc[us Grani]anus q. Aug[g. (269)

XVviri, die im folgenden Text der Inschrift erscheinen, in der Liste der Zeilen 65-68 jedoch fehlen:

Nr. Nomenklatur der Edition Nomenklatur Pighi Buchstaben Zeile

\begin{tabular}{|c|c|c|c|}
\hline $2 *$ Ofilius Macedo & & I 3 & $70,207,272$ \\
\hline $3^{*}$ Saevinius Proculus & & I7 & 208,269 \\
\hline $4 *$ Calpurnius Maximus $\left[\cdot{ }_{2} \cdot\right]$ & (nicht identifiziert) & 22 & 25 \\
\hline I I* Salvius Tuscus & & I 3 & 69 \\
\hline I 2* Gargilius Antiquus & & 17 & 208 \\
\hline I $8 *\left[\cdot{ }^{\text {Is }} \cdot\right]$ rnus pr. & & $2 \mathrm{I}$ & $207,[\cdots \mathrm{rnu}] \mathrm{s}$ pr. $(272)$ \\
\hline I9* Vetina Mamertinus & & I 6 & $70,270,301$ \\
\hline
\end{tabular}

Das Kollegium der XVviri umfasste im Jahr 204 n. Chr. also 20 Mitglieder und vier überzählige Mitglieder aus dem Kaiserhaus: Septimius Severus, Caracalla, Geta und Plautianus.

Die Vornamen der XVviri wurden nicht angegeben, nach einer Regel, die in der Inschrift für alle männlichen Namen gilt, mit Ausnahme der Nomenklaturen der Mitglieder der kaiserlichen Familie. Hier wird bereits eine Entwicklung erkennbar, die sich im 3. Jahrhundert auf die Verwendung von Vornamen auswirkte. Die meisten XVviri haben eine Nomenklatur, die aus zwei Elementen, dem nomen gentilicium + Cognomen, besteht. Nr. is Cassius Pius Marcellinus erhält im Dokument stets eine dreiteilige Nomenklatur.

Vier Fälle sind besonders zu kommentieren, da die Untersuchung ihrer Nomenklatur die Textkonstitution beeinflusst. 


\section{Nonius Arrius Mucianus}

Der XVvir Nr. 3 heißt in der Gesamtliste in Z.65/66 [·.35 $] \mid$ us M[• $\left.{ }_{16} \cdot\right]$, in Z. 69 Nonius Mucianus, in Z.85/86 [· $\left.{ }_{156} \cdot\right] \mid\left[\cdot{ }_{14} \cdot\right]$ cianus, in Z. 207 Nonius Arriu[s] Mucianus und schließlich in Z. 272 Nonius Arri[us Mucia]nus. Die dreiteilige Form, die zweimal bezeugt ist (Z. 207 und 272), scheint in Z.65/66 besser zu passen als die zweiteilige Form, die nur einmal bezeugt ist. In Z.65/66 wird demnach $[\cdot 25 \cdot$ Nonius Arri] $\mid$ us M[ucianus $\cdot 9 \cdot]$ und am Anfang der Z. 86 [Nonius Arrius $M u]$ cianus ergänzt.

\section{Antius Crescens Calpurnianus}

Der Nomenklatur des XVvir Nr. I4 erscheint dreimal und ist in allen Fällen beschädigt. In Z. 49/50 heißt es [· $30 \cdot] \mid$ Crescens Calpurnianus; in der Gesamtliste in Z. 67 heißt es $[\cdot 28 \cdot]$ nianus; in Z. 27 I heißt es [· $\cdot \cdot]$ s Crescens Calpurnianus. In jeder der drei Erwähnungen seines Namens verschwindet der Anfang seiner Nomenklatur in mehr oder weniger großen Lücken. Es leuchtet nicht ein, dass die Nomenklatur dieses XVvir ohne das anfängliche Gentilicium auskommen sollte, wie es von den Herausgebern früherer Ausgaben gefordert wurde. Vielmehr ist davon auszugehen, dass sein eher kurzes Gentilicium jedes Mal in der Lücke zu Beginn seiner Nomenklatur verschwunden ist.

Er wird in der Regel mit Antius Crescens Calpurnianus, praetor, iuridicus Britannniae um 198 n. Chr., Konsul um 200 n. Chr. und pontifex Vulcani in Ostia identifiziert, wo er seinen Ursprung haben könnte. ${ }^{21}$ Man sollte also das kurze Gentilicium Antius am Anfang seiner Nomenklatur ergänzen:

- am Ende von Z. 49: [·24. Antius]|Crescens Calpurnianus;

- in Z. 67 mit dem ersten Cognomen Crescens: [... Antius Crescens Calpur]nianus;

- in Z. 27r: [... Antiu]s Crescens Calpurnianus. ${ }^{22}$

\section{Fulvius Fuscus Granianus}

XVvir Nr. 20 wird einmal F[ulvius] Fuscus (Z. 70), einmal Fulvius Granianus (Z. 208) und am Ende der Inschrift (Z. 269) Fulvius Fusc[us Grani]anus genannt. Bei seinem ersten Auftreten (Z.67f.) hat seine Nomenklatur die Form $\left[\cdot{ }_{4} I \cdot\right] \mid$ Gra[n]ianus, und bei seinem zweiten Auftreten (Z. 86/87) ist er erkennbar in der Form $\left[\cdot{ }^{132} \cdot\right] \mid[\cdot 7 \cdot]$ Gran[ianus]. Im zweiten Fall ist es angebracht, nicht nur wie Pighi das Gentilicium Fulvius, sondern auch das Cognomen Fuscus zu ergänzen, womit sich die Lücke am Anfang von Z. 87 schließen läßt: $[\cdot$ I25 $\cdot$ Fulvius] $[$ Fuscus] Gran[ianus] (Z. 86/87).

2 I PIR 2 A 780; Barbieri, Albo 34; Licordari, EOS, II (1984) 35.

22 Der Ausdruck q(uaestor) d[esignatus, der vorangeht, muss demnach zu q(uaestor) $d$ [es. oder zu q(uaestor) d[esig. abgekürzt werden, um für das Gentilicium Antius Platz zu gewinnen. 
Andererseits erlaubt der verfügbare Raum am Ende von Z. 67 in der Gesamtliste nicht, das Cognomen Fuscus hinzuzufügen, und wir müssen uns mit der folgenden Ergänzung zufriedenstellen: $[\cdot 29 \cdot$ Fulvius] $\mid$ Gra[n]ianus (Z. 67/68).

\section{4. [Iulius?] Pompeius Rusonianus}

Auch die Nomenklatur von XVvir Nr. I 3 wirft einige Schwierigkeiten auf. Sowohl am Anfang seines Namens als auch am Ende ist oft eine Lücke, die uns den Beginn seiner Nomenklatur oder den genauen Ausdruck für seine Präsidentschaft des Kollegiums im Jahr 204 n. Chr. (magister collegii) vorenthält. ${ }^{23}$ In Z. 6I erscheint er als Pompeius Rusonianus ma[· $36 \cdot]$ ohne Lücke vor seinem Namen. In Z.66f. heißt er [·40.] $\mid$ Rusonianus $m[\cdot 28 \cdot]$. In Z. 87f. ist lesbar [· $\left.{ }_{164} \cdot\right] \mid$ Pompeius Rus[· $\left.{ }_{\text {I45 }} \cdot\right]$. In Z. I42f. heißt es $\left[\cdot{ }_{160} \cdot\right] \mid$ peius $R u s\left[\cdot{ }_{I} 63 \cdot\right]$. In Z. 207 heißt er $[\cdot 6 \cdot]$ Pompeius Rusonianu[· $36 \cdot]$. Seiner Nomenklatur geht hier eine Lücke von sechs Buchstaben direkt nach dem vollständigen Namen von Nonius Arrius Mucianus voraus, wonach nie ein Titel folgt. Schließlich erscheint sein Name in Z. 270 als P[ompeius] Rusonianus magist[er]. Hier erscheint der Titel des magister voll ausgeschrieben und ohne Erwähnung des Kollegiums.

In einer Inschrift von Gabii, die ein Stieropfer für die Magna Mater der Götter bezeugt, nennt sich derselbe Pompeius Rusonianus, cos, XVvir sacris faciundis. ${ }^{24} \mathrm{Er}$ wird in der Regel mit einer Persönlichkeit identifiziert, ${ }^{25}$ die durch den Stempel einer fistula aquarum bekannt ist und dort Iulius Ponpeius 〈sic〉 Rusonianus genannt ist. ${ }^{26}$ Man könnte durchaus einwenden, dass die beiden Nomenklaturen zu zwei verschiedenen Personen gehören. Aber wir folgen der communis opinio und vereinheitlichen die beiden Nomenklaturen, wobei Pompeius Rusonianus ein Polyonym ist, dessen erweiterte Nomenklatur Iulius Pompeius Rusonianus war.

Frühere Ausgaben haben zu Recht den Namen Iulius in der Lücke von sechs Buchstaben in Z. 207 mit der Nomenklatur [Iulius] Pompeius Rusonianu[s ...] wiederhergestellt, wodurch eine Lücke geschlossen werden kann, die sonst kaum zu erklären wäre. Es ist daher angebracht, die Wiederherstellung des Gentiliciums Iulius auch in anderen unvollständigen Fällen der Nomenklatur dieses XVvir vorzuschlagen:

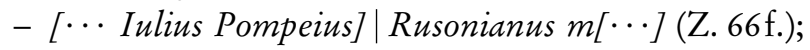

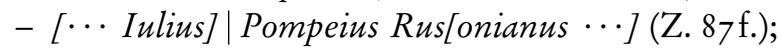

- [‥ Iulius Pom-] peius Rus[onianus ‥] (Z. I42f.).

23 Je nachdem, an welcher Stelle dieser Titel steht, der unterschiedlich als mag(ister) coll(egi) abgekürzt werden kann, ohne von dem Ausdruck XVvir(orum) gefolgt zu werden, gibt es eine mehr oder weniger große Leerstelle für die Nomenklatur des $X$ Vvir, die in den Aufzählungen darauf folgt.

24 CIL XIV 2790 (ILS 4II8).

25 $\mathrm{PIR}^{2} \mathrm{C} 476$.

26 CIL XV 7475. 
Trotz des Beispiels von Cassius Pius Marcellinus, dessen Nomenklatur immer drei Elemente aufweist, gibt es unbestreitbar zwei- und dreiteilige Varianten für die Nomenklaturen von Nonius Arrius Mucianus und Fulvius Fuscus Granianus, deren Nomenklatur mit drei Elementen gut dokumentiert ist. Für [Iulius] Pompeius Rusonianus muss die dreiteilige Form zwangsläufig wegen einer sonst nicht zu erklärenden Lücke von sechs Buchstaben postuliert werden. Auch bei [Antius] Crescens Calpurnianus muss vernünftigerweise von einer Nomenklatur mit drei Elementen ausgegangen werden, da das Gentilicium zwangsläufig auftreten muss, wenn man nicht von einem Bruch der onomastischen Gebräuche ausgehen will.

Auf die Namen einiger XVviri folgt die Nennung eines Amtes. Der Vorsitz des Kollegiums wird ausdrücklich für Manilius Fuscus im Jahr 203 n. Chr. und für Iulius Pompeius Rusonianus im folgenden Jahr erwähnt. Von Fall zu Fall kann die Erwähnung der Präsidentschaft erhebliche Unterschiede erfahren. Ti. Manilius Fuscus, Magister im Jahr 203 n. Chr., war zum Zeitpunkt der Proklamation von Septimius Severus in Pannnonien legatus der XIII. Legion, Gemina, in Dakien, deren Gouverneur P. Septimius Geta der Bruder von Severus war. ${ }^{27}$ Nach der Niederlage von Pescennius Niger wurde Manilius Fuscus die Provinz Syria anvertraut, obwohl er noch Prätor war; 195 oder $196 \mathrm{n}$. Chr. erlangte er das Konsulat in Abwesenheit. Er wurde unter die Arvalbrüder aufgenommen. Seine Präsidentschaft des Kollegiums der XVviri im Vorbereitungsjahr der ludi saeculares ist ein weiterer Beweis für die große Wertschätzung seiner Person, die sich mit einem Prokonsulat der Provinz Asia im Jahr 2 ro n. Chr. und einem zweiten Konsulat im Jahr 225 fortsetzt. Was Iulius Pompeius Rusonianus betrifft, so ist das Datum seines Konsulats unbekannt. Sein Vorsitz des Kollegiums der XVviri im Jahr 204 n. Chr., dem Jahr der ludi saeculares, erklärt sich aufgrund seiner Herkunft aus Lepcis Magna, die mit gutem Gründen nach onomastischen Studien von A. R. Birley und G. Di Vita-Evrard gefordert wird. ${ }^{28}$ Er hat möglicherweise auch bei der Einführung der Di Patrii von Lepcis Magna, Herkules und Liber Pater, bei den Riten am Rande der Säkularspiele eine Rolle gespielt.

In drei Fällen wird die Funktion, die die XVviri zum Zeitpunkt der Säkularspiele ausübten, präzisiert: $X$ Vvir Nr. I $8^{*}\left[\cdot{ }^{\prime}{ }^{\cdot}\right] \mathrm{rnus}$, wahrscheinlich ein $[\mathrm{Pa}-$ te]rnus oder ein [Mate]rnus, ist pr(aetor); XVvir Nr. 20 Fulvius Fuscus Granianus ist q(uaestor) Augg(ustorum); XVvir Nr. 17 Venidius Rufus ist cur(ator) alvei Tiberis. In zwei Fällen ist das genannte Amt noch nicht angetreten: ${ }^{29} X V v i r$ Nr. 16

$27 \mathrm{PIR}^{2} \mathrm{M}$ I 37 .

28 Die Elemente Iulius, Pompeius und die seltene Form Rusonianus sind unter den Namen aus Lepcis Magna gut repräsentiert. Dazu Birley (I988) i60 und Vita-Evrard (1982) 453-465, insbesondere 465. Die noch laufenden Arbeiten von Khaled Marmouri beschäftigen sich mit diesen Fragen.

29 Dies wird durch das Partizip designatus angegeben. Designatus kann voll ausgeschrieben sein oder in verschieden abgekürzten Formen auftreten: des(ignatus), de$\operatorname{sign}($ atus). 
Vlpius Soter ist co(n)s(ul) designatus und XVvir Nr. Is Cassius Pius Marcellinus ist $q$ (uaestor) designatus. Diese Fälle bestärken die Annahme, dass die beiden fehlenden Buchstaben hinter dem Namen von XVvir Nr. $4 *$ Calpurnius Maximus einem Amt entsprechen müssten; ${ }^{30}[\operatorname{pr}($ aetor $)]$ wäre am plausibelsten, weil es als einziges mit zwei Buchstaben abgekürzt wird. ${ }^{31}$

Einige der XVviri haben konsularischen Rang, andere prätorianischen. XVvir Nr. 20 Fulvius Fuscus Granianus, q(uaestor) Augg(ustorum) ist eines der jüngsten Mitglieder des Kollegiums, weil er gerade erst in den Senat eingetreten war: Er verdankt seine Kooptation sicherlich der anzunehmenden Verwandschaft zur kaiserlichen Familie und zu der von C. Fulvius Plautianus. ${ }^{32}$ Diese verwandtschaftlichen Beziehungen erklären seine Stellung als Quästor der Augusti, ein unbestreitbares Zeichen der kaiserlichen Gunst. Er ist mit dem Magister des Kollegiums Iulius Pompeius Rusonianus der zweite Lepcitaner, der in das Kollegium kooptiert wurde. XVvir Nr. Is Cassius Pius Marcellinus ist nur q(uaestor) designatus, er hat die Quaestur noch nicht angetreten und ist noch kein Mitglied des Senats. Diese wenigen Daten über die Karriere und das Alter der XVviri lassen den Schluss zu, dass es eine gewisse Vielschichtigkeit im Hinblick auf ihre Kooptation gibt, eine Vielschichtigkeit, die bestimmt wurde durch demografische Zufälle und politische Entscheidungen. ${ }^{33}$ Mehr als ihr Alter oder ihre Senatswürde ist es möglicherweise ihre Anciennität im Kollegium, die ihre Position in der Hierarchie einer der Listen bestimmt. In diesen Listen sind unterschiedliche Gruppen von XVviri bei der Ausübung von rituellen Handlungen genannt. XVvir Nr. 6 Ti. Manilius Fuscus war im Jahr 204 n. Chr. seit acht oder neun Jahren Konsular. XVvir Nr. I7 Venidius $R u f u s^{34}$ hatte das Konsulat erst kürzlich erreicht: Seine erweiterte Nomenklatur war Q. Venidius Rufus Marius Maxim[us ...] Calvinianu[s]; er war sicherlich mit dem großen General von Septimius Severus L. Marius Maximus Perpetuns Aurelianus verwandt. ${ }^{35}$ Dieser hatte sich bei der Belagerung von Byzanz und in der Schlacht von Lyon hervorgetan; außerdem stand er in Beziehung zu der italienischen Familie der Egnatii Proculi (mütterliche Familie des Kaisers Gallienus). ${ }^{36}$

30 In dieser Lücke kann nicht, wie Pighi gefordert hatte, die Senatorenwürde von Calpurnius Maximus angegeben sein mit [v(ir) c(larissimus)], weil die Senatorenwürde der $X$ Vviri nur kollektiv im Plural mit CC(larissimi) VV(iri) erscheint. Siehe Act. Sev. 26 und 29.

3 I Quaestor ist manchmal mit Q(uaestor) abgekürzt. Das Partizip designatus kann nicht mit einem einzigen Buchstaben abgekürzt werden.

32 Die Fulvii (Herkunftsfamilie der Mutter von Septimius Severus) sind in Lepcis Magna belegt, ebenso die Granii.

$33 \mathrm{Zu}$ den Kooptationen in großen Priesterkollegien der römischen Religion siehe Schumacher (1984) 5I-269.

$34 \mathrm{PIR}^{2} \mathrm{~V} 369$.

35 $\mathrm{PIR}^{2} \mathrm{M}$ 308. Zu Marius Maximus siehe Birley (1997) 2678-2757; Christol (2016) $447-467$.

36 Chausson (I997) 2 I I-33I. 
Venidius Rufus folgte noch als Prätor Manilius Fuscus 198 n. Chr. an die Spitze der Provinz Syria und erlangte das Konsulat zwischen I 99 und 203 n. Chr. Das Amt des curator Alvei Tiberis, das er im Jahr 204 innehatte, entspricht dem Beginn eines konsularischen Ranges, der 205 n. Chr. mit der Leitung von Germania inferior erweitert wurde. XVvir Nr. 9 Aiacius Modestus ist im Mai/Juni 204 n. Chr. immer noch im Rang eines Prätors; im folgenden Jahr erhält er als Proprätor die Leitung der Provinz Arabia. Inschriftliche Widmungen, die er dort verfassen ließ, zeugen von seiner Beteiligung an den ludi saeculares. ${ }^{37}$ Während seiner Amtszeit in Arabien wird er consul in absentia.

Einzig der Name von XVvir Nr. I 8* [· Is $\cdot]$ rnus pr. ist noch unbekannt. Es könnte sich um [Tarrutenius Pate]rnus handeln. In diesem Fall ist er möglicherweise ein Verwandter von XVvir Nr. I I Salvius Tuscus. ${ }^{38}$ Alternativ wäre denkbar: Eine Inschrift von Tarragona ${ }^{39}$ stellt eine Widmung durch einen Senator namens P. Alfius Avitus Numer(ius) Maternus an seinen Vater P. Alfius P. f. Gal. Maximus Numer(ius) Licinianus dar. Dieser war nacheinander XVvir stlitibus iudicandis, quaestor urbanus, tribunus plebei candidatus und praetor Parthicarius zu einem nicht bekannten Zeitpunkt im 2. Jahrhundert, aber nach der Herrschaft von Trajan. Eine Inschrift aus Rom ${ }^{4}$ macht ein Mitglied der gleichen Familie namens [... Max]imus Numerius Av[itus ...] bekannt. Unter Bezug auf die Arbeiten von A. Caballos Rufino ${ }^{4}$ und P. Le Roux ${ }^{42}$ verweisen wir auf die Familie der Alfii, welche möglicherweise aus Tarragona stammt. Es ist wichtig, an dieser Stelle darauf hinzuweisen, dass die Namen Avitus, Maximus, Numerius und Maternus in dieser Familie zur Zeit der Antoninen vorkommen. ${ }^{43}$ Wenn sich herausstellt, dass XVvir Nr. I 8* [· I5·]rnus pr. ein [Alfius Avitus Mate]rnus war, könnte er möglicherweise MaritSen Nr. Is [ $\cdots$ A]vitus sein. Dies würde die Anzahl der Matronen, die mit einem XVvir verheiratet waren, auf drei erhöhen. Ebenso könnte er der Vater oder Onkel von Puer Nr. 7 Alfius Avitus sein, von Puella Nr. 6 [A]lfia Vestin[a] Maxim[a], PuerLus Nr. I6 Alfius Maximus, sogar von PuerLus

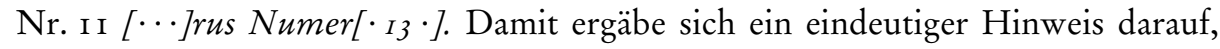

37 Christol (I97I) I 24-I40.

$38 \mathrm{Zu}$ diesem Netzwerk von Verwandten aus der Gegend um die Stadt Brescia und zur Familie von Didius Iulianus mit Einbezug der Nachkommen des Prätorianerpräfekten Tarrutenius Paternus und der Nummii siehe Chausson (2000) 843-879. Nonius Arrius Mucianus, XVvir Nr. 3, stammt von dort, und MaritSen Nr. 89 heißt Nummius Faustinianus.

39 CIL II 4IIO.

40 CIL VI I 474.

4I Caballos Rufino (I990) 47.

42 Le Roux (I982) 439-464, bes. 458; ders. (2008) 1003-1027, bes. I009. Die Bibliografie ist zu ergänzen mit Christol/Loriot (200I) 97-I 2 I; dies. (2004) 8I-86.

43 Die Form Avitianus ist in der ersten Hälfte des 3. Jh. häufiger in einer anderen senatorischen Familie aus Spanien belegt, den Alfenii. 
dass die Familien einiger XVviri an den Zeremonien der Säkularspiele beteiligt waren. ${ }^{44}$

Puella Nr. 8 ist eine Non[ia $\cdot{ }^{\circ} \cdot$ V]aleriana, die eine enge Verwandte von XVvir Nr. 3 Nonius Arrius Mucianus sein könnte. Sein Alter ist aufgrund der Homonymie, die in der zweiten Hälfte des 2. Jahrhunderts unter den Nonii von Brescia herrschte, schwer zu definieren. ${ }^{45}$ Es ist sehr wahrscheinlich, dass er mit M. Nonius Arrius Mucianus, ${ }^{46}$ ordentlicher Konsul des Jahres $20 \mathrm{I}$ n. Chr., identifiziert werden muss. Aber es ist nicht sicher, ob er der Ehemann einer Sextia T. f. Asinia Polla war. ${ }^{47}$ Diese war eine Nachfahrin der Sextii Africani Laterani, einer wichtigen Familie, die Septimius Severus unterstützte, ${ }^{48}$ und der Asinii Polliones. Das Paar $M$. Nonius Arrius Mucianus und Sextia T. f. Asinia Polla könnten die Eltern des Konsuls von $20 \mathrm{I}$ n. Chr. sein. Der fast gleichnamige M. Nonius Arrius Mucianus

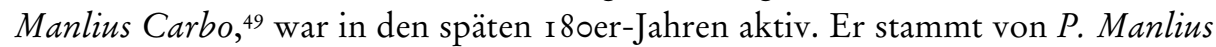
Carbo ab, einem Arvalbruder in den I 2oer-Jahren, und könnte mit Ti. Manilius Fuscus verwandt sein..$^{50}$ Senatorische Verwandte, die sich in der X. Augusteischen Region konzentrieren, aus der auch Aiacius Modestus stammt, könnten bestimmte Kooptierungen in das Kollegium nachvollziehbar machen.

\section{b. Vestalinnen}

Zwei Vestalinnen erscheinen je zweimal in der Inschrift:

Nr. Nomenklatur der Inschrift Nomenklatur nach Pighi Zeile

\begin{tabular}{llll}
\hline I & $[$ Numisia $] \mid$ M[aximilla $]$ & {$[$ Numisia] $\mid$ Ma[ximilla $]$} & I2 If. \\
& {$[$ Numisia $] \mid$ Maximilla } & {$[$ Numisia] $\mid$ Maximilla } & I $84 \mathrm{f}$. \\
2 & {$[$ Terentia Flavola $]$} & {$[$ Terentia Flavola $]$} & I 22 \\
& Terentia F[la]vola & Terentia F[la]vola & I 85
\end{tabular}

44 Die Inschriften, die zum Zeitpunkt seiner Amtszeit in Arabien erstellt wurden (siehe Christol I97I), erlauben es uns, den vollständigen Namen von $Q$ Aiacius Modestus Crescentianus zu kennen. Ebenso die Namen seiner Frau Danacia Quartilla Aureliana und der Söhne (möglicherweise nach 204 geboren) Q. Aiacius Censorinus Celsinus Arabianus und L. Aiacius Modestus Aurelianus Priscus Agricola Salvianus. Es ist jedoch nicht möglich, andere Spuren dieser Familie in den Listen der Act. Sev. zu finden, auch wenn die Nomenklaturen der Aiacii Überschneidungen mit den Familien anderer XVviri zulässt.

45 Einen Versuch, Ordnung in diese Homonyme zu bringen, machten Chausson und Gregori (20I5) 28I-294.

$46 \mathrm{PIR}^{2} \mathrm{~N}$ I I 4 .

47 CIL V 4355, Brixia.

$48 \mathrm{Zu}$ dieser Familie siehe Chausson (2014) I 29-1 57 und ders. (2017) 47-73.

$49 \mathrm{PIR}^{2} \mathrm{~N}$ is 5 .

so Die Formen Manilius und Manlius sind beide abwechselnd in der Familie des Ti. Manilius Fuscus belegt, siehe weiter unten, S. 430. 
Numisia Maximilla ist bereits ab $20 \mathrm{I}$ n. Chr. als Obervestalin belegt; in dieser Funktion nimmt sie zweifellos an den Zeremonien teil. ${ }^{\text {I }}$ Terentia Flavola ist im Jahr 2 I 5 n. Chr. als Obervestalin bezeugt. ${ }^{52}$ Sie ist wahrscheinlich nach Numisia Maximilla die Ranghöchste des Kollegiums, weswegen sie an deren Seite die Vestalinnen am sacrum hostiae praecidaneae und der supplicatio der Matronen repräsentiert und ihr später als Obervestalin folgt.

Nach dem derzeitigen Stand der Untersuchung scheint keine familiäre Verbindung dieser beiden Vestalinnen mit den XVviri, den Matronen oder Kindern der ludi saeculares $\mathrm{zu}$ bestehen.

\section{c. I Io Matronen und ihre Ehemänner}

\section{Paare mit senatorischem Rang}

Es wurde bereits erwähnt, dass die Liste der senatorischen Paare am meisten gelitten hat. Von den is Zeilen, die die Namen von 9I Matronen und ihren Ehemännern auf fast $22 \mathrm{~m}$ Schriftlänge tragen, sind Fragmente lediglich über eine Länge von 2,63 m (knapp i $2 \%$ ) verteilt. Ganze Zeilen sind verschwunden. Nur die Namen der Paare 84, 89 und 90 sind fast vollständig erhalten geblieben, ansonsten ist bestenfalls der fast vollständige Name eines einzelnen Mitglieds des Paares verfügbar. Die Namen von 52 Paaren sind vollständig verschwunden, sodass nur für 39 Paare Daten verfügbar sind, manchmal nur ein oder zwei Buchstaben.

Diese Ausgabe hat sich in erster Linie auf die Verbesserung der Lesarten konzentriert, dabei wurden einige Buchstaben gewonnen, die manchmal den Anfang eines Namens oder Cognomens enthalten. Die Verteilung der Namen der Paare wurde dann Zeile für Zeile berechnet. Die augusteische und die severische Inschrift geben beide die Zahl der Matronen mit i so an, wobei die severische Iulia Domna immer namentlich nennt, der 109 Matronen angeschlossen sind. Der Name eines Paares belegt etwa 30 Buchstaben, was bei Zeilen mit etwa I90 Buchstaben erlaubt, die Namen von sechs bis sieben Paaren pro Zeile zu veranschlagen. ${ }^{53}$ Einige Namen von Paaren werden von einem Zeilenwechsel betroffen. Bis auf wenige Aus-

$5 \mathrm{I} \mathrm{PIR}^{2} \mathrm{~N} 2 \mathrm{I} 9$.

$52 \mathrm{PIR}^{2} \mathrm{H}$ 44. Sie gehört der wichtigen senatorischen Familie der Hedii an.

53 Einige Paare haben kürzere Namen, vor allem dank der Abkürzung des Gentils, wie beim Paar Nr. I Fl. Pollitta Manili [Fusci] (insgesamt 2 I Buchstaben). Andere sind aufgrund einer dreiteiligen Nomenklatur für die Matrone länger, wie z. B. für das Paar Nr. 84 Domitia Flaccill[a] Ulpi Antonin[i] (24 Buchstaben), das Paar Nr. 89 Ta[ri]a Cornelia Asiana Nummi Faustiniani (39 Buchstaben), das Paar Nr. 90 C[l. D]ryantilla Platonis Corneli Optati (32 Buchstaben). Pighis Berechnungen wurden mehr oder weniger durch unsere eigenen Ergänzungen bestätigt. Wir haben die Räume der verschiedenen Paare einmal vom Anfang der Liste her und zur Kontrolle noch einmal vom Ende her eingeteilt. Die Liste der besser erhaltenen Matronen aus dem Ritterstand bietet Parallelen: In Z. 203 sollten die Namen von etwa sieben bis acht Paaren erscheinen, in Z. 204 sechs bis sieben Paare. 
nahmen, Nachlässigkeit des Steinmetzen oder Bruch des Steins, gibt es kein vacat zwischen den Namen, aber sehr oft Punkte zur Wortabtrennung. Dies schafft eine große Regelmäßigkeit im Ablauf des langen Textes mit Namen.

Liste der 9I Matronen senatorischen Ranges und ihrer Ehemänner

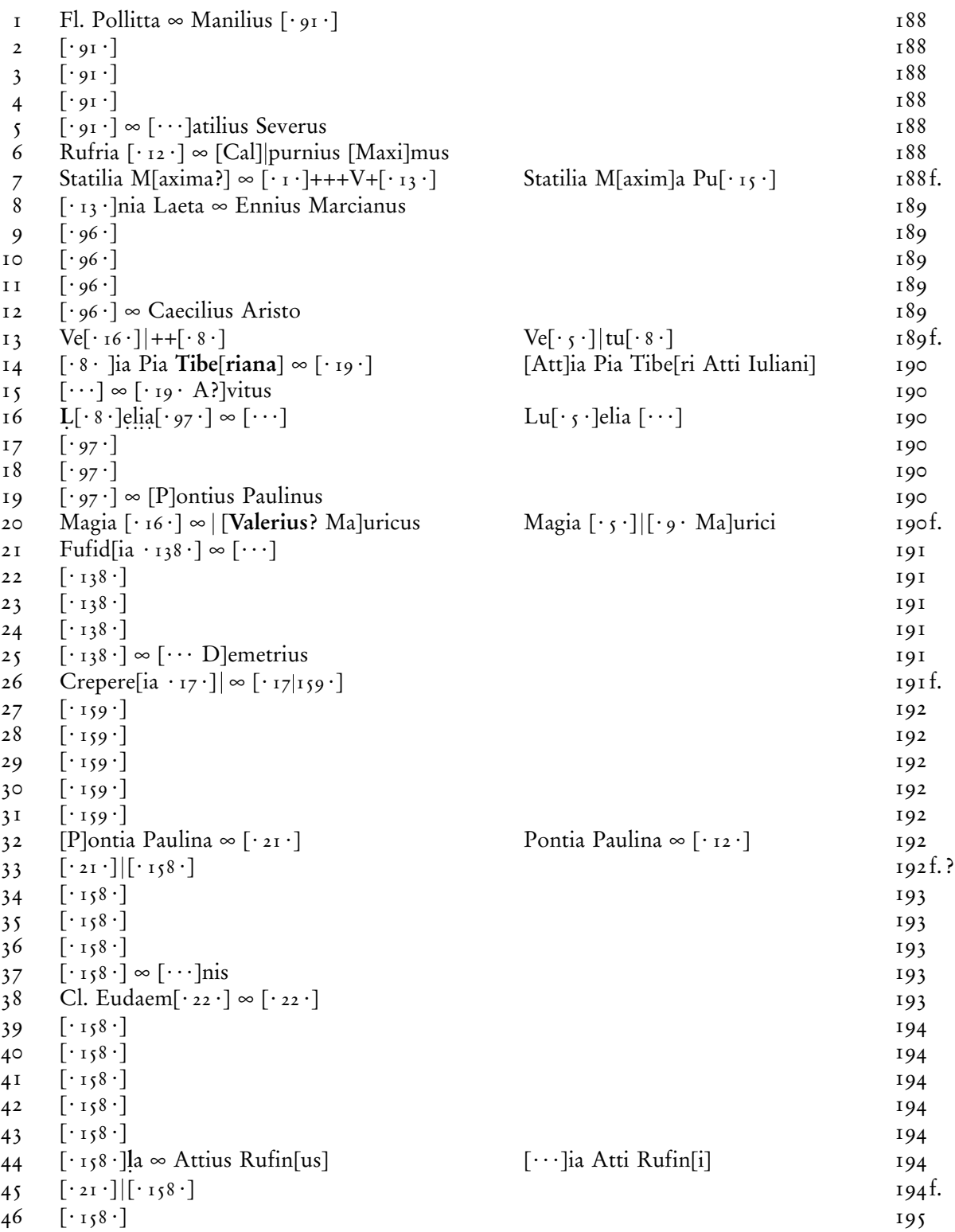




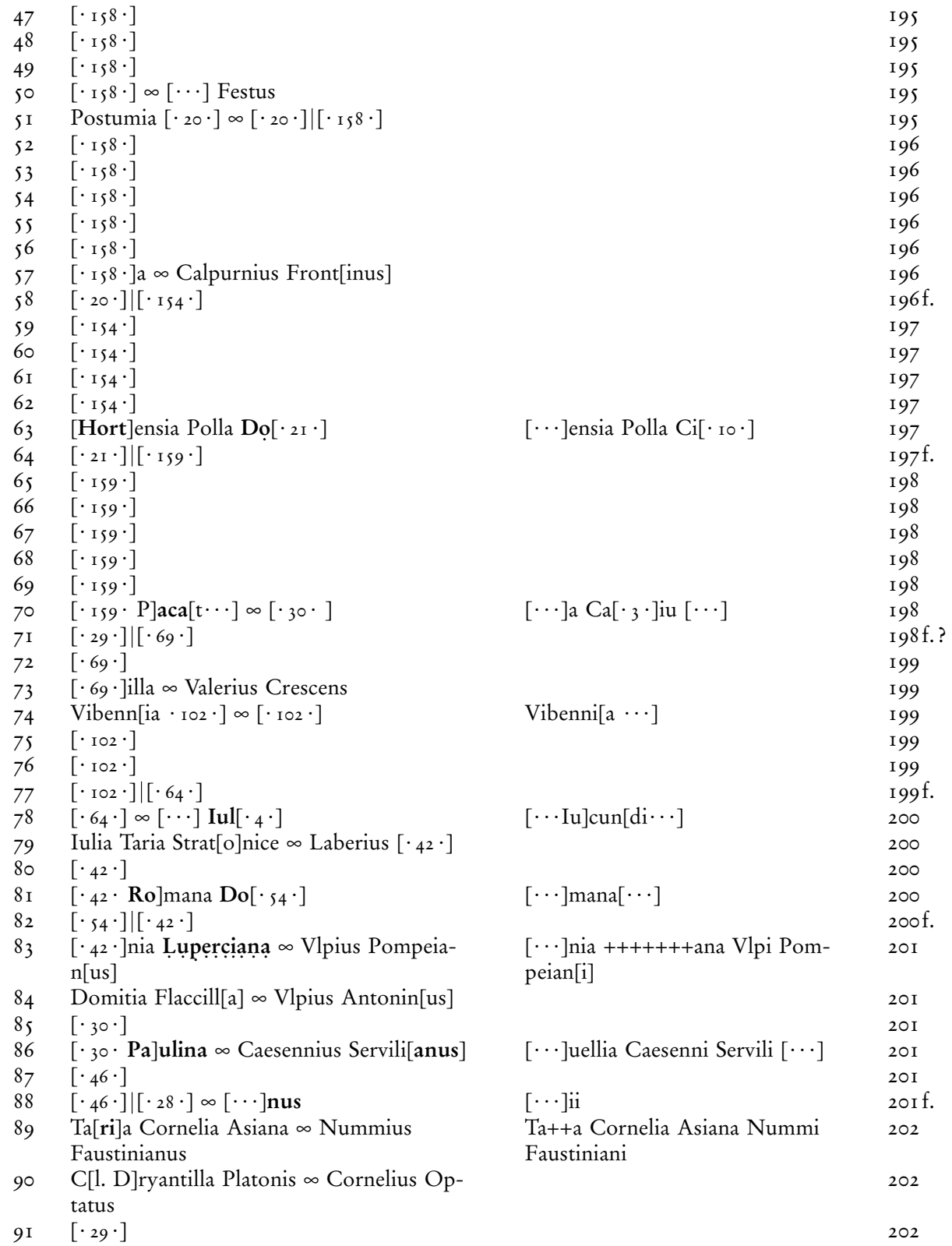

195

In den wenigen Fällen, in denen wir das Ende des Namens eines Ehemanns im Genitiv und den Beginn der Nomenklatur der nächsten Matrone haben - besonders am Anfang und Ende der Liste -, folgt dem Namen des Ehemanns keine senatorische Funktion, im Gegensatz zu einigen $X$ Vviri. Der Fall von MaritSen Nr. 6 Calpurnius Maximus, einem Mitglied des Kollegiums der XVviri, zeigt, dass 
auch ein Priesteramt nicht angegeben war. Die Liste besteht somit nur aus onomastischen Elementen im Nominativ für Frauen und Genitiv für Männer.

Frauen haben Nomenklaturen mit zwei (Gentilicium + Cognomen) $)^{54}$ oder drei Elementen. ${ }^{55}$ Männer haben Nomenklaturen mit nur zwei Elementen. ${ }^{56}$ Nach einer bereits für die XVviri bekannten Praxis sind alle Ehemänner der Matronen ohne Vornamen. Diese Beobachtung erlaubt es, für das Paar Nr. I4 [·8·]ia Pia Tibe $[\cdot 25 \cdot]$, die Buchstaben Tibe nicht als die des Anfangs des Vornamens des Ehemanns, wie von Pighi vorgeschlagen, zu interpretieren. Es handelt sich vielmehr um das letzte Cognomen von MatrSen Nr. I4 [· $8 \cdot$ ]ia Pia Tibe[riana $\cdot 19 \cdot]^{57}$ oder das Gentilicium Tiberius ihres Mannes. ${ }^{5}$ In drei Fällen wurde das Gentilicium, das zur Kategorie der sehr weit verbreiteten Kaisergentilicia gehört, abgekürzt: $F l$. (MatrSen Nr. I); Cl. (MatrSen Nr. 38 und 90).

In den meisten Fällen macht die Unterscheidung von weiblichen oder männlichen Endungen deutlich, welche Nomenklaturen einer Matrone oder ihrem Mann zugeordnet sind. Ein Problem zeigt sich in Z. 193. Die Ansammlung der Buchstaben $\left[\cdot{ }_{15} 8 \cdot\right] N I S$ CL EVDAEM[·22 $]$ hatte Pighi zögern lassen. Er hat sich schließlich dafür entschieden, die Buchstaben NIS einem männlichen Cognomen zuzuordnen und die folgenden Buchstaben einer weiblichen Nomenklatur Cl(audia) Eudaem $[\cdots]$. In einer Fußnote bemerkte er, dass die Alternative möglich sei. ${ }^{59}[\cdots]$ nis wäre dann das Ende eines gräzisierten weiblichen Cognomens, wie Platonis der MatrSen Nr. 90. Anschließend würde der Name des Ehemannes mit Cl(audi) Eudaem [...] folgen. Die in dieser Edition vorgenommene Einteilung der Paare, die auf der durchschnittlichen Berechnung der Nomenklaturen beruht, schließt diese Alternative jedoch aus und ermöglicht es, die von Pighi bevorzugte Lesart auf eine zuverlässigere Grundlage zu stellen. Wir haben es also mit dem Ende des Cognomens von MaritSent Nr. $37[\cdot 158 \cdot]$ nis zu tun, das der Genitiv eines Cognomens auf -io, wie Scipio oder Glabrio, oder auf -o, wie Falco, sein könnte. Es folgt der Name von MatrSen Nr. 38, einer Cl(audia) Eudaem[onis?]. In Z. I98 waren die Buchstaben $A C A$ rätselhaft. Pighi hatte sie leider in $[\cdots] a$ $\mathrm{Ca}[\cdots]$ getrennt, obwohl es keinen Punkt gibt, der diese Trennung unterstützen würde. Eine neue Interpretation ermöglicht es, $[\cdots P] a c a[t \cdots]$ vorzuschlagen,

54 Nr. I und 84 .

55 Nr. 79,89 und 90.

56 Nr. 5, 6, 8, I2, 19, 44, 57, 73, 83, 84, 89, 90.

57 Tibe[ri als Gentilicium des Ehemannes zu ergänzen, ist weniger befriedigend, weil die Form zwar mit Sicherheit belegt, aber als Gentilicium im Senatorenstand äußerst selten war.

58 Die an Tibe[ anschließende Lücke von 2s Buchstaben müsste die Namen von MaritSen Nr. I4, MatrSen Nr. Is und die meisten Namen von MaritSen Nr. is [A]vitus enthalten. Dies könnte zu einer Änderung der Nummerierung der Matronen führen, die allerdings in den großen Lücken der Zeilen I9I-198 eine Neuanpassung finden würde.

59 Pighi (194I) 242, Anm. I. 
wahrscheinlich ein Cognomen von MatrSen Nr.70, die eine [P]aca[ta] oder [P]aca[tiana] gewesen sein könnte. Diese Cognomina erscheinen auch in den Nomenklaturen von Puer Nr. I4 Claudius Pacatianus und Puella Nr. 20 Valleria? $\cdot 2 \cdot$ Inia Pacata.

Andere verbesserte Lesarten oder Ergänzungen ergeben sich für die von Pighi in Z. 200 gelesenen Buchstaben [ $\cdots] M A N A[\cdots]$, die zur Nomenklatur von MatrSen Nr. 8 I gehören. Die Form [ $\cdots$ Ro]mana hat eine Parallele im Namen von Puella Nr. Io Flavia Rom[a]na. ${ }^{60}$ In Z. 201 hatte Pighi für das Ende der Nomenklatur von MatrSen Nr. 86 die Buchstaben [‥JVELLIA gelesen, in denen er das Gentilicium [S] uellia erkannte. Dieses Gentilicium ist seit der Zeit von Augustus im Senatorenstand kaum noch verbreitet. Eine neue Lesart ergibt stattdessen, die Buchstaben $[\cdots]$ VLINA vorzuschlagen, die leicht zu [Pa]ulina ergänzt werden können. Da die Nomenklatur der Ehemänner aus nur zwei Elementen besteht, liegt es nahe, als Ehemann dieser [Pa]ulina einen Caesennius Servili[anus] anzunehmen und nicht Servili[us]. Dieses Agnomen leitet sich von den Servilii Vatiae Isaurici ab, von denen ein Zweig von Caesennii aus der Zeit der Antoninen abstammt. ${ }^{61}$ In Z. 197 hatte Pighi den Namen [...]ensia Polla Ci[…] gelesen. Es liegt nahe, die onomastische Sequenz [Hort]ensia Polla Do[·2I $\cdot$ ] für MatrSen Nr. 63 zu erkennen. ${ }^{62}$ Das Gentilicium von MatrSen Nr. 89 in Z. 202 (Ta* a nach Pighi) muss man als Ta[ri]a lesen. Das bringt diese Ta[ri]a Cornelia Asiana in Beziehung zu MatrSen Nr. 79 Iulia Taria Strat[o]nice. Schließlich scheint das Cognomen von MatrSen Nr. 83 (******ana nach Pighi) mit der üblichen Vorsicht als Luperciana lesbar zu sein, obwohl nur der untere Teil der Buchstaben erhalten ist.

Wie bereits in der Einleitung erwähnt, wird in dem hier vorliegenden prosopografischen Teil der Edition der severischen Säkularakten nur eine Begründung für neue Lesarten und Ergänzungen geliefert. Ein ausführlicher prosopografischer Kommentar zu dem hier vorgestellten Text wird am Ende des Kapitels zwar skizziert, weitere Ergebnisse werden durch eine in Arbeit befindliche Publikation geliefert.

\section{Paare aus dem Ritterstand}

Die Namensliste der 109 Matronen, die Iulia Domna begleiten, wird mit den Namen von I 8 ritterlichen Matronen und ihren Ehemännern im Genitiv fortgesetzt. Dieser Teil der Liste wird, wie oben erwähnt, durch den Ausdruck [E]quest-

60 Es gelang, nach dem Cognomen $[\cdots$ Ro]mana die Buchstaben DO $[\cdots]$ zu lesen, die von den Vorgängern nicht gesehen wurden. Sie können der Beginn eines anderen Cognomens von MatrSen Nr. 8 I (z. B. Do[mitiana]) oder das Gentilicium ihres Mannes (z. B. Do[miti]) gewesen sein.

6 I $\mathrm{Zu}$ dem Netzwerk von Familien siehe Chausson (2005) I07-I 55; ders. (2006) 32-69; ders. (2010) I75-190.

62 Wie bei MatrSen Nr. 8 I können die Buchstaben DO der Anfang eines zweiten Cognomens oder des Gentiliciums ihres Ehemannes sein. 
res (Z. 202) eingeleitet, gefolgt von einem kleinen vacat, was keinen Zweifel am Status dieser Matronen lässt.

Liste der I 8 Matronen ritterlichen Ranges und ihrer Ehemänner

Nr. Nomenklatur

Abweichung bei Pighi

Zeile

\begin{tabular}{|c|c|c|c|}
\hline 92 & Iulia Suem[ias Bassiana] $\infty$ [Varius Marcellus] & Iulia Suem[ia Vari Marcelli] & 202 \\
\hline 93 & {$[\cdot 27 \cdot \mid \cdot 26 \cdot]$} & & $202 \mathrm{f}$. \\
\hline 94 & {$[\cdot 26 \cdot]$ a Vrḅạana $\infty$ Flavius Drusianus } & {$[\cdots]$ Virbiana $[F]$ lavi Drusiani } & 203 \\
\hline 95 & Caesennia Tusidiana $\infty$ Livius Rogatus & & 203 \\
\hline 96 & Claudia V[al]entina $\infty$ Aquilius Agri[cola $]$ & Claudia V[al]entina Aquili Agre[stis] & 203 \\
\hline 97 & {$[\cdot 27 \cdot]$} & & 203 \\
\hline 98 & {$[\cdot 27 \cdot]$ elia Flaviana $\infty$ Tarronius $[\cdot 50 \cdot]$} & & 203 \\
\hline 99 & {$[\cdot 50 \cdot]$} & & 203 \\
\hline 100 & {$\left[\cdot{ }_{23} \cdot\right] \infty[\cdots]$ Campanus trib. } & & 204 \\
\hline IOI & Octavia Athenais $\infty$ Flavius Clemens trib. & & 204 \\
\hline 102 & Semproni[a Sp]oletina $\infty$ Cornelius Fel[ix trib.] & Semproni[a Sp]oletina Corneli Fel[icis] & 204 \\
\hline 103 & {$[\cdot 22 \cdot] \infty[\cdots]$ ratus trib. } & {$[\cdot 26 \cdot]$ ati trib. } & 204 \\
\hline IO4 & Maria Passen[ia(na) $] \infty[\cdot 45 \cdot$ trib. ?/primipil. ?] & & 204 \\
\hline 105 & {$\left[\cdot 45 \cdot \mid \cdot{ }^{5} \cdot\right] \infty[\cdots]$ inus primipil. } & & $204 \mathrm{f}$. \\
\hline 106 & Aelia Gemellina $\infty$ Armenius Iulianus & & 205 \\
\hline 107 & Antonia Tironi[l]la $\infty$ Iulius Max[imus] & & 205 \\
\hline 108 & [A] elia Marciana $\infty$ Cossin $\left[\right.$ ius $\left.\cdot 33^{\cdot}\right]$ & [A]elia Marciana Cossen $[\mathrm{i} \cdots]$ & 205 \\
\hline I०9 & {$\left[\cdot 33^{\cdot}\right] \infty[\cdots]$ striṣ $[[\cdots]]$} & {$[\cdot 27 \cdot] \operatorname{tri}[\mathrm{b}]$.} & 205 \\
\hline
\end{tabular}

Von den I 8 ritterlichen Paaren sind die Namen von drei Paaren vollständig verschwunden. ${ }^{63}$ In drei weiteren Fällen blieben nur noch wenige Fragmente des Namens des Mannes übrig, die nicht verwertbar sind. ${ }^{64}$ Zwölf von achtzehn Paaren sind somit mit wesentlichen Elementen bekannt, in vielen Fällen sind beide Namen vollständig oder fast vollständig.

Die Nomenklatur der ritterlichen Matronen beruht größtenteils auf zwei Elementen (Gentilicium + Cognomen) mit der wahrscheinlichen Ausnahme von $M a t r E q$ Nr. 92. Die Nomenklatur der Ehemänner aus dem Ritterstand beruht auf zwei Elementen, auch hier ohne Vornamen. Im Gegensatz zu den senatorischen Ehemännern, für die kein Amt angegeben zu sein scheint, führen einige Ehemänner den Rang eines Tribunus oder Primipilus, zumindest von Nr. I00 bis I05. Die Namen der letzten Ehemänner, wahrscheinlich von Nr. 106 bis I09, scheinen nicht von Rang oder Titel gefolgt zu sein.

Das Verständnis der Hierarchie der Liste ist nicht ohne Folgen für die Erstellung des Textes. Wir wissen nicht, welchen Rang in der ritterlichen Hierarchie die Ehemänner der ersten acht Matronen der Liste einnehmen; anschließend werden die Ehefrauen der Ritter aufgelistet, die den Titel tribunus tragen, sowie zumindest die Frau eines Mannes, der den Rang eines primipilus oder primipilaris innehatte.

63 Nr. 93, 97 und 99.

64 Nr. I03, I05 und I09. 
Die Liste schließt mit Frauen von Ehemännern, die keinen Titel tragen, wie am Anfang. Die Reihenfolge der Aufzählung basiert demnach auf einer Hierarchie, die auf der ritterlichen Würde beruht. Bei möglichen Ergänzungen ist darauf zu achten, die Untergruppen auf dieser Liste klar voneinander abzugrenzen, um den Ehemännern einen ihnen zustehenden Titel zuweisen zu können.

Die erste Matrone auf dieser Liste (MatrEq Nr. 92) ist Iulia Domnas eigene Nichte, eine junge Frau, die um 203 oder 204 ihren Sohn Bassianus, den zukünftigen Kaiser Elagabal, geboren hat. Ihr Mann, Sex. Varius Marcellus, ein Ritter aus Apameia in Syrien, war damals procurator aquarum, centenarius. ${ }^{65}$ In der Grabinschrift, die MatrEq Nr. I um 2 I7/2 I 8 mit ihren Kindern auf dem Sims des Grabes ihres verstorbenen Mannes in Velletri errichten liess, ist der vollständige Name von Iulia Suem[‥] mit Iulia Soaemias Bassiana erhalten. ${ }^{66}$ Diese Parallele ermöglicht, die Form Suem[ias] mit $S$ der von Pighi gewählten Form [Suemia] vorzuziehen. Außerdem ist für MatrEq Nr. 92 als einziger der ritterlichen Matronen mit der Ergänzung des Cognomens Bassiana eine dreiteilige Nomenklatur wahrscheinlich. Dieses Cognomen ist insofern von Bedeutung, als es vom Vater von Iulia Domna und von Caracalla als Kind getragen wurde und ein Zeichen der Zugehörigkeit zur kaiserlichen Familie war. Die Anwesenheit des Paares an erster Stelle der ritterlichen Paare ergibt sich aus der verwandschaftlichen Beziehung zwischen MatrEq Nr. 92 und der herrschenden Familie sowie dem Rang des Mannes, den er der kaiserlichen Gunst zu verdanken hatte. ${ }^{67}$

Während der Status von MaritEq Nr. I bekannt ist, kann das Gleiche für die folgenden sieben Matronen nicht gesagt werden. Bei den folgenden vier Ehemännern tragen die ersten beiden (Nr. I०० und IоI) und der vierte (Nr. I०3) den Rang eines trib(unus). Es handelt sich hier um eine Gruppe von Tribunen, und die Buchstaben TRIB können auch nach dem Namen von MaritEq Nr. IO2 ergänzt werden. Es lässt sich nicht feststellen, wo die Aufzählung der Ehefrauen von Tribunen beginnt. Es kann daher nicht ausgeschlossen werden, dass es unter den Ehemännern Nr. 96 bis 99 möglicherweise bereits Tribune gegeben hat.

Der Rang von MaritEq Nr. Ios unmittelbar nach der Gruppe der Tribune ist nicht bekannt. MaritEq Nr. 106 trägt explizit den Grad eines primipil(aris), das heißt eines ehemaligen und entlassenen primipilus. MaritEq Nr. Ios kann daher entweder ein weiterer tribunus oder bereits ein primipilaris gewesen sein.

65 $\mathrm{PIR}^{2} \mathrm{~V} 282$.

66 CIL X 6569 (ILS, 478), Velitrae.

67 Patrice Faure weist mich darauf hin, dass im commentarium der Name von Iulia Suemias nach ihrem gewaltsamen Tod im Jahr 222 nicht getilgt wurde, wogegen dies beim Namen von Geta im Jahr 2 I I der Fall war. Es gibt gut dokumentierte Fälle der Tilgung des Namens der Mutter von Antoninus Elagabal. Da ihr Name in der Liste der Acta Severiana bereits alt war und nicht aus einer wichtigen Inschrift der Regierungszeit ihres Sohnes (2I8-222) stammt, wurde ihr Name hier nicht entdeckt oder gar nicht gesucht. 
Den Namen der nachstehenden Ehemänner (Nr. 106 und I07) folgen keine Titel. Es ist daher unwahrscheinlich, dass nach dem unvollständigen Namen von $M a-$ ritEq Nr. 108 ein Titel oder Rang erschien. Der Name des letzten Paares (Nr. I09) verschwindet fast vollständig in einer Lücke (Z. 205). Am Ende der Nomenklatur sind noch drei Buchstaben erhalten, während ein vierter Buchstabe unter einer Beschädigung auf der Oberfläche des Steins erraten werden kann. ${ }^{68}$ Pighi hatte diese Buchstaben als tri $[b$ interpretiert in der Meinung, dass auch der letztgenannte Ritter ein tribunus gewesen sei. Wie bereits erwähnt, befanden sich die Namen der tribuni weiter oben auf der Liste, mindestens von MaritEq Nr. Ioo bis MaritEq Nr. I04. Anschließend erschien mindestens eine Ehefrau eines primipilaris (MaritEq Nr. I06), was darauf hindeutet, dass die Liste der Ehefrauen von Tribunen abgeschlossen war. Es scheint, dass die vier Buchstaben TRIS eher als Teil des Cognomens oder eines Amtes von MaritEq Nr. Io9 zu verstehen sind. Es ist in der nachfolgenden Beschädigung des Steins nicht auszumachen, ob danach noch einige Buchstaben folgten.

Bei den nachstehenden Paaren wird der Lesung von Pighi nicht gefolgt:

Paar Nr. 94: Das Cognomen von MatrEq Nr. 94 ist kaum lesbar. Pighi hatte [..] Virbiana [F]lavi Drusiani vorgeschlagen. Wir lesen ein $A$ als letzten Buchstaben des Gentiliciums der Matrone und schlagen die Form Vrbiana für das Cognomen vor, ohne darauf beharren zu wollen. Das anfängliche $F$ des Gentiliciums des Mannes kann man noch schwach erkennen.

Paar Nr. 96: Pighi hatte für MaritEq Nr. 96 folgende Nomenklatur vorgeschlagen: Aquili Agre[stis]. Das Cognomen ist jedoch als solches nicht belegt. Wir ziehen es vor, ein $I$ anstelle des $E$ zu lesen und schlagen die verbreitete und gut belegte Form Aquili Agri[colae] vor.

Die MatrEq Nr. I०4 Maria Passen[...] kann bei Gebrauch eines Gentiliciums als Cognomen eine Maria Passen[ia] gewesen sein oder eine Maria Passen[iana], wenn das Cognomen von einem Gentilicium abgeleitet wurde. Schließlich ist MaritEq Nr. IO3 mit einem gewonnenen Buchstaben ein [ ‥] ratus trib(unus) anstelle eines [..] ]atus trib(unus), während MaritEq Nr. I08 ein Cossin[ius ...] und nicht ein Cossen[ius ...] war.

68 Über einige Zentimeter ist die Oberfläche des Steins abgerieben. Dadurch sind das Ende der Nomenklatur von MaritEq Nr. I09 und der Anfang des Wortes [sellis]tern [ia] nicht lesbar. Es ist nicht sicher, ob es sich um ein bewusstes Aushämmern dieses Stücks handelt oder um ein vacat, welches das Ende der Liste der Matronen anzeigte. Es wäre schwer zu verstehen, wenn sowohl die letzten Buchstaben eines Namens, ein mögliches vacat und die ersten fünf Buchstaben des Wortes [sellis]tern[ia] getilgt wären. Viel plausibler ist, dass der Stein hier durch den Aufprall auf andere Blöcke gelitten hat oder dass der Steinmetz einen Fehler gemacht hat, den er verschwinden lassen wollte. 
Die ausdrückliche Erwähnung von ritterlichen Matronen wurde in der augusteischen Inschrift nicht aufgenommen. Man muss deswegen nicht auf eine severische oder bereits domitianische Innovation schließen. Es ist nicht bekannt, ob es unter den i Io augusteischen Matronen bereits Frauen aus dem Ritterstand gab. Die geringe Anzahl von i 8 ritterlichen im Vergleich zu 91 senatorischen Matronen und ihr Status erlauben kaum Beziehungen zu den anderen Listen. ${ }^{69}$ Die XVviri haben einen bedeutend höheren Rang und sind weit entfernt vom Ritterstand. Alle 27 Puellae scheinen Töchter von Senatoren gewesen zu sein, von den 27 Pueri scheint nur der vorletzte mit Sicherheit aus dem Ritterstand zu stammen. Dies mag auch für den letzten der Fall sein, ist aber viel unsicherer. Es gibt also keine Parallele zwischen den ritterlichen Matronen einerseits und den anderen Gruppen andererseits. Nur eine onomastische Untersuchung seltener Namen könnte ermöglichen, die geografische Herkunft der Matronen zu verfolgen. ${ }^{70}$

Einige Ehemänner waren Offiziere aus dem Ritterstand. Vier, vielleicht fünf oder sogar sechs, waren Tribune. Einer und vielleicht auch ein zweiter war ein primipilaris. $^{{ }^{11}}$ Tribune sind vor den primipilares und in größerer Zahl aufgeführt. Die Liste dieser Ehemänner wurde zuletzt von Patrice Faure bearbeitet. ${ }^{2}$ Ihm zufolge - und nach Dobson ${ }^{73}$ - hätten diese tribuni zur stadtrömischen Garnison gehören können, wahrscheinlich zu den Prätorianern, womit ein hoher Rang der militärischen Hierarchie erreicht wäre. Wenn sie Prätorianer wären, würde dies der

69 Es ist zu beachten, dass zwischen MatrEq Nr. 95 Caesennia Tusidiana keine besondere Beziehung zu MaritSen Nr. 85 Caesennius Servili[anus] gedacht werden sollte. MatrEq Nr. 95 gehörte einer munizipalen, zweifellos italischen Familie an, während MaritSen Nr. 85 aus einer großen senatorischen Familie stammte, die seit julischclaudischer Zeit Konsulate erhalten hatte und mit der Familie von Antoninus Pius verbunden war.

70 Bei MatrEq Nr. 95 Caesennia Tusidiana und MatrEq Nr. Io3 Semproni[a Sp]oletina wurde mangels einer besseren Interpretation die traditionelle Integration des Cognomens beibehalten.

7I Die Abkürzung PRIMIPIL., die nur für MaritEq Nr. Ios bezeugt ist, wird hier zu primipil(aris) aufgelöst, einem von Faure bevorzugten Begriff, auch wenn er primipil(i) nicht vollständig ausgeschlossen hat, jedoch für weniger wahrscheinlich hält (siehe folgende Anm.). Tatsächlich veranlasst die Länge der Abkürzung, hier die Form primipil(aris) vor der primipil(i)-Form vorzuziehen. P. Faure wies mich darauf hin, dass es sich bei der primipil(i)-Form nur um einen weiteren Buchstaben handelte. Er fügte hinzu, dass in einem militärischen Kontext die Abkürzung $P P$ gegenüber $P R I$ MIPIL bevorzugt worden wäre; der Redaktor der Inschrift wählte eine Form, die keine Mehrdeutigkeit zulässt.

72 Dieser Abschnitt des commentarium wurde von P. Faure wiederholt untersucht: Faure (20I3), Bd. I, 373 (zu den Ehefrauen der centuriones) und 424 (zum Verhältnis zwischen Ritterstand und Centurionat), Bd. 2, 598 f., Nr. 78-82 zu einer Prosopografie der Ehemänner. Sein Buch bietet einen Überblick über die frühere Geschichtsschreibung im Zusammenhang mit der Zuordnung dieser Tribune, entweder zur stadtrömischen Garnison oder zum Stab der Legionen. 
besonderen Bedeutung entsprechen, die den Prätorianern unter Septimius Severus beigemessen wurde. Die Prätorianer waren im Jahr 193 n. Chr. entlassen worden. In einem breiteren Umfeld außerhalb Italiens neu rekrutiert und von Plautianus angeführt, bildeten sie eines der Fundamente der severischen Macht. Ihr Präfekt Plautianus war ein naher Verwandter des Kaiserhauses, der auch bei den Zeremonien der Säkularspiele anwesend war. Die Anwesenheit der Ehefrauen von Offizieren der stadtrömischen Prätorianergarde bei dem wichtigen staatstragenden Akt der supplicatio würde die Bedeutung sichtbar machen, die Septimius Severus ihnen zumaß.74 Nach einer mündlichen Mitteilung von Michel Christol waren diese ritterlichen Tribune als tribuni angusticlavii eher höhere Offiziere der Legionen. Diese ritterlichen Tribune sind oft Söhne von Rittern und die Anwesenheit ihrer Frauen bei den feierlichen Handlungen der Matronen könnte in diesem Fall eher auf das Gewicht ihrer Familien zurückzuführen sein.

Die primipilares profitierten von dem Rang als Ritter, der ihnen am Ende des Militärdienstes verliehen wurde. Wie mir Patrice Faure sagte, vertreten sie die provinzielle Legionsarmee. ${ }^{75}$ Auf diese Weise könnten verdienstvolle Offiziere belohnt worden sein. Unabhängig vom Status der Tribune und des einzigen primipilaris stellt sich die Frage, wie der Rang der letzten vier Ehemänner (Nr. I06I09), die danach erscheinen, sein kann.

\section{d. Pueri}

Fast sechzig Zeilen später erscheinen die Listen der Kinder, denen das Singen des carmen saeculare obliegt. Zuerst 27 Jungen (Z. 26I-263), dann 27 Mädchen (Z. 263-266). Diese beiden Gruppen waren eng mit der Gruppe der Matronen verbunden, wie Z. 260 zeigt: [ $\cdots$ Inde pueri] senatores, item puellae, mat[ro]nae carmen cecinerunt. Quorum nom [ina infra subscripta sunt: vacat $(2 I)] .^{6}$

74 Michel Christol, François Bérard und Patrice Faure waren bereit, mit mir diese Fragen zu diskutieren. Es sei ihnen an dieser Stelle gedankt.

75 P. Faure unterstreicht, dass der einzige primipilaris ausdrücklich belegt und nach den tribuni erwähnt wird. Dies zeigt, dass er erstmals primipilaris war und keinen Zugang zum Tribunat der stadtrömischen Garnison hatte.

$76 \mathrm{Zu}$ Beginn von Z. 260 deckt das Adjektiv senatores, das sich auf die Pueri beziehen muss, nicht die gesamte Gruppe ab, da nur 25 der 27 Pueri senatorischen Ranges sind. Der vorletzte, Puer Nr. 26, ist ein römischer Ritter, während der letzte, Puer Nr. 27, von ungewissem Rang ist. Vielleicht ist er der Sohn eines römischen Ritters, der noch nicht mit dem equus publicus ausgezeichnet war. Obwohl das Wort senatores perfekt in die Lücke passt, sollte Z. 260 nicht vollständig bis zum Rand mit einer Ergänzung gefüllt werden. In diesem Bereich des Steins war der Text aus unerklärbaren Gründen nicht bis an den Rand beschrieben. Zur Begründung siehe Kommentar zur Textkonstitution S. $358 \mathrm{f}$. 
Liste der 27 Pueri

Nr. Nomenklatur

Abweichung bei Pighi

Zeile

\begin{tabular}{|c|c|c|c|}
\hline I & {$\left[\cdot{ }_{\text {I2 }} \cdot\right]$ s Maximus } & & $26 \mathrm{I}$ \\
\hline 2 & $\mathrm{I}[\mathrm{ul}] \mathrm{iu}[\mathrm{s}$ F]austinus & $\mathrm{I}[\mathrm{un}] \mathrm{iu}[\mathrm{s}$ F]austinus & $26 \mathrm{I}$ \\
\hline 3 & Iulius Crescens & & $26 \mathrm{I}$ \\
\hline 4 & Iul. Ca[s]sius Paulinus & & $26 \mathrm{I}$ \\
\hline 5 & $\mathrm{Clo}[\cdot 23 \cdot]$ & Clo[dius Marcellinus] & $26 \mathrm{I}$ \\
\hline 6 & {$[\cdot 23 \cdot] \mathrm{m}\left[\cdot 10^{\cdot}\right]$} & & $26 \mathrm{I}$ \\
\hline 7 & Alfius Avitus & & $26 \mathrm{I}$ \\
\hline 8 & Opratius $\mathrm{Ti}[\mathrm{t}]$ ianus & & $26 \mathrm{I}$ \\
\hline 9 & Flavius Iulius Latron[ianus] & & $26 \mathrm{I}$ \\
\hline IO & {$[\cdot 40 \cdot]$} & & $26 \mathrm{I}$ \\
\hline II & {$\left[\cdot 40^{\circ}\right]$} & & $26 \mathrm{I}$ \\
\hline I 2 & {$\left[\cdot{ } I_{4} \cdot\right]$ ianus } & {$[\cdots]$ anus } & 262 \\
\hline I 3 & Vmbilius [Ma]ximinus & & 262 \\
\hline I 4 & Claudius Pacatianus & & 262 \\
\hline Is & $\mathrm{Iu}[\mathrm{l}] \mathrm{ius} \mathrm{Sa}[\mathrm{t}]$ yrus Dryan[tianus $]$ & $\mathrm{Iu}[1]$ ius $\mathrm{Sa}[\mathrm{t}]$ yrus Dryan[s] & 262 \\
\hline 16 & {$\left[\cdot{ }^{\prime 6} \cdot\right]$ s Maxim $[\cdot 7 \cdot]$} & $\operatorname{Maxim}[\cdots]$ ius & 262 \\
\hline 17 & {$[\cdot 7 \cdot]$ s Vlpius Attianus Iun(ior) } & & 262 \\
\hline I 8 & Laberius Pompeianus & & 262 \\
\hline 19 & Cattius Clemẹnț[inus $\cdot 46^{\circ}$ ] & & 262 \\
\hline 20 & {$[\cdot 46 \cdot]$} & & 262 \\
\hline $2 \mathrm{I}$ & {$[\cdot 46 \cdot]$} & & 262 \\
\hline 22 & [Baburius Herc(?)]ulanius & {$[\cdots]$ ulanius } & 263 \\
\hline 23 & Baebius Mạrcellinus & & 263 \\
\hline 24 & Aelius Anțipater & & 263 \\
\hline 25 & Corfin[iu]s Felix $\{s\}$ & & 263 \\
\hline 26 & Corṇ $\left[\cdot{ }^{\circ} 5^{\circ}\right]$ s eq. $\mathrm{R}$. & $\operatorname{Cor}\left[\cdot 15^{\cdot}\right]$ eq. R. & 263 \\
\hline 27 & Licin[iu]s Aemil[ia]nus Ingen(uus) & & 263 \\
\hline
\end{tabular}

In der Liste der Matronen musste die Platzierung der Namen der Ehefrauen und ihrer Ehemänner genau berechnet werden. Die Liste der Pueri dagegen enthält wie die der Puellae nur einfache Namen. Bei den erhaltenen Namen hat der kürzeste $^{77}$ eine Länge von I 2 Buchstaben, der längste ${ }^{78}$ von 24 Buchstaben. Daraus ergibt sich eine durchschnittliche Länge von etwa I 8 Buchstaben pro Nomenklatur. Die Namen von vier Pueri sind somit ganz verloren gegangen, ${ }^{79}$ und von zwei anderen sind nur wenige unbrauchbare Buchstaben erhalten geblieben. ${ }^{8 \circ}$ In einem Fall erinnern uns die Buchstaben CLO am Anfang der Nomenklatur auf einleuchtende Weise an das Gentilicium Clo[dius], ${ }^{81}$ ohne jedoch den Zweig der senatorischen Clodii eindeutig identifizieren zu können, zu dem dieser Puer gehören könnte. ${ }^{82}$

77 Nr. 7.

78 Nr. 9, Nr. I5.

79 Nr. Io, Nr. i I, Nr. 20, Nr. 2 I.

80 Nr. 6: $[\cdots] m[\cdots]$; Nr. I 2: [ $\cdots]$ ianus.

8 I Die Nomenklatur von Puer Nr. 5 wird in der Form Clo[ $\cdot 23 \cdot]$ nur transkribiert, die unbegründete Ergänzung von Pighi Clo[dius Marcellinus] aber ausgeschlossen.

82 Ein Verzeichnis der senatorischen Clodii des 3. Jahrhunderts bei Chausson (1998) I $77-2$ I 3 . 
In einem anderen Fall ${ }^{8_{3}}$ sträuben sich die Buchstaben [ $\left.\cdots\right]$ VLANIVS zunächst gegen eine Interpretation, da die Endung selten ist. ${ }^{84}$ Der Name Urgulanius sollte ausgeschlossen werden, denn dieser äußerst seltene Name ging über eine berühmte Freundin Livias, Urgulania, ${ }^{85}$ in der julisch-claudischen Zeit in die Familie der Plautii Silvani über und ist im Senatorenstand nach der Mitte des I. Jahrhunderts nicht mehr belegt. Eine vielleicht gewagte Hypothese kann versucht werden: Eine Inschrift aus Hippo ${ }^{86}$ die ungenau für das 3 . Jahrhundert datiert ist, erwähnt einen Baburius Herculanius, c(larissimus) p(uer), patronus der Kolonie von Hippo, der durch den ordo dieser Stadt geehrt wird. Er ist der Sohn eines L. Baburius Iuvenis $c$ (larissimus) $v$ (ir) und der Bruder eines L. Baburius Invenis c(larissimus) p(uer), der ebenfalls in Hippo mit einer Doppelinschrift geehrt wurde. ${ }^{87}$ Der Vater oder der gleichnamige Bruder ließ in Rom einen kleinen Altar errichten, der der Fortuna Tutela gewidmet war. ${ }^{88}$ Wir schlagen vor, hinter Puer Nr. $22\left[\cdot{ }^{14} \cdot\right]$ ulanius [Baburius Hercjulanius zu identifizieren. Die damit ergänzten I 2 Buchstaben entsprechen in etwa den I4 von Bärbel Schnegg für diese Lücke berechneten. Somit begann die Zeile mit der Nomenklatur dieses Jungen. In der senatorischen Ordnung des 2. bis 3. Jahrhunderts war er die einzige Person, deren Name eine -ulanius Endung hatte. Die Ergänzung erscheint noch plausibler, als Puella Nr. 2 I eine [B]aburia Va[…] ist: Wir hätten also wie bei den Alfii einen weiteren Fall von Bruder und Schwester in den beiden Kindergruppen. Die Familie der Baburii hatte wichtige Verbindungen zu anderen senatorischen Familien in Afrika. Wie M. Corbier betont, empfahl Fronto einem Einwohner von Cirta, C. Arrius Antoninus, auf die Wünsche einer bestimmten Baburiana einzugehen. ${ }^{89}$ Die hier vorgeschlagene Ergänzung, unterstützt durch die Parallele in der Liste der Puellae und durch die Einzigartigkeit der Namensendung auf -ulanius, würde es ermöglichen, die Gruppe der in Hippo bezeugten senatorischen Baburii besser zu datieren. Wenn die beiden Baburii, Puer Nr. 22 und Puella Nr. 21, Bruder und Schwester waren, nahmen sie mehr oder weniger die gleiche Position in der Liste ein. Es ist denkbar, dass Geschwisterpaare bei der Aufführung des carmen saeculare oder der Prozession vom Palatin auf das Kapitol in irgendeiner Form choreografisch kenntlich

83 Nr. 22.

84 Eine umfassende Durchsicht der PIR ${ }^{2}$ und des Kolloquiums EOS haben die Bestätigung ergeben.

85 PIR $^{2} \mathrm{~V}$ ioio.

86 AE, I958, 138 .

87 AE, I958, I 37. Zu dieser Familie Corbier (1982) 68 5-754, bes. 720-721.

88 CIL VI 178 (ILS, 3722): Deae Fortunae Tutelae |L(ucius) Baburius Iuvenis.

89 Fronto, ad am. II, 8, 2-4; PIR $^{2}$ B 2. Bemerkenswert ist, dass sich der folgende Brief in der Sammlung mit Fällen von Hippo Regius beschäftigt, von wo die Baburii in Bezug auf die Wahl der patroni hervorgegangen sind. Der Brief, in dem Baburiana erwähnt wird, bezieht sich auf die Empfehlung von Männern: Es ist davon auszugehen, dass die beiden Schreiben miteinander verbunden sind. 
gemacht waren. Auch die beiden Alfii, Puer Nr. 7 und Puella Nr. 6, nehmen in der Reihenfolge der beiden Listen etwa den gleichen Platz ein. Man kann sich fragen, ob ihnen in ihrer Gruppe je eine gleichwertige Position bei der Prozession zugewiesen wurde, um mit den Geschwisterpaaren einen Effekt der Symmetrie zu erzeugen. Ein systematisches Vorgehen ist jedoch nicht zu erkennen..$^{90}$

Keiner der Pueri hat einen Vornamen. Angesichts des fragmentarischen $\mathrm{Zu}$ stands der Liste haben zehn von ihnen ${ }^{91}$ eine Zwei-Elemente-Nomenklatur (Gentilicium + Cognomen) und drei eine Drei-Elemente-Nomenklatur. ${ }^{92}$ Für die Pueri Nr. 16 und 17 stellen die Lücken in Z. 262 einige Probleme bei der Unterscheidung zwischen den beiden Nomenklaturen dar. Die von Puer Nr. I6 belegt mindestens

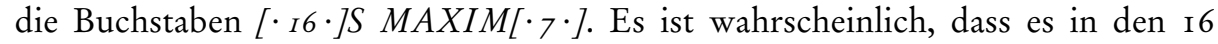
Buchstaben der Lücke zwei onomastische Elemente gab und dass dieser Junge eine Drei-Elemente-Nomenklatur hatte. Die sieben fehlenden Buchstaben hinter den Buchstaben MAXIM decken wahrscheinlich das erste Element der Nomenklatur des nächsten Jungen ab. Dieser, Puer Nr. I7, heißt [·7·]S VLPIVS ATTIANVS $I V N($ ior $)$. Dies würde bedeuten, dass er eine viergliedrige Nomenklatur hatte; das Wort Iun(ior) ist jedoch kein Cognomen, es ist vielmehr ein Merkmal, um diesen Puer von seinem gleichnamigen Vater zu unterscheiden.

Diese Liste hat zwei Besonderheiten hinsichtlich der Schreibweisen. Das Gentilicium von Puer Nr. 8 namens Opratius Titianus ist in der Tat ein Ocratius. ${ }^{93}$ So ist der Name in die Liste der Pueri eingetragen, die am lusus Troiae teilgenommen haben (PuerLus Nr. I3), und zwei Inschriften von Volubilis bestätigen dies. ${ }^{94}$ Diese erwähnen einen Ritter namens Ocratius Titianus, ${ }^{95}$ Bruder eines T. Ocratius Valerianus clarissimus, Quästor der Provinz Baetica und wahrscheinlich Vater von Puer Nr. 8.96 Das Cognomen von Puer Nr. 25, Corfin[iu]s Felix\{s\}, weist eine phonetisch bedingte Verschreibung auf. Das Gentilicium von Puer Nr. 2 befindet sich an der Bruchlinie zwischen zwei Fragmenten und die verschiedenen Restaurationen haben zu einem Zwischenraum geführt. Es scheint, dass es I[ul]iu[s F]austinus und nicht I[un]ius heißen sollte, wie von den früheren Herausgebern vorgeschlagen. Keine schräge Linie ermöglicht es, auf ein $N$ zu schließen, während dünne Reste von vertikalen Stäben nahelegen, ein $L$ anzunehmen. Aber die Exis-

90 Es ist unklar, ob Puer Nr. 9 Flavius Iulius Latron[ianus] und Puella Nr. Io Flavia Rom[a]na, die ebenfalls etwa die gleichen Listenpositionen besetzen, geschwisterlich verbunden werden können. Es gibt keine Möglichkeit, Puer Nr. I4 Claudius Pacatianus und Puella Nr. I9 Corn[eli]a Claudia Pia in Beziehung zueinander zu bringen.

9 I Nr. 2, 3, 7, 8, I3, I4, I8, 23, 24, 25.

92 Nr. 4, 9, I5.

$93 \mathrm{PIR}^{2} \mathrm{O}$ I I. Auf dem Stein ist Titianus und nicht Tatianus zu lesen, wie eine Notiz in der PIR ${ }^{2}$ nach Romanelli und Pighi festhält.

94 ILM, I 27; ILM, 92 (AE, I966, 603).

95 $\mathrm{PIR}^{2} \mathrm{O}$ I 2.

$96 \mathrm{PIR}^{2} \mathrm{O}$ I 3 . 
tenz eines C. Iunius Faustinus [Pl]a[ci]dus Postumianus, ${ }^{97}$ consul suffectus um 205 n. Chr. und Vorfahre eines C. Iunius Faus[ti]nus Postumianus, Statthalter von Britannien, schlecht datiert in der zweiten Hälfte des 3. Jahrhunderts, ${ }^{98}$ machen es nötig, diese neue Lesung nur mit größter Vorsicht vorzuschlagen. ${ }^{99}$

Das Gentilicium von Puer Nr. I, [ $\left.\cdot_{I 2} \cdot\right]$ s Maximus, ist verloren. Das ist bedauerlich, denn die Liste beginnt mit ihm und die ersten Personen in den Listen sind besonders wichtig. Die erste Matrone ist die Frau des Magisters des Kollegiums der XVviri, der für die Vorbereitungen der ludi saeculares im Jahr $203 \mathrm{n}$. Chr. verantwortlich ist. Die erste Puella ist höchstwahrscheinlich die Tochter dieses Paares. Es ist anzunehmen, dass Puer Nr. I, [· $\left.{ }_{12} \cdot\right]$ s Maximus, auch mit einem Mitglied des Kollegiums der XVviri verwandt war. Sein Cognomen ist alltäglich, aber es bietet sich ein Querverweis auf einen XVvir an, den wir identifiziert haben, Calpurnius Maximus (Nr. 4*). Dessen Frau ist MatrSen Nr. I 2. Bei einer Ergänzung von Puer Nr. I zu [Calpurniu]s Maximus ließen sich neun in die mit I 2 Buchstaben von B. Schnegg berechnete Lücke einfügen. ${ }^{100}$ Unter den ersten Pueri sind drei Iulii (Nr. 2, I[ul]iu[s F]austinus; Nr. 3, Iulius Crescens; ${ }^{\circ 1}$ Nr. 4, Iul. Ca[s]sius Paulinus). ${ }^{102}$ Der XVvir Nr. I 3, Iulius Pompeius Rusonianus, Magister des Kollegiums 204 n. Chr., ist ein Iulius. Es kann jedoch nicht gesagt werden, ob Puer Nr. 4 Iul. Ca[s]sius Paulinus mit dem XVvir Nr. Is Cassius Pius Marcellinus verwandt war. Weil vier der ersten acht Puellae wahrscheinlich Töchter von XVviri waren, ist die Eingliederung des Sohns eines $X$ Vvir plausibel, wie wir später sehen werden.

Als zweites Cognomen von Puer Nr. Is sollte nicht Dryan[s] ergänzt werden, wie von Pighi vorgeschlagen; diese Form ist im Senatorenstand nicht bezeugt. Die Form Dryan[tianus] ist vorzuziehen; sie findet sich in einer senatorischen Familie in Lykien, die in verwandtschaftlicher Beziehung zum Usurpator Avidius Cassius steht. $^{103}$

$97 \mathrm{PIR}^{2} \mathrm{I} 75 \mathrm{I}$.

$98 \mathrm{PIR}^{2} \mathrm{I} 752$.

$99 \mathrm{Zu}$ den afrikanischen Iunii Faustini: Mastino, Ibba (2014) 353-385, bes. 359.

Io० Wir haben gesehen, dass XVvir Nr. I $8^{*}[\cdot 15 \cdot]$ rnus ein [Alfius $\cdots$ Mate]rnus sein könnte. Man kann alternativ die Zugehörigkeit von Puer Nr. I [· $\left.{ }_{22} \cdot\right] s$ Maximus zur Familie der Alfii vorschlagen, da Puer Nr. 7 ein Alfius Avitus, PuerLus Nr. I 6 ein Alfius Maximus und Puella Nr. 6 eine [AJlfia Vestin[a] Maxi[ma] ist. Es ist zu bedenken, dass in den jeweiligen Gruppen von Pueri und Puellae wohl nur ein Kind eines $X$ Vvir beteiligt war. Wichtig ist aber, dass die auffällige Präsenz der Alfii unter den Pueri und Puellae und Pueri des lusus Troiae die Identifizierung von XVvir Nr. I $8 *\left[\cdot{ }^{2}\right.$. $\left.\cdot\right]$ rnus als [Alfius $\cdots$ Mate]rnus stärkt.

ıо I Puer Nr. 3 ist ein Iulius Crescens: Die Alltäglichkeit des Cognomens erlaubt keine gesicherte Annäherung an XVVir Nr. I4 [Antius] Crescens Calpurnianus oder an $X$ Vvir Nr. 9 Aiacius Modestus Crescentianus.

I02 Auch Puer Nr. 9, Flavius Iulius Latron[ianus], war ein Iulius, möglicherweise war er der Bruder von Puella Nr. io, Flavia Rom[a]na.

I03 Der Konsular Ti. Claudius Dryantianus Antoninus (PIR 2 C 859) war der Schwie- 
Der Status der letzten beiden Pueri verdient einen Kommentar. Puer Nr. 26 ist ein Corn[· Is $]$ s eq. R. ${ }^{104}$ Dieser Junge ist mit dem equus publicus ausgestattet; vielleicht ist er der Sohn eines Ritters. ${ }^{105}$ Puer Nr. 27 kommt gleich nach diesem jungen Ritter, und mit ihm schließt die Liste. Die Nomenklatur lautet wie folgt: Licin[iu]s Aemil[ia]nus INGEN. Auf die Buchstaben INGEN folgt ein vacat. Wenn man zu Ingen(uus) ergänzen müsste, so bleiben Bedeutung und Funktion des Wortes nicht selbstverständlich. Kein Cognomen im gesamten Eintrag wird abgekürzt, was hier auch aus Platzgründen gar nicht nötig ist, da ein vacat folgt. Wenn es sich um ein zweites abgekürztes Cognomen handelt, ist der Fall im gesamten commentarium einzigartig. In diesem Fall ist nicht klar, warum die drei abgekürzten Buchstaben nicht eingraviert worden sind, obwohl es genügend Platz gab. Könnte INGEN ein Hinweis auf den sozialrechtlichen Status dieses Puer sein? Dieser Junge scheint nicht mit dem equus publicus ausgestattet zu sein, im Gegensatz zu dem vor ihm genannten. Es wäre verlockend, ihn mit PuerLus Nr. 28 Licini[us $\left.\cdot_{I 0} \cdot e\right] q$. R. fil. zu identifizieren, der ebenfalls am Ende der Liste erscheint. Wir sehen, dass PuerLus Nr. 28 der Sohn eines Ritters ist, aber nicht mit dem equus publicus ausgestattet, wahrscheinlich, weil er zu jung war. Wenn es sich um dieselbe Person handelt, sollte man davon ausgehen, dass der Begriff ingen(uus) kein Cognomen ist, sondern eine rechtliche Qualifikation wie >frei geboren< bezeichnet. Dieser in Rechtslehrbüchern bekannte Begriff wird in Inschriften nicht häufig verwendet, was gegen diese Interpretation spricht. Es handelt sich wohl eher um ein Cognomen Ingen(uus), auch wenn in diesem Fall die Abkürzung nicht erklärt werden kann, die nicht den in der gesamten Inschrift verwendeten Praktiken entspricht. ${ }^{106}$

\section{e. Puellae}

Nach einem vacat folgt die Liste der Puellae, welche durch das Wort Puellae (Z. 263) eingeführt wird.

gersohn von Avidius Cassius und der Vater von MatrSen Nr. 90, C[l. D]ryantilla Platonis. Puer Nr. I5, Iu[l]ius Sa[t]yrus Dryan[tianus], stammt aus dieser Familie über den weiblichen Zweig ab.

I04 Pighi hatte für sein Gentilicium nur $\operatorname{Cor}[\cdots]$ gelesen. Ein noch erkennbares $N$ erlaubt für Puer Nr. 26 Corn[elius] zu ergänzen.

Io5 Es besteht die Möglichkeit, dass Puer Nr. 26 der Sohn von Paar Nr. I02 ist: Semproni[a Sp]oletina und Cornelius Fel[ix trib.].

Io6 Werner Eck, dem ich für seinen Hinweis zu diesem Wort danke, schlägt vor, dass der letzte Puer der Liste der Sohn eines Freigelassenen sein könnte, der in den Genuss einer restitutio natalium gekommen war: Das Wort ingen(uus), ein Adjektiv in diesem Fall, würde diesen rechtlichen Vorgang verfolgen und den Status des Sohnes präzisieren. 
Liste der 27 Puellae

Nr. Nomenklatur

Abweichung bei Pighi

Zeile

\begin{tabular}{|c|c|c|c|}
\hline I & Manilia Lucana Pọ[llitta $]$ & Manilia Lucana & 263 \\
\hline 2 & {$[\cdot 47 \cdot]$} & $\mathrm{P}[\cdots]$ & 263 \\
\hline 3 & {$[\cdot 47 \cdot]$} & & 263 \\
\hline 4 & {$\left[\cdot{ }^{\prime} 4 \cdot\right]$} & & 264 \\
\hline 5 & {$\left[\cdot{ }^{\prime} 4 \cdot\right]$ lia Crispina Arrian $[\mathrm{a}]$} & & 264 \\
\hline 6 & [A]lfia Vestin[a] Maxi[ma] (Barbieri) & {$[\mathrm{Ru}]$ fia Vestin[a] Maxi[ma] } & 264 \\
\hline 7 & [Sa]lvia Postu[mia] Varia & [Fla]via Postu[ma] Varia & 264 \\
\hline 8 & Non $[$ ia $\cdot$ ıo $\cdot$ V]aleriana & & 264 \\
\hline 9 & Aemilia Iunia C[lemen]tina & & 264 \\
\hline IO & Flavia Rom[a]na & & 264 \\
\hline I I & Antonia $[\cdot 53 \cdot]$ & & 264 \\
\hline I 2 & {$[\cdot 53 \cdot]$} & & 264 \\
\hline I 3 & {$[\cdot 53 \cdot]$} & & 264 \\
\hline I 4 & {$[\cdot 53 \cdot] \mid\left[\cdot{ }^{1} 4 \cdot\right]$} & & $264 f$. \\
\hline Is & {$\left[\cdot{ }^{\prime} 4 \cdot\right]$ Maxima Iuniana } & & 265 \\
\hline 16 & Flavia [A]ntonia Polynic[e] (Solin) & Flavia $[$ A $]$ ntonia $* *$ ynic $[\cdots]$ & 265 \\
\hline I7 & {$\left[\cdot{ }_{3} \cdot\right]$ lia Casta Statịanilla } & {$[\mathrm{P}]$ ia Casta $\mathrm{Si} * *\left[\cdot{ }_{2} \cdot\right]$ nilla } & 265 \\
\hline I 8 & Arri[a C?]or[nelia?] Clementina & Arri $[\mathrm{a} \cdot 4 \cdot] \mathrm{r}\left[\cdot_{4} \cdot\right]$ Clementina & 265 \\
\hline 19 & Corn[eli]a Claudia Pia & & 265 \\
\hline 20 & $\mathrm{Va}[$ leria? $\cdot 2 \cdot]$ nia Pacata & {$\left[\cdot{ } 2_{2} \cdot\right]$ nia Pacata } & 265 \\
\hline $2 \mathrm{I}$ & {$[\mathrm{B}]$ aburia $\mathrm{Va}[\cdot 53 \cdot]$} & Baburia $V^{*}[\cdots]$ & 265 \\
\hline 22 & {$[\cdot 53 \cdot]$} & & 265 \\
\hline 23 & {$[\cdot 53 \cdot]$} & & 265 \\
\hline 24 & {$\left[\cdot{ }_{53} \cdot\right] \mid\left[\cdot{ }_{14} \cdot\right]$} & & $265 \mathrm{f} . ?$ \\
\hline 25 & {$\left[\cdot{ }^{\prime}{ }_{4} \cdot\right]$ ạ Nepotiana } & {$[\cdots]$ Nepotiana } & 266 \\
\hline 26 & Domitia Diotima & & 266 \\
\hline 27 & Preçilia Au[g]urina (Degrassi, Barbieri) & "recina $\mathrm{Au}[\mathrm{g}]$ urina & 266 \\
\hline
\end{tabular}

Von den 27 Puellae fehlen die Namen von neun vollständig, das heißt von einem Drittel. ${ }^{107}$ Wie bei den Pueri belegen die Puellae Nomenklaturen von I 2 bis 22 Buchstaben. Damit kann die Anzahl der fehlenden Namen in den Lücken berechnet werden. 12 der erhaltenen Namen haben eine dreiteilige Nomenklatur; ${ }^{108}$ drei haben eine zweiteilige Nomenklatur. Für die verbleibenden drei ist die Art der Nomenklatur offen. ${ }^{109}$

Seit der Ausgabe von Pighi haben Bearbeiter der Listen Korrekturen zu zwei Nomenklaturen vorgenommen. Pighi hatte den Namen von Puella Nr. 27 in *recina Au[g]urina transkribiert; A. Stein hatte die Namen [G]recina oder [Ar]recina vorgeschlagen. ${ }^{110}$ Die endgültige und hier übernommene Lösung wurde von

107 Das Gentilicium von zwei Puellae (Nr. I 5 und 25) ist vollständig verschwunden. Für zwei Puellae (Nr. 5 und I7) beschränkt es sich auf die drei Buchstaben [ $\cdots$ ]lia. Von der Nomenklatur von Puella Nr. I I ist nur das Gentilicium Antonia [ $\cdots]$ erhalten. Io8 Nr. I, 5, 6, 7, 8, 9, I5, I6, I7, I 8, I9 und 20.

I09 Eine zweiteilige Nomenklatur haben Nr. 10, 26 und 27; für Nr. I I, 2 I und 25 können diesbezüglich keine Aussagen gemacht werden.

I Io PIR 2 A I073 und $\mathrm{PIR}^{2}$, Bd. 2, S. XV der Addenda et Corrigenda. 
A. Degrassi und G. Barbieri gefunden: ${ }^{11}$ Puella Nr. 27 ist eine [P]r(a)ecilia Au[g]urina. ${ }^{112}$ Die korrekte Lesart ihres Gentiliciums erlaubt, sie in Beziehung zu setzen mit C. Praecilius Augurinus Vettius Festus Crispinianus Vibius Verus Cassianus, ${ }^{113}$ c(larissimus) i(uvenis), IIIvir capitalis und Tribun der VII. Legion Gemina. Für den letzten Namen von Puella Nr. I6 hatte Pighi **ynic[...] transkribiert. ${ }^{114} \mathrm{H}$. Solin erkannte den Namen Polynic[e], ${ }^{115}$ was eine Autopsie des Steins bestätigte. Puella Nr. I6 ist daher eine Flavia [A]ntonia Polynic[e].

Die neue Edition der severischen Säkularakten bietet Gelegenheit, einige Lesarten $\mathrm{zu}$ verbessern:

Puella Nr. I7: Pighi hatte den Namen zu [P]ia Casta Si**[·2 $\cdot$ nilla auf bellinische Weise wiederhergestellt. Diese Namensschöpfung ist zwar rührend, aber es würde sich um einen Namen ohne Gentilicium, dafür mit mindestens vier weiteren Elementen handeln. Dies ist für die Listen der Matronen, Pueri und Puellae atypisch. Eine erneute Lesung des ersten Elements ermöglicht es, die Form $[\cdot 3 \cdot]$ lia zu bestimmen, die ein Gentilicium abdeckt. Was den Namen betrifft, so ermöglicht die Autopsie eine Korrektur in Statianilla. Puella Nr. 17 ist daher eine $[\cdot 3 \cdot]$ lia Casta Statianilla. Es ist immer noch schwierig, ihr eine Familie unter den Trägern des Cognomens Castus $^{116}$ oder des Agnomens Statianilla, das vom Namen Statius abgeleitet ist, zuzuordnen. ${ }^{17}$

I I $A l b o$ Nr. 435 .

II 2 PIR $^{2} \mathrm{P} 92 \mathrm{I}$.

II 3 PIR $^{2}$ P 9 I9.

I 4 Im Jahr 1943 hat Groag (PIR ${ }^{2}$ F 4II) diese Form als Phryniche oder als Bithynica interpretiert.

I Is Solin (2003) I 44 .

I 6 Vor Kurzem hat G. Camodeca eine Zusammenstellung der Träger des Cognomens Castus im Senatorenstand erarbeitet; Camodeca (2014-2015) I 59-167. Der legatus von Thrakien des Jahres I84/I85 n. Chr., Iulius P. f. Quir. Castus (PIR ${ }^{2}$ I 25 I) trägt ein Gentilicium, das einen Querverweis auf Puella Nr. I7 ermöglicht. Es sei hier an den Senator C. Iulius Septimius Castinus ( $\mathrm{PIR}^{2}$ I 566) erinnert, ein vertrauenswürdiges Mitglied der severischen Familie und Freund von Caracalla, später von Antoninus Elagabal getötet. Man kann die Hypothese wagen, dass der legatus von Thrakien des Jahres I 84 / 8 s n n. Chr eine Tochter von C. Septimius Severus, Prokonsul von Afrika I73/I74 und Cousin von Septimius Severus (PIR ${ }^{2} S_{485}$ ), geheiratet hat und dass C. Iulius Septimius Castinus sein Sohn und möglicher Vater von Puella Nr. I7 $[\cdot 3 \cdot]$ lia Casta Statianilla war. In diesem Fall wäre diese Puella mit dem Kaiserhaus verwandtschaftlich verbunden.

I 7 Eine Fl(avia) Statianilla, c(larissimae) m(emoriae) f(eminae) mit einer Herkunft aus Sufetula (PIR ${ }^{2}$ F 44I) ist die Großmutter des clarissimus L. Servaeus Amicus Potitianus (PIR ${ }^{2}$ S 558), der wiederum Vater der clarissima puella Servaea Novella Rufina Potitiana ( $\mathrm{PIR}^{2} \mathrm{~S} 563$ ) und Servaea Fl(avia) Statianilla Valeriana (PIR ${ }^{2} \mathrm{~S} 562$ ) ist. Über diese Familie M. Christol, Flavii et Servaei à Sufetula, in L'Africa romana (im Druck). 
Puella Nr. I8: In Pighis Ausgabe trägt sie die Nomenklatur Arri[a $\cdot 4 \cdot] r[\cdot 4 \cdot]$ Clementina. Eine erneute Lesung reduziert die erste Lücke auf zwei Buchstaben und lässt ein $O$ vor dem $R$ erkennen. Somit ist es nun möglich, eine Arri[a $C$ ?]or[nelia?] Clementina zu erkennen.

Puella Nr. 20: Pighi las als Namen von Puella Nr. 20 [· $12 \cdot]$ nia Pacata. In der anfänglich kürzeren Lücke sind die Buchstaben $V A$ unmittelbar nach dem Namen der vorangehenden Puella zu unterscheiden. Puella Nr. 20 ist eine Val· $7 \cdot$ Inia Pacata, plausibel wäre eine Va[leria? $\cdot 2 \cdot$ Inia Pacata. Die Buchstaben $[\cdot 2 \cdot]$ nia könnten das Gentilicium [Iu]nia abschließen.

Puella Nr. 21: In Pighis Ausgabe wurde ihr Name in Baburia $V^{*}[\cdots]$ transkribiert. Das anfängliche $B$ ist nicht mehr lesbar. Andererseits gelingt es uns, ein $A$ nach $\operatorname{dem} V$ zu entschlüsseln: Es war also eine [B]aburia Va[ $\cdots$ ] oder eine [B]aburia Va[leriana] bei einer zweiteiligen Nomenklatur oder eine [B]aburia Va[leria $\cdots$ ] bei einer dreiteiligen Nomenklatur. Wie Puer Nr. 22, dessen Name wahrscheinlich [Barburius Herc]ulanius lautete, gehörte sie zu der senatorischen Familie der $B a-$ burii aus Hippo Regius.

Der Fall Puella Nr. I verdient eine besondere Betrachtung. Ihr Name wurde als Manilia Lucana entschlüsselt und in Übereinstimmung mit Pighi kann man sie als Tochter von XVvir Nr.6, Ti. Manilius Fuscus, und MatrSen Nr. I, Fl. Politta, betrachten. ${ }^{118}$ Nach ihrem Namen las Pighi den Buchstaben $P$, den er dem Beginn des Namens der nächsten Puella zuordnete. Anstelle eines einfachen $P$ kann jedoch noch ein anschließendes $O$ gelesen werden. Da Puella Nr. I die Tochter einer Fl. Politta ist, wird ihr die dreiteilige Nomenklatur Manilia Lucana Po[llitta] gegeben. ${ }^{119}$ Damit müsste man auf die Kenntnis der Nomenklatur von Puella Nr. 2 vollständig verzichten; es wäre aber bestätigt, dass die Puella Nr. I tatsächlich die Tochter der MatrSen Nr. I ist.

Eine weitere Annäherung ermöglicht das Vorhandensein des Cognomens Lucana bei den Manilii. Zur gleichen Zeit ist eine Manilia Lucilla ${ }^{120}$ die Frau von C. Caesonius Macer Rufinianus, dem Konsul um 197/8 n. Chr. und Prokonsul von Afrika um 2 I 2-2 I 5 n. Chr. ${ }^{\text {I2I }}$ Die beiden Cognomina Lucana und Lucilla sind sehr ähnlich und können innerhalb derselben Familie auftreten, wie die Onomastik von Domitia Lucilla, Tochter von Cn. Domitius Lucanus zeigt. Auf der Grundlage dieser Parallele ist es plausibel vorzuschlagen, dass Manilia Lucilla, verheiratet mit C. Caesonius Macer Rufinianus, Suffektkonsul um 197/8 n. Chr., Prokonsul von Afrika um 2 I2-21 5 n. Chr., comes von Severus Alexander, eine Schwester von Ti. Manilius Fuscus und die Tante von Manilia Lucana Po[llitta] war. Dies würde eine

II $8 \mathrm{PIR}^{2} \mathrm{M}$ i44.

I 9 Die agnominale Form Po[llittiana] kann ebenfalls möglich sein.

I20 $\mathrm{PIR}^{2} \mathrm{M}$ I45.

I $2 \mathrm{I} \mathrm{PIR}^{2} \mathrm{C} 2 \mathrm{IO}$. 
sehr enge Verbindung zwischen den Caesonii, die im Laufe des 3. Jahrhunderts so wichtig waren, und den Manilii schaffen. Das Cognomen Fuscus, das bei den Manilii vorkommt, ${ }^{122}$ könnte aus einer entfernten Allianz mit den Pedanii Salinatores Fusci oder mit den Seii stammen. ${ }^{123}$ Das Gentilicium Manilius nimmt seit der Allianz mit den Caesonii auch die synkopierte Form Manlius an. ${ }^{124}$ Dies deutet darauf hin, dass Ti. Manilius Fuscus und seine Schwester Manilla Lucilla Nachkommen einer angesehenen Familie aus dem 2. Jahrhundert waren. $\mathrm{Zu}$ dieser gehörten wahrscheinlich P. Manlius $\mathrm{Carbo}^{125}$ (ein Arvalbruder unter Hadrian), $M$. Nonius Macrinus Manlius Carbo ${ }^{126}$ (ein enger Verwandter von XVvir Nr. 3 Nonius Arrius Mucianus) oder Manlia Scantilla, die Frau von Kaiser Didius Iulianus. ${ }^{127}$

Puella Nr. I ist daher die Tochter des XVvir Nr. 6, des Magisters des Kollegiums im Jahr 203 n. Chr. Auch Puella Nr. 8 ist zweifellos die Tochter des XVvir Nr. 3. Es ist nicht ausgeschlossen, dass Puella Nr. 6 eine Tochter des XVvir Nr. I 8* ist, wenn es sich bei diesem tatsächlich um einen Alfius handelt. Von den ersten acht Puellae der Liste sind die Namen von fünf Puellae bekannt, von denen drei wahrscheinlich Töchter von $X$ Vviri sind.

Es ist daher angebracht, den Fall von Puella Nr. 7 zu untersuchen. Pighi veröffentlichte ihren Namen mit [Fla]via Postu[ma] Varia. Das Cognomen Varia ist die weibliche Form von Varus und ist in verschiedenen Familien verbreitet. Das zweite Element wird eher Postu[mia] lauten, wegen der Parallele zu MatrSen Nr. 5 I, einer Postumia [...]. Eine Postumia Varia ist bekannt, allerdings schlecht datiert. ${ }^{128}$ Bekannt ist auch ein T. Flavius Postumius Varus, ${ }^{129}$ Konsul um 250 n. Chr. und Nachkomme von M. Postumius Festus, ${ }^{130}$ Konsul um I 60 n. Chr. und Freund von Fronto. $\mathrm{Zu}$ bedenken ist außerdem, dass der Mann von MatrSen Nr. 50 ein Festus ist. In der Nähe dieses afrikanischen Beziehungsnetzes sind auch die Naevii zu sehen. ${ }^{131}$ Die Existenz dieser Gruppe hatte zunächst auf die Spur des Gentiliciums [Na]evia für Puella Nr. 7 geführt. Für das Gentilicium kann man jedoch vor den Buchstaben VIA einen geraden Buchstaben erkennen, der ein $E$ oder ein $L$ sein könnte. Da diese Puella in einer Gruppe auftritt, in der mehrere Töchter von $X$ Vviri identifiziert werden können, ist die Lesung eines $L$ vorzuzie-

I 22 Der XVvir Nr. 6 hat einen gleichnamigen Sohn: Manilius Fuscus (PIR² M I 36 ).

I $23 \mathrm{Zu}$ diesem Netzwerk siehe Chausson (2013) I67-1 86 und Chausson/Gregori (201 5) 28 I-294.

I 24 Dies wird durch die folgenden Nomenklaturen belegt: L. Caesonius Ovinius Manlius Rufinianus Bassus (AE, 1964, 223), ist der Sohn von C. Caesonius Macer Rufinianus und Manilia Lucilla.

I $25 \mathrm{PIR}^{2} \mathrm{M}$ I 54 . Über diese Person Scheid (I990) Nr. 94, S. $54 \mathrm{f}$.

I26 PIR ${ }^{2} \mathrm{M}$ II 5 .

I 27 PIR $^{2}$ M I66.

I $28 \mathrm{PIR}^{2} \mathrm{P} 906$.

I $29 \mathrm{PIR}^{2} \mathrm{P} 900$.

I30 PIR ${ }^{2}$ P 886.

I 3 I $\mathrm{Zu}$ den verschiedenen Familien: Mastino/Ibba (2014) 353-385, bes. 364-365. 
hen. ${ }^{1{ }^{2} 2}$ Damit kann zu dem Gentilicium [Sa]lvia ergänzt werden, und der Name von Puella Nr. 7 lautet demnach [Sa]lvia Postu[mia] Varia.

Diese neue Lesart verschiebt das Familienfeld ein wenig, auch wenn es ein Zweig derselben Familie ist. Es ermöglicht eine Parallele zu einer Vibia L. f. Salvia Varia, ${ }^{133}$ die zwei der drei Elemente der Nomenklatur von Puella Nr. 7 teilt. Diese Frau errichtete in Brescia zwei Ehrinschriften für Postumia P. f. Paulla, ${ }^{134}$ der Frau des Konsuls Iuventius Secundus. ${ }^{135}$ Eine Inschrift ${ }^{136}$ widmete sie mit ihren drei Kindern Nummius Albinus, Nummia Varia ${ }^{137}$ und L. Roscius Alianus Paculus Salvius Iulianus, ${ }^{13^{8}}$ dem späteren Konsul von 223 n. Chr. Die andere Ehrung widmete sie allein. ${ }^{139}$ Der Konsul von 223 n. Chr., der Nachkomme einer konsularischen Linie, wird das Konsulat anno suo besetzt haben und somit um I90/I9I n. Chr. geboren worden sein; er ist vielleicht sogar identisch mit PuerLus Nr. 8 Rosc[ius · $19 \cdot]$. Seine Mutter Vibia L. f. Salvia Varia, Frau des ordentlichen Konsuls von i 87 n. Chr., L. Roscius Rlianus Paculus, ${ }^{140}$ geboren in den I6oer-Jahren, ist damit eine Generation älter als Puella Nr. 7 [Sa]lvia Postu[mia] Varia. Puella Nr. 7 ist also ihre Nichte oder ihre Großcousine: Sie ist die Tochter von XVvir Nr. I I* Salvius Tuscus. Dieser, ein Bruder oder höchstens ein Cousin ersten Grades von Vibia Salvia Varia, wurde in den I6oer-Jahren geboren. Er kann mit L. Cornelius Salvius Tuscus ${ }^{\mathrm{II}}$ identifiziert werden, einem jungen Senator, der I 8 I unter die Salii Palatini aufgenommen wurde und möglicherweise Sohn von P. Salvius Iulianus, ${ }^{142}$ I75 n. Chr. ordentlicher Konsul und Enkel des Juristen

I 32 Man sollte sich nicht durch eine Rille links von der Bruchstelle täuschen lassen, die den Eindruck einer horizontalen Linie in der Mitte des Buchstabens erweckt. Diese Rille überschneidet die senkrechte Linie des Buchstabens und gehört nicht zum Buchstaben, sondern zu der Bruchlinie des Fragments. Vom Buchstaben selbst ist unten klar eine horizontale Linie erkennbar, die in ihrer Länge auf ein $L$ und nicht ein $E$ hinweist.

I 33 FOS Nr. 650; $\mathrm{PIR}^{2} \mathrm{~V} 60 \mathrm{I}$.

I 34 PIR $^{2}$ P 903; FOS Nr. 650. Postumia Paulla wurde außerdem durch den Konsul $M$. Iuventius Caesianus, durch den Prätor M. Laelius Fiminus Fulvius Maximus und einen P. Postumius Marianus geehrt.

I35 PIR ${ }^{2}$ I 888.

I 36 CIL V 4353 (I. I., X, 5, I, I 43), Brixia: Honori $\mid$ Postumiae P(ublii) f(iliae) $\mid$ Paullae $\mid$ Iunentii Secund(i) co(n)s(ulis) (uxoris), | Vibia L(ucii) f(ilia) Saluia Varia |cum Nummiis $\mid$ Albino et Varia | et L(ucio) Rosci[o A]elian(o) Paculo |Saluio Iuliano filiis.

I $37 \mathrm{PIR}^{2} \mathrm{~N} 240$.

I $38 \mathrm{PIR}^{2} \mathrm{R} 92$.

I 39 CIL V 4354 (I. I., X, 5, I, I44), Brixia: Honori | Postumiae P(ublii) f(iliae) Paullae | Iunentii Secund(i) $\mid \operatorname{co}(n)$ s(ulis) (uxoris), | Vibia L(ucii) f(ilia) Saluia Varia $\mid$ ob adfectionem et $\mid$ pietatem eius in se eximiam.

I40 $\mathrm{PIR}^{2} \mathrm{R}$ 9I.

I4I PIR ${ }^{2} \mathrm{C}$ I433.

I $42 \mathrm{PIR}^{2} \mathrm{~S}_{1}$ 6. Die Salvii Iuliani sind irgendwann unter der Herrschaft von Antoninus Pius oder Mark Aurel Patrizier geworden. 
L. Octavius Cornelius Salvius Iulianus \#milianus, ${ }^{\mathrm{I} 43}$ gewöhnlicher Konsul im Jahr I 48 n. Chr. und Onkel mütterlicherseits des Kaisers Didius Iulianus. Die Familie der Salvii Iuliani ist mit Postumia Paulla verwandt, ${ }^{144}$ einer nahen Verwandten von Senator P. Statius Paullus Postumius Iunior ${ }^{145}$ und Nachfahrin, in einem uns unbekannten Grad, mit dem Redner und Freund von Fronto, M. Postumius Festus, Konsul im Jahr i6o n. Chr. und Ehemann einer Paulla. ${ }^{146}$

Es ist daher davon auszugehen, dass vier von den acht Puellae am Anfang der Liste Töchter oder enge Verwandte von XVviri waren. Es ist nicht ausgeschlossen, dass Puella Nr. 5 [· I4 Jlia Crispina Arrian[a] auch die Tochter von einem XVvir ist. Wenn ihr Name [Iu]lia ist, könnte sie die Schwester eines der drei Pueri namens Iulii sein: Nr. 2 I[ul]iu[s F]austinus; Nr. 3 Iulius Crescens; Nr. 4 Iul. Ca[s]sius Paulinus. In ihrem Fall ist es aber nicht möglich, eine Ergänzung zu [Ofi]lia und damit eine Beziehung zu XVvir Nr. 2* Ofilius Macedo herzustellen. Auch die Ergänzung [Gargi]lia und damit eine mögliche Beziehung zu XVvir Nr. I2* Gargilius Antiquus kann ausgeschlossen werden.

So wären in den Listen der Pueri und Puellae die ersten genannten Namen weitgehend die von Kindern der Priester, die mit der Organisation der ludi saeculares betraut waren. ${ }^{147}$ Es ist sehr wahrscheinlich, dass es unter den Kindern der XVviri Brüder und Schwestern gab. Andererseits ist nicht bekannt, ob bei den Kindern der XVviri mehrere Brüder unter den Pueri oder mehrere Schwestern unter den Puellae teilgenommen haben. Es ist vernünftiger anzunehmen, dass jede Familie nur durch ein Kind in jeder Gruppe vertreten war.

I43 $\mathrm{PIR}^{2} \mathrm{~S}$ I35.

I 44 XVvir Nr. I I* Salvius Tuscus ist der Sohn, Enkelsohn oder Ehemann einer Postumia. Das Thema der ehelichen Verbindungen zwischen den Salvii, Nummii und Postumii ist besonders komplex und wird in einem Artikel behandelt, der derzeit in Arbeit ist.

I45 $\mathrm{PIR}^{2} \mathrm{~S}$ I 36 .

I $46 \mathrm{PIR}^{2} \mathrm{P} 879$.

I 47 Die Namen der Pueri Nr. 5 und 6 sind besonders beschädigt und verbergen sich hinter der Buchstabenfolge Clo[ $\left.\cdot_{23} \cdot\right] m\left[\cdot{ }_{10} \cdot\right]$. Ihre Position lässt vermuten, dass sie Söhne von $X$ Vviri waren. Aber kein XVvir des Jahres 204 hieß Clo[dius]; es kann jedoch angenommen werden, dass der Puer in der ersten Position seiner polyonymen Nomenklatur einen anderen Namen als das väterliche Gentilicium trug, was vorkommen kann. Der Buchstabe $M$ ist in der Nomenklatur verschiedener XVviri vorhanden: Nr. $2 *$ Ofilius Macedo; Nr. 3 Nonius Arrius Mucianus; Nr. 9 Aiacius Modestus; Nr. Io Fabius Magnus; Nr. Is Cassius Pius Marcellinus; Nr. I9 Vetina Mamertinus; ohne Erwähnung von Nr. 4 * Calpurnius Maximus $\left[\cdot{ }_{2} \cdot\right]$, der bereits als möglicher Vater von Puer Nr. I [· $\left.{ }_{12} \cdot\right]$ s Maximus identifiziert wurde; oder Nr. I3 Iulius Pompeius Rusonianus, möglicher Vater von einem der drei Pueri Nr. 2, Nr. 3 und Nr. 4, die alle Iulius heißen. 
Übereinstimmungen der Namen bei den Kindern und den XVviri

\begin{tabular}{|c|c|c|c|c|c|}
\hline $\mathrm{Nr}$. & Pueri & Nr. & XVviri & $\mathrm{Nr}$. & Puellae \\
\hline & & 6 & Manilius Fuscus & I & Manilia Lucana Pọ[litta] \\
\hline I & {$\left[\cdot{ }{ }_{2} \cdot\right]$ s Maximus } & $4 *$ & Calpurnius Maximus $\left[\cdot{ }_{2} \cdot\right]$ & & \\
\hline 2 & $\mathrm{I}[\mathrm{ul}] \mathrm{iu}[\mathrm{s}$ F]austinus & I 3 & Iulius Pompeius Rusonianus & 2 & {$[\cdot 47 \cdot]$} \\
\hline 3 & Iulius Crescens & & & 3 & {$[\cdot 47 \cdot]$} \\
\hline 4 & Iul. Ca[s]sius Paulinus & Is & Cassius Pius Marcellinus & 4 & {$\left[\cdot{ }{ }_{4} \cdot\right]$} \\
\hline & & $2 *$ & Ofilius Macedo & 5 & {$\left[\cdot{ }^{\prime} 4 \cdot\right]$ lia Crispina Arrian $[\mathrm{a}]$} \\
\hline & & I $2 *$ & Gargilius Antiquus & & \\
\hline 5 & $\mathrm{Clo}[\cdot 23 \cdot]$ & & & & \\
\hline 6 & {$\left[\cdot{ }_{23} \cdot\right] \mathrm{m}\left[\cdot{ }_{10} \cdot\right]$} & & & & \\
\hline 7 & Alfius Avitus & $18 \%$ & $\begin{array}{l}{\left[\cdot{ }^{\cdot} \text { is } \cdot\right] \text { rnus pr }=[\text { Alfius }} \\
\cdots \text { Mate }] \text { rnus pr }\end{array}$ & 6 & [A]lfia Vestin[a] Maxi[ma] \\
\hline & & II $*$ & Salvius Tuscus & 7 & {$[$ Sa]lvia Postu[mia] Varia } \\
\hline & & 3 & Nonius Arrius Mucianus & 8 & Non[ia $\cdot$ io $\cdot$ V]aleriana \\
\hline 8 & Opratius Ti[t]ianus & & & & \\
\hline 9 & $\begin{array}{l}\text { Flavius Iulius Latron[i- } \\
\text { anus] }\end{array}$ & & & $\begin{array}{r}9 \\
10\end{array}$ & $\begin{array}{l}\text { Aemilia Iunia C[lemen]tina } \\
\text { Flavia Rom[a]na }\end{array}$ \\
\hline IO & {$[\cdot 40 \cdot]$} & & & & \\
\hline I I & {$[\cdot 40 \cdot]$} & & & I I & Antonia $[\cdot 53 \cdot]$ \\
\hline I 2 & {$\left[\cdot{ }^{\prime} 4 \cdot\right]$ ianus } & & & I 2 & {$[\cdot 53 \cdot]$} \\
\hline I3 & Vmbilius [Ma]ximinus & & & I 3 & {$[\cdot 53 \cdot]$} \\
\hline $\mathrm{I} 4$ & Claudius Pacatianus & & & I 4 & {$\left[\cdot{ }_{53} \cdot\right] \mid[\cdot{ } 4 \cdot]$} \\
\hline is & $\begin{array}{l}\mathrm{Iu}[\mathrm{l}] \text { ius Sa[t]yrus Dryan- } \\
\text { [tianus] }\end{array}$ & & & Is & {$\left[\cdot{ }^{\prime} 4 \cdot\right]$ Maxima Iuniana } \\
\hline I 6 & {$\left[\cdot{ }_{1} 6 \cdot\right]$ s $\operatorname{Maxim}[\cdot 7 \cdot]$} & & & I6 & Flavia [A]ntonia Polynic[e] \\
\hline I7 & $\begin{array}{l}{[\cdot 7 \cdot] \text { s Vlpius Attianus }} \\
\text { Iun(ior) }\end{array}$ & & & I7 & {$[\cdot 3 \cdot]$ lia Casta Stạtianinilla } \\
\hline I 8 & Laberius Pompeianus & & & & \\
\hline 19 & Cattius Clemẹnț[inus $\left.\cdot{ }_{46} \cdot{ }^{\cdot}\right]$ & & & I 8 & $\begin{array}{l}\text { Arri[a C?]or[nelia?] Cle- } \\
\text { mentina }\end{array}$ \\
\hline & & & & I9 & Corn[eli]a Claudia Pia \\
\hline 20 & {$\left[\cdot 4^{6} \cdot\right]$} & & & 20 & Va[leria? $\left.\cdot{ }_{2} \cdot\right]$ nia Pacata \\
\hline $2 \mathrm{I}$ & {$[\cdot 46 \cdot]$} & & & & \\
\hline 22 & [Baburius Herc]ulanius & & & $2 \mathrm{I}$ & {$[\mathrm{B}]$ aburia $\mathrm{Va}[\cdot 53 \cdot]$} \\
\hline & & & & 22 & {$[\cdot 53 \cdot]$} \\
\hline 23 & Baebius Mạrcellinus & & & 23 & {$[\cdot 53 \cdot]$} \\
\hline 24 & Aelius Anțipater & & & 24 & {$[\cdot 53 \cdot] \mid\left[\cdot \mathrm{I}_{4} \cdot\right]$} \\
\hline 25 & Corfin[iu]s Felix $\{s\}$ & & & 25 & {$\left[\cdot{ }^{\prime}{ }_{4} \cdot\right]$ a Nepotiana } \\
\hline 26 & $\operatorname{Corn}\left[\cdot{ } I_{5} \cdot\right]$ s eq. $R$ & & & 26 & Domitia Diotimạ \\
\hline 27 & Licin[iu]s Aemil[ia]nus & & & 27 & Prẹçilia Au[g]urina \\
\hline
\end{tabular}

Es ist auch sinnvoll, unter den Puellae der verbleibenden Liste nach Verwandten der Matronen zu suchen. So ist beispielsweise nicht auszuschließen, dass Puella Nr. 26, Domitia Diotima, mit MatrSen Nr. 84, Domitia Flaccill[a], der Ehefrau eines Vlpius Antonin[us] verwandt sein könnte. MatrSen Nr. 84 entstammt einer konsularischen Familie aus Prusias ad Hypium, während ihr Mann mit C. Vlpius Antoninus, Legat von Lycia-Pamphylia, identifiziert werden sollte. Dieser wurde 
in Sagalassos mit seinem Sohn C. Vlpius Antoninus Tertullus geehrt. ${ }^{148}$ Die Untersuchung um die Verwandten der Puellae hat sehr weitreichende Verzweigungen, die über die Familien der XVviri hinausgehen.

\section{f. Unbestimmte Gruppe von Pueri des lusus Troiae}

Liste der erhaltenen Namen der Pueri, die am Reiterspiel des lusus Troiae teilgenommen haben

Nr. Nomenklatur

Abweichung bei Pighi

Zeile

\begin{tabular}{|c|c|c|c|}
\hline I & {$[\cdots$ A $] \operatorname{emi}\left[1 \cdot 35^{\circ}\right]$} & {$[\cdots] \mathrm{emi}[\cdots]$} & 307 \\
\hline 2 & {$[\cdot 35 \cdot S]$ atyrus $\operatorname{Do}[\cdots]$} & {$[\cdots$ S $]$ atyrus $\operatorname{Dr}[\cdots]$} & 307 \\
\hline 3 & {$[\cdots] \mathrm{s}$ Regillu $[\mathrm{s}]$} & {$[\cdots]$ s $\operatorname{Regu}[\cdots]$} & 308 \\
\hline 4 & Marcius Vic[tor $\cdots]$ & & 308 \\
\hline 5 & Virius $[\cdot 20 \cdot]$ & & 309 \\
\hline 6 & {$[\cdot 20 \cdot]$ Musiarcus } & & 309 \\
\hline 7 & Iunius $[\cdots]$ & Iunius [Faustinus] & 309 \\
\hline 8 & $\operatorname{Rosc}[$ ius $\cdot 19 \cdot]$ & $\operatorname{Rosc}[\cdots]$ & 310 \\
\hline 9 & {$[\cdot 19 \cdot \mathrm{C}]$ ornelianus } & & 310 \\
\hline IO & Clodius Mar $[\cdots]$ & Clodius Mar[cellinus] & 310 \\
\hline I I & {$[\cdots]$ rus Numer $\left[\cdot{ }^{1}{ }_{3} \cdot\right]$} & {$[\cdots]$ rus, Numit $[\cdots]$} & $3 \mathrm{II}$ \\
\hline I 2 & {$\left[\cdot{ }_{13} \cdot\right]$ nus Aper } & {$[\cdots]$ ius Aper } & $3 \mathrm{II}$ \\
\hline I 3 & Ocratius Titianus & & 3 II \\
\hline I 4 & {$[\cdots]$ us } & & $3 \mathrm{I} 2$ \\
\hline is & Bassaeus $\left[\cdot{ }^{\prime} \mathrm{O} \cdot\right]$ anus & & 312 \\
\hline I6 & Alfius Maximus & & 312 \\
\hline 17 & $\operatorname{Suf}[\cdots]$ & Sue $[\cdots]$ & $3 \mathrm{I} 2$ \\
\hline I 8 & {$[\cdots]$ s Silianus } & & 313 \\
\hline 19 & $+\left[\cdot{ }^{1} \mathrm{o} \cdot\right]$ atianus & $\mathrm{C}[$ laudius Pac $]$ atianus & 313 \\
\hline 20 & Flav[ius $\cdot 7 \cdot] \operatorname{co}[\cdots]$ & Flav $[\cdot 7 \cdot] \operatorname{ce}[\cdots]$ & 313 \\
\hline $2 \mathrm{I}$ & {$[\cdots]$ Placidu $[\mathrm{s} \cdot \mathrm{io} \cdot]$} & & 314 \\
\hline 22 & {$[\cdot 10 \cdot$ Ma $]$ rcellinus } & [Baebius Ma]rcellinus & $3 \mathrm{I} 4$ \\
\hline 23 & $\mathrm{~A}[\cdots]$ & $\mathrm{M}[\cdots]$ & 314 \\
\hline 24 & {$[\cdots]$ omini $[\cdot[6 \cdot]$} & {$[\cdots] \operatorname{omin}[\cdots]$} & 315 \\
\hline 25 & {$[\mathrm{Ne}]$ ratius Priscụ $[\mathrm{s}]$} & & 315 \\
\hline 26 & Bab $\left[\cdot{ }_{12} \cdot\right]$ us & $\mathrm{Ba}\left[\cdot{ }{ }_{2} \cdot\right]$ us & 316 \\
\hline 27 & $\operatorname{Vettiu}[s \cdots]$ & & 316 \\
\hline 28 & Licini[us $\cdot \mathrm{Io} \cdot \mathrm{e}] \mathrm{q}$. R. fil. & $\operatorname{Licini}\left[\cdot{ }^{\prime}\right.$ Is $\cdot$ e $] q$. R. fil. & 317 \\
\hline 29 & $\mathrm{C}[\cdots] ?$ & $\mathrm{C}[\cdots$ ? ingen. $]$ & 317 \\
\hline
\end{tabular}

Wie bereits erwähnt, ist es sehr schwierig, die Begrenzungen dieser Liste zu bestimmen. Ihre Darstellung ist durch den Steinmetz im Vergleich zu den vorangehenden Listen ausgedehnt worden, weil auf der Seite des Steinblocks für diesen letzten Teil der Inschrift ausreichend Platz zur Verfügung stand. Diese Freiheit des Steinmetzen und die wechselnden Abstände zwischen den Nomenklaturen machen eine genaue Berechnung unmöglich. Außerdem fehlen die seitlichen Begren-

I 48 Eich/Eich/Eck/Waelkens (20I8), ISagalassos 43a und b. Ich danke Benoît Rossignol, der mich auf diese vor Kurzem publizierte Inschrift aufmerksam gemacht hat. 
zungen des Textes. ${ }^{149}$ In der obigen Liste wurden die erkennbaren Namen der Pueri nummeriert. Mögliche weitere Namen, die in dem beschriebenen Raum links und rechts der erhaltenen Fragmente möglich wären, sind nicht berücksichtigt. Ebenso schwierig ist die Bestimmung von Anfang und Ende der Liste. Den Anfang stellen vielleicht die Buchstaben EMI von Z. 307 dar, die als Teil eines Gentiliciums gelten könnten. Ein eindeutiger Name ist in der Fortsetzung der Zeile mit $[\cdot 35 \cdot$ S]atyrus Do[? ?.] erkennbar, der hier PuerLus Nr. 2 ist. Ob in Z. 317 das $C[\cdot ? \cdot]$ nach einem vacat das Ende der Liste ist oder den Anfang einer weiteren Nomenklatur darstellt, lässt sich nicht mit Sicherheit sagen.

Klar ist hingegen, dass Opratius Ti[t]ianus, der als Puer Nr. 8 das carmen saeculare gesungen hat, ebenfalls an den Reiterspielen des lusus Troiae teilgenommen hat. Er erscheint als PuerLus Nr. I 3 Ocratius Titianus, an dieser Stelle mit der korrekten Schreibweise für das Gentilicium Ocratius. Weitere Pueri des carmen hinter den Bruchstücken von Namen dieser Liste erkennen zu wollen, ist sehr gewagt. ${ }^{\text {I5 }}$ Dieser Ansatz von Pighi wurde offenbar allein aus systematischen Gründen verfolgt und sollte infrage gestellt werden. Der wichtigste Beitrag dieser Ausgabe besteht darin, die Namen auf dem Stein einer genauen Autopsie unterzogen zu haben, um die vorhandenen Buchstaben und Pighis Ergänzungen kritisch zu beurteilen. Diese beruhen zu sehr auf den anderen Listen und sind manchmal völlig willkürlich. Sie sollten in dem neu edierten Text ausgeschlossen werden.

Ergänzungen Pighis, die nicht übernommen werden:

PuerLus Nr. 7: Pighi ergänzte den Namen Iunius [Faustinus] nach Puer Nr. 2 des carmen saeculare, den er zu I[un]iu[s F]austinus vervollständigt hatte. Es handelt sich bei diesem Knaben aber eher um einen I[ul]iu[s F]austinus. Deshalb wird für die Nomenklatur von PuerLus Nr. 7 auf die Bestimmung eines Cognomens verzichtet.

PuerLus Nr. ıo: Pighi ergänzte diesen Namen zu Clodius Mar[cellinus]. Das Cognomen Marcellinus bleibt eine Möglichkeit, allerdings gibt es daneben weitere: Marsus, Marcianus, Marullus. Die vollständige Nomenklatur bleibt deshalb mit Clodius Mar $[\cdots]$ offen.

PuerLus Nr. 19: Pighi hat in ihm Cllaudius Pac]atianus, den Puer Nr. I4 des carmen saeculare erkannt. Dies ist nicht völlig von der Hand zu weisen, aber auch hier sind andere Möglichkeiten für ein Cognomen denkbar, zum Beispiel St]atianus. Der schlechte Zustand des Steins macht die Lesung des Anfangsbuchstabens

I 49 Einzig die Nomenklatur von Septimius Severus und seinen Söhnen (Z. 273-279) kann Annäherungswerte über die Breite des beschriebenen Raumes auf der Seite des cippus geben, dessen genaue Tiefe unbekannt ist.

I 50 Es bleibt unsicher, ob man PuerLus Nr. 28, Licini[us - го e]q. R. fil., mit Puer Nr. 27, Licin[iu]s Aemil[ia]nus Ingen(uus), identifizieren kann, ebenso ob PuerLus Nr. I9, *[· $10 \cdot]$ atianus, mit Puer Nr. I4, Claudius Pacatianus, identisch ist. 
$C$ des Gentiliciums unmöglich, der Buchstabe bleibt nicht entzifferbar. Für den Namen dieses PuerLus bleibt also $+\left[\cdot 1_{0} \cdot\right]$ atianus.

PuerLus Nr. 22: Die Ergänzung von Pighi zu [Baebius Ma]rcellinus beruht auf Puer Nr. 23. Obwohl diese Möglichkeit bestehen könnte, wird hier auf eine vollständige Ergänzung verzichtet und es bleibt bei $\left[\cdot{ }_{10} \cdot\right.$ Ma]rcellinus.

PuerLus Nr. 29: Hinter der letzten erkennbaren Nomenklatur hatte Pighi $C[\cdots$ ? ingen.] ergänzt, wobei er sich auf die Nomenklatur von Puer Nr. 27 Licin[iu]s Aemil[ia]nus Ingen(uns) stützte. Abgesehen vom Problem, das die Buchstaben INGEN stellen und worauf weiter oben eingegangen worden ist, bleibt unsicher, ob der Buchstabe $C$ den ersten Buchstaben eines Gentiliciums darstellt und sich damit auf einen PuerLus bezieht. Daher lassen wir diese Frage, wie oben bereits angedeutet, offen.

Einige Buchstaben wurden nach unserer Autopsie im Vergleich mit der Edition von Pighi anders gelesen oder hinzugefügt. Folgende neue Lesarten und Interpretationen haben sich ergeben:

PuerLus Nr. 2: Der Name von PuerLus Nr. 2 ist der erste der Liste, der mit Sicherheit als Name lesbar ist. Pighi hatte $[\cdots$ S]atyrus $\operatorname{Dr}[\cdots]$ ediert, wobei er sich auf die Parallele zum Namen von Puer Nr. is Iu[l]ius Sa[t]yrus Dryan[tianus] stützte. ${ }^{I S I}$ Eine Autopsie hat für den Buchstaben $R$ ergeben, dass es sich eindeutig um ein $O$ handelt, das vollkommen unbeschädigt ist. Vielleicht handelt es sich um den Anfang eines Cognomens Do[mitianus], was dem Gentilicium Do[mitius] vorzuziehen ist. ${ }^{152}$ Hier erscheint PuerLus Nr. 2 demnach als [ $\cdots$ S]atyrus Do[ $\cdots$ ] und wird klar von Puer Nr. is Iu[l]ius Sa[t]yrus Dryan[tianus] unterschieden, der möglicherweise sein Bruder oder Cousin ist.

PuerLus Nr. 3: Pighi hatte dessen Namen als $[\cdots]$ s Regu[ $\cdots]$ ediert. Die Autopsie ergab ein $[\cdots] s$ Regillu[s]. Das Cognomen Regillus ist im Senatorenstand gut belegt, besonders unter der Nachkommenschaft von Annia Regilla, der Ehefrau von Herodes Atticus.

PuerLus Nr. 8: Die Buchstaben ROSC sind sehr markant nach einem vacat zu lesen. Zweifelsohne ist hier das Gentilicium Rosc[ius] zu ergänzen. Die Ergänzung lässt sich mit Hinweis auf XVvir Nr. I $5^{*}$ stützen, der möglicherweise der Vater von Puella Nr. 7 [Sa]lvia Postu[mia] Varia und mit einer Familie der Roscii verbunden war.

I I I Weiter oben ist ausgeführt, dass das von Pighi angenommene Cognomen Dryan[s] eher Dryan[ianus] lauten muss.

I 52 Das vacat zwischen $[\cdots$ S Jatyrus und $D o[\cdots]$ ist nicht groß genug, um von einem Zwischenraum zwischen zwei Nomenklaturen ausgehen zu können. 
PuerLus Nr. I I: Pighi hatte in Z. 3 I I zwei Pueri voneinander unterschieden:

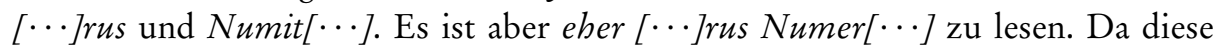
beiden Wörter nicht durch das bei der Aufzählung der PuerLus erhebliche vacat voneinander abgegrenzt sind, werden die beiden Namensteile einem einzigen $P u$ erLus zugeordnet. Das zweite Element des Cognomens ist möglicherweise $\mathrm{Nu}$ mer[ianus], obwohl auch Numerius als Cognomen in severischer Zeit belegt ist. Auf der anderen Seite fehlt das Gentilicium vollständig, ebenso das erste Cognomen. Damit lässt sich die Familie dieses Puer nicht identifizieren. ${ }^{\text {I53 }}$

PuerLus Nr. I3: Pighi hat diesen Teilnehmer des lusus Troiae als [...]ius Aper identifiziert. Eine Autopsie ergibt aber eher einen $\left[\cdot{ }_{13} \cdot{ }\right]$ nus Aper. Auch wenn der Hauptteil seiner Nomenklatur fehlt, bleibt das erhaltene Cognomen Aper interessant. Es taucht in der Familie des XVvir Nr. 3 Nonius Arrius Mucianus auf, der mit M. Nonius Arrius Paulinus Aper verwandt ist. ${ }^{154}$ Dieser wiederum war mit einer [Roscia?] Pacula verheiratet. Die Cognomina Mucianus und Paulinus, die im Namensbestand dieser Familie auftauchen, könnten das verstümmelte Cognomen $\left[\cdot{ }_{13} \cdot\right.$ nnus dieses PuerLus Nr. I 3 vervollständigen. Man kann davon ausgehen, dass PuerLus Nr. I 3 zu der Familie der Nonii gehörte und mit XVvir Nr. 3 verwandt war. ${ }^{155}$

PuerLus Nr. I7: Pighi hatte den Namen des Schriftstellers Sue[tonius] gelesen. Abgesehen von der Tatsache, dass in der zweiten Hälfte des 2. Jahrhunderts keine senatorischen Suetonii bekannt sind, ${ }^{156}$ ist der dritte Buchstabe größer als in der Inschrift üblich und trägt die typischen Eigenschaften eines $F$. Die Buchstabenfolge $S V F$ erlaubt, das Gentilicium Suf[enas] vorzuschlagen, das im Senatorenstand der antoninischen Zeit gut belegt ist. Bekannt ist ein P. Sufenas Verus, Prokonsul der Provinz Lycia et Pamphylia und Suffektkonsul im Jahr I32/I 33 n. Chr. ${ }^{157}$ Sein möglicher Sohn P. Suf[enas ...] war der Suffektkonsul von I 52 n. Chr. ${ }^{158}$ PuerLus Nr. I7 könnte ein entfernter Abkömmling dieser beiden Männer sein.

I53 Das Element Numerius ist im Namenbestand der Alfii belegt, die unter den Pueri und Puellae sehr präsent sind.

I 54 PIR $^{2} \mathrm{~N}$ iा 6.

I5s Das Cognomen Aper ist für einen wichtigen Zweig der Familie der senatorischen Flavii charakteristisch. Diese waren zweifelsohne mit den Nonii aus Brescia verbunden. Andererseits findet man das Cognomen Aper auch in der Familie von Septimius Severus: Ein Cousin des Vaters des Kaisers nannte sich P. Septimius Aper (PIR ${ }^{2} \mathrm{~S}$ 438), Suffektkonsul im Jahr I 53 n. Chr.; ein naher Verwandter der Dynastie war $C$. Septimius Severus Aper (PIR ${ }^{2}$ S 489), Konsul im Jahr 207 n. Ch.

I 6 Das Gentilicium Suetrius ist im Senatorenstand der severischen Zeit gut belegt; für die Buchstabenfolge SVE könnte es eine Alternative darstellen.

I $57 \mathrm{PIR}^{2} \mathrm{~S} 964$.

I 58 PIR $^{2}$ S 966. 
PuerLus Nr. 20: Die neue Lesart des Namens von PuerLus Nr. 20 als Flav/ius $\cdot 7 \cdot] c o[\cdots]$ anstelle von Flav [ius $\cdots]$ ce $[\cdots]$ bei Pighi verlangt eine Interpretation der beiden Buchstaben CO. Da sich an das Gentilicium Flavius eine Lücke von sieben Buchstaben anschließt, können zwei Vorschläge gemacht werden:

- Die Lücke von sieben Buchstaben enthielt ein erstes Cognomen und die Buchstaben $\mathrm{CO}$ gehörten als drittes Element zu einem weiteren Cognomen mit einer agnominalen Form wie CO[rnelianus]. Diese Hypothese ist vorzuziehen.

- Die Lücke von sieben Buchstaben umfasste ein sehr kurzes Cognomen mit einem folgenden Abstand. Die Buchstaben $\mathrm{CO}$ markierten dann den Beginn des Gentiliciums des nächsten Puer (der dann in die Liste aufgenommen werden müsste).

PuerLus Nr. 24: Eine neue Autopsie bringt den Gewinn eines weiteren Buchstabens $I$ nach der Buchstabenfolge OMIN. Es handelt sich hierbei entweder um das Gentilicium [C]omini[us] oder das Agnomen [C]omini[anus], was bereits Pighi in Erwägung gezogen hatte. Dieser Puer ist ein Verwandter der Cominii, einer senatorischen Familie, die mit der Stadt Concordia verbunden war.

PuerLus Nr. 26: Eine Autopsie ergibt für den von Pighi nicht mehr erkennbaren dritten Buchstaben ein $B$ und damit als Anfang eines Gentiliciums die Buchstabenfolge $B A B$. Dies ist der Buchstabenfolge $B A E$ vorzuziehen, da der dritte Buchstabe im oberen Teil deutlich eine Rundung nach rechts erkennen lässt. Das Gentilicium Bae[bius] wird somit ausgeschlossen und dem Gentilicium Baburius der Vorzug gegeben. ${ }^{159}$ Dadurch ist eine Annäherung an Puer Nr. 22 [Baburius

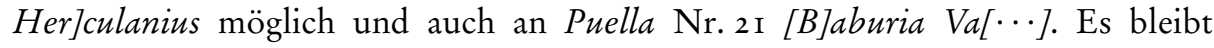
unsicher, ob dieser Puer im carmen saeculare mitgesungen und gleichzeitig auch an dem Reiterspiel des lusus Troiae teilgenommen hat. Wir haben bei Puer Nr.6, Alfius Avitus, und PuerLus Nr. 16, Alfius Maximus, gesehen, dass es sich um zwei verschiedene Pueri handelte.

Es ergeben sich demnach mögliche Verbindungen zwischen den Pueri, die am lusus Troiae teilnehmen und den XVviri sacris faciundis. Daneben können die PuerLus Brüder der Pueri und der Puellae des carmen saeculare gewesen sein. Nur für Ocratius Titianus kann man mit Sicherheit davon ausgehen, dass er an beiden Aktivitäten teilgenommen hat. Es ist möglich, dass andere, wie Claudius Pacatianus oder PuerLus Nr. 28, LICINI[us - Io e]Q. R. FIL., an carmen und lusus teilgenommen haben, aber die Beweise dafür fehlen.

I 59 Die Möglichkeit bestünde, da Puer Nr. 23 ein Baebius Marcellinus ist. 


\subsection{Der Aufbau der einzelnen Listen}

Nach diesen vorläufigen Beobachtungen, die noch nicht als vollständige Prosopografie gelten können, ist es dennoch möglich, Umrisse der Gruppen der Matronen und der Kinder zu definieren. Römische Rituale führen zu einem Konservativismus, der erlaubt, mit Hilfe des augusteischen commentarium das severische besser $\mathrm{zu}$ verstehen.

\section{a. Auswahlkriterien für die Teilnahme an den Riten}

Das augusteische commentarium liefert wertvolle Informationen über die Zahl, das Alter und die Bedingungen der Matronen, Pueri und Puellae, die einige Formulierungen im severischen commentarium erhellen.

\section{Matres familias}

Die an den Säkularspielen teilnehmenden Matronen werden im augusteischen und severischen commentarium auf verschiedene Weise definiert. Im augusteischen werden sie zweimal matres familiae ${ }^{160}$ und wahrscheinlich dreimal matres familias nuptae $^{161}$ genannt. Der Begriff matronae ${ }^{162}$ wird dreimal verwendet, einmal werden sie als feminae ${ }^{163}$ bezeichnet. Das augusteische commentarium erwähnt darüber hinaus das Mindestalter der Matronen von 25 Jahren. ${ }^{164}$ Außerdem wird an zwei $^{165}$ bzw. vier Stellen ${ }^{166}$ die Zahl der beteiligten Matronen mit i I 0 angegeben.

Das severische commentarium definiert die Matronen siebenmal einheitlich als Matronen. ${ }^{167}$ Ihre Zahl von $C X$ wird nicht verwendet; im Allgemeinen werden die Matronen als ro9 Begleiterinnen von Iulia Domna angegeben. ${ }^{168}$ Der senatorische Stand der Matronen wird nicht durch Attribute wie senatoriae oder clarissimae gekennzeichnet, dagegen werden die ritterlichen Matronen als equestres aufgeführt. ${ }^{169}$

I60 Act. Aug. 80, I09.

I6 I Act. Aug. I23. In Act. Aug. I25f. und izof. hat B. Schnegg diesen Ausdruck überzeugend ergänzt, siehe den Kommentar zur Textkonstitution der Act. Aug. zu diesen Stellen.

I62 Act. Aug. 78, Ior und I38.

I63 Act. Aug. 73.

I64 Act. Aug. I7.

165 Act. Aug. Ior und I23; hier ist die Zahl i io erhalten.

I66 Act. Aug. I 25 f. und I 30 f.; hier wurde die Zahl i ıo ergänzt.

I67 Act. Sev. 63, I06, I28, I 59, I60, I84, I 88.

I68 Act. Sev. I 28, I 59, I 84.

169 Act. Sev. I88: [Supplicaver(unt) m]ATRONAE am Anfang der Aufzählung der senatorischen Matronen; Act. Sev. 202: [E]QUESTRES am Anfang der Aufzählung der ritterlichen Matronen. 
Aus diesen Beobachtungen lassen sich einige Schlussfolgerungen ziehen:

- Es ist nicht mehr möglich zu erfahren, ob Livia I7 v. Chr. die Prozession der Matronen eröffnet hat, wie es Iulia Domna 204 n. Chr. tat. Die institutionelle Stellung der Kaiserin wurde in den 220 dazwischenliegenden Jahren immer klarer definiert. Im severischen commentarium ist für die Frau von Septimius Severus eine eigentliche Vorrangstellung belegt. Es stellt sich die Frage, welche Rolle für Domitia Longina an den domitianischen Säkularspielen vorgesehen war. ${ }^{170}$

- Laut dem augusteischen commentarium waren die beteiligten Frauen matres familiae. Man muss davon ausgehen, dass dies auch für die severischen Matronen der Fall war. Das bedeutet, dass sie zum Zeitpunkt der Säkularfeier Mütter lebender Kinder waren. Es bleibt offen, ob der Ausdruck mater familias impliziert, dass eine Frau Mutter von Kindern war, die noch nicht im heiratsfähigen Alter waren bzw. die toga virilis noch nicht angelegt haben, oder ob sich dieser Ausdruck auch auf Kinder beziehen kann, die bereits erwachsen sind.

- Unter Augustus mussten die teilnehmenden Matronen älter als 25 Jahre sein. Sie waren also spätestens 42 v. Chr. geboren. Entsprechend sollten die Matronen von 204 spätestens I79 n. Chr. geboren sein. Mütter, deren Kinder an der Zeremonie teilnahmen, mussten zwischen 25 und etwa 45 Jahre alt sein. Es lässt sich kaum klären, ob einige von ihnen älter waren. MatrSen Nr. I ist die Frau von XVvir Nr. 6, Ti. Manilius Fuscus, der das Konsulat um 195/6 n. Chr. bekleidete und zu dieser Zeit zwischen 32 und 35 Jahre alt war. Im Jahr 204 n. Chr. war er etwa 40 Jahre alt. Da römische Frauen jünger als ihre Männer sein können, lassen sich keine Schlussfolgerungen für das Alter einer Ehefrau ziehen. Es ist davon auszugehen, dass die Mehrheit der Matronen von 204 Zwischen I 64 und I 79 n. Chr. geboren wurden.

Das augusteische commentarium sieht vor, dass die Trauer der Matronen reduziert werden muss. ${ }^{171}$ Für 204 fand die Auswahl der Matronen bereits im Jahr 203 statt. Es ist nicht mehr auszumachen, ob diejenigen, die in der Zwischenzeit einen Trauerfall zu beklagen hatten, ausgeschlossen wurden. Eher ist davon auszugehen, dass Matronen in diesem Fall ihre Trauer verkürzen sollten, anstatt von der Ausübung der Riten ferngehalten zu werden.

\section{Kinder patrimi et matrimi}

Ebenso verdient die Darstellung der Kinder in beiden Dokumenten Aufmerksamkeit. Im augusteischen commentarium ist zweimal festgelegt, dass Jungen und Mädchen zum Zeitpunkt der Säkularspiele Vater und Mutter haben sollten, die

I 7088 n. Chr. war der Sohn von Domitian und Domitia Longina schon lange gestorben. Somit war diese während der ludi saeculares nicht mehr die Mutter eines lebenden Kindes. $\mathrm{Zu}$ dieser Kaiserin siehe Chausson (2003).

I7I Act. Aug. II I-I I4. 
beide noch lebten. ${ }^{172}$ In den commentaria werden die jeweils 27 Kinder Pueri oder Puellae genannt: Das augusteische commentarium erwähnt die Puellae einmal als virgines; im severischen commentarium verhindert eine Lücke in Z. 234 die Kenntnis der ursprünglichen Bezeichnung. ${ }^{173} \mathrm{~B}$. Schnegg ergänzt überzeugend nach dem augusteischen commentarium die wesentlichen Elemente patrimi et matrimi und die Anzahl von 27, die im fragmentarischen severischen commentarium nicht erscheinen. Im commentarium von 204 werden die Kinder immer Pueri und Puellae genannt. ${ }^{174}$ Die Pueri sind in Z. 260 vielleicht zweimal als senatores beschrieben. ${ }^{175}$

Wie bereits erwähnt waren einige der Kinder Söhne und Töchter der XVviri und/oder der beteiligten Matronen. Es scheint sinnvoll, diese Beziehung auszuweiten und davon auszugehen, dass die Mütter der 27 Pueri und 27 Puellae unter den 109 Matronen waren. Desgleichen ist es möglich, dass auch die Mütter der 40-50 Pueri, die beim lusus Troiae mitmachten, unter den rog Matronen waren. Da einige Pueri und Puellae Geschwister waren, muss die Zahl der Mütter dieser Kinder gegen 30 , eher noch gegen 40 gelegen haben. In jedem Fall gehörten sie ausschließlich dem Senatorenstand an. Diese Mütter von an den Säkularspielen teilnehmenden Kindern stellten etwa ein Drittel oder sogar die Hälfte der 9I senatorischen Matronen dar.

\section{Das Alter der Knaben}

Der im augusteischen commentarium gewählte Ausdruck pueri deutet darauf hin, dass die Knaben noch nicht die toga virilis angelegt hatten und noch nicht I4/I 5 Jahre alt waren. Die Mädchen, als puellae und virgines bezeichnet, waren noch nicht im heiratsfähigen Alter und sollten das Alter von I2/I 3 Jahren nicht überschritten haben.

Die Frage nach dem Alter der Kinder hängt damit zusammen, über welche Fähigkeiten sie verfügten. Sie mussten für den Vortrag des carmen saeculare vor dem Apollo-Tempel ohne ihre Mütter über Gesangsfähigkeiten, für das Reiterspiel des lusus Troiae über gewisse Reitfertigkeiten verfügen. Sueton weist auf Reitveranstaltungen unter Augustus hin, an denen pueri maiores und minores teilnahmen und die nicht ohne Unfallgefahr waren. Das genaue Alter erwähnt Sueton allerdings nicht. ${ }^{176}$ Es ist anzunehmen, dass die Knaben wegen der Unfallgefahr erfah-

I72 Act. Aug. 20: PVEROS VIRGINESQVE PATRIMOS MATRIM[osque · 3 I ·; entsprechend ergänzt in Act. Aug. I47.

I73 Act. Sev. $234 \mathrm{f}$.

I74 Act. Sev. 234f., 249, 25 If., 260.

I75 Die zwei letzten Pueri der Liste, ein Ritter und ein möglicher Sohn eines Ritters, wurden nicht wie die ritterlichen Matronen (Act. Sev. 202) durch eine allgemeine Überschrift, die ihre Nähe zum Ritterstand angibt, eingeführt.

I76 Sueton, Aug. 43, 2: Sed et Troiae lusum edidit frequentissime maiorum minorumque puerorum, prisci decorique moris existimans clarae stirpis indolem sic notescere. In hoc 
rene Reiter sein mussten ${ }^{177}$ und sehr bald die toga virilis erhalten konnten, was Sueton mit maiores bezeichnet.

Eine Schwierigkeit für die Chronologie bietet Puer Nr. I9, Cattius Clementinus. Er kann ohne Problem mit Sex. Catius Clementinus Priscillianus identifiziert werden, ${ }^{178}$ ordentlicher Konsul des Jahres 230 n. Chr. als Kollege von L. Virius Agricola. ${ }^{179}$ Wenn Cattius Clementinus einer konsularischen Familie angehörte, konnte er das Konsulat im Alter von 33/35 Jahren, im Jahr 230 erreichen. Er wäre also um I95/I97 n. Chr. geboren und im Jahr 204 zwischen sieben und neun Jahre alt gewesen.

ludicro Nonium Asprenatem lapsu debilitatum aureo torque donavit passusque est ipsum posterosque Torquati ferre cognomen. Mox finem fecit talia edendi Asinio Pollione oratore graviter invidioseque in curia questo Aesernini nepotis sui casum, qui et ipse crus fregerat (Er ließ sogar das Trojaspiel sehr häufig von größeren und kleineren Jungen aufführen, da er darin eine alte und ehrenvolle Sitte sah und glaubte, dass die Nachkommen einer berühmten Familie so bekannt würden. Bei einer solchen Veranstaltung war Nonius Asprenas zu Fall gekommen und dadurch ganz aus der Fassung gebracht worden; da beschenkte er ihn mit einer goldenen Halskette und erlaubte ihm persönlich und seinen Nachkommen, den Beinamen Torquatus zu führen. Bald aber hörte er auf mit Veranstaltungen dieser Art, weil sich der Redner Asinius Pollio im Senat heftig und voller Entrüstung darüber beklagte, dass sein Enkel Aeserninus gestürzt sei und sich sogar das Bein dabei gebrochen hätte). Nach diesen Unfällen beendete Augustus die lusus-Troiae-Veranstaltungen zwar nicht, sondern verzichtete nur auf ihre Häufigkeit, die groß gewesen sein könnte (edidit frequentissime).

I77 Es ist durchaus möglich, wie Véronique Boudon-Millot postuliert (der ich für den Hinweis auf diesen Text danke), dass eine medizinische Abhandlung, die in das galenische Corpus eingeflossen ist, aber ihrer Meinung nach in die severische Zeit zu datieren ist, das Karussell des lusus Troiae erwähnt; Pseudo-Galen, Thériaque à Pison

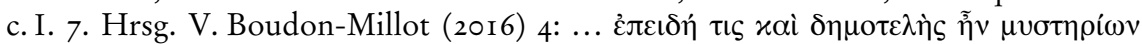

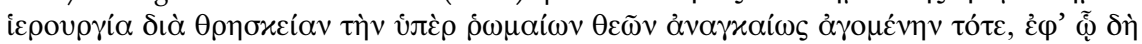

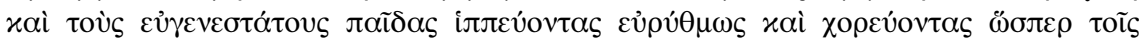

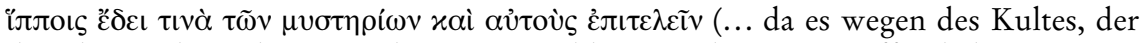
damals zu Ehren der römischen Götter obligatorisch war, ein öffentliches Mysterienfest gab, bei dem auch die Kinder der besten Familien, sozusagen im Rhythmus reitend und tanzend mit ihren Pferden, einige der Mysterien ausführen mussten). Es ist nicht ausgeschlossen, dass es sich um einen lusus Troiae handelt, der immer wiederkehrende ludi begleitet hat. Die Teilnahme der Kinder an den Mysterien der Feier erlaubt, ihre Rolle im Verlauf der Zeremonien zu bestimmen. Das Dokument betont die reiterliche Choreografie, die anspruchsvoll gewesen sein musste.

I78 PIR ${ }^{2}$ C 564. Dieses Kind ist vielleicht verwandt mit P. Catius Sabinus (PIR ${ }^{2}$ C 57I), Suffektkonsul der 200er-Jahre, curator aedium sacrarum im Jahr 2 10 n. Chr. zusammen mit Elius Romanus und Konsul II im Jahr 216, wahrscheinlich ein Günstling Caracallas.

I79 PIR $^{2}$ V 703. Es bleibt ungewiss, ob man diesen mit PuerLus Nr. 5, Virius [ $\cdots$ ] (PIR ${ }^{2}$ $\mathrm{V}$ 702), identifizieren kann, der ebenso im Patrizier L. Virius Lupus Iulianus ( $\mathrm{PIR}^{2} \mathrm{~V}$ 7I3) erkannt werden kann, ordentlicher Konsul im Jahr 232 n. Chr. 
Es ist daher anzunehmen, dass die singenden Pueri und Puellae um die Zeit der Bürgerkriege von 193-I97 n. Chr. geboren wurden. ${ }^{180}$ Möglicherweise waren einige von ihnen etwas älter und um 190-194 n. Chr. geboren worden, wie zum Beispiel die Pueri des lusus Troiae, die vielleicht auch in maiores und minores unterteilt waren.

Für die drei Säkularspiele können für das Alter der teilnehmenden Matronen und Kinder folgende Schlussfolgerungen gezogen werden (mögliche Zeitspanne der Geburten):

$$
\text { I7 v. Chr. (Augustus) } \quad 88 \text { n. Chr. (Domitian) } 204 \text { n. Chr. (Severus) }
$$

\begin{tabular}{llll}
\hline Matronae & $57-42$ v. Chr. & $48-63 \mathrm{n}$. Chr. & 164-179 n. Chr. \\
$\begin{array}{l}\text { Pueri } \\
\text { Puellae }\end{array}$ & $29-24$ v. Chr. & $76-8 \mathrm{I} \mathrm{n.} \mathrm{Chr.}$ & 192-197 n. Chr. \\
$\begin{array}{l}\text { Pueri des } \\
\text { lusus Troiae }\end{array}$ & $29-24$ v. Chr. & $76-8 \mathrm{I} \mathrm{n.} \mathrm{Chr.}$ & 192-197 n. Chr. \\
& $3 \mathrm{I}-27 \mathrm{v}$ v. Chr. & $74-78 \mathrm{n}$. Chr. & 190-194 n. Chr.
\end{tabular}

- Im Jahre I7 v. Chr. unter Augustus könnten die Matronen die Töchter der Protagonisten der Unruhen während der 4oer-Jahre gewesen sein und Ehefrauen der Teilnehmer an den Kämpfen der 3oer-Jahre. ${ }^{\text {I8I }}$ Die meisten der Kinder wurden in den 2oer-Jahren, im ersten Jahrzehnt des Friedens nach den Bürgerkriegen geboren.

- Unter Domitian waren die Matronen, die unter Claudius und Nero geboren wurden, auch Töchter oder sogar Ehefrauen der Akteure des Bürgerkriegs von 68-69 n. Chr., und sie gehörten zweifellos zu den Anhängern der von Vespasian und Titus belohnten partes Flavianae während der Zensur von 73-74 n. Chr. Diese dominierte das politische Leben unter den drei flavischen Kaisern. Die Kinder wurden unter Vespasian und Titus in der Zeit des wiederhergestellten Friedens geboren.

I80 Die römische rituelle Orthopraxie verlangte, dass der Gesang perfekt ausgeführt werden muss. Kinder unter sieben Jahren dürften dazu kaum in der Lage sein. Außerdem unterliegen Knaben in der frühen Adoleszenz dem Stimmbruch, die Knaben der ludi saeculares sangen aber mit den Mädchen und den Matronen zusammen, sodass ihre Stimmen wahrscheinlich keinen Kontrast zu den weiblichen darstellten. Bei Radio-France können Kinder und Jugendliche zwischen neun und fünfzehn Jahren um einen Master-Abschluss konkurrieren; an der Akademie von Santa Cecilia in Rom gibt es verschiedene Workshops für Kinder zwischen sechs und fünfzehn Jahren, wobei die allerjüngsten ohne Vorbildung antreten können. Das Alter von sieben Jahren scheint eine Mindestanforderung zu sein.

I 8 I Livia, geboren um 59/58 v. Chr., war im Jahr I7 Anfang vierzig, damit gehörte sie zu den älteren Matronen und war in der Tat Tochter und Frau von Protagonisten der Unruhen der 4oer- und 3oer-Jahre. Im Jahre I 7 war sie die Mutter von Tiberius, der 42 v. Chr. geboren und fünfundzwanzig Jahre alt war, und Drusus, 38 geboren und einundzwanzig Jahre alt. Diese waren also erwachsene Männer. 
- Im Jahre 204 n. Chr., unter Septimius Severus, waren die Matronen, die Iulia Domna $^{182}$ begleiteten, wie diese unter Marc Aurel geboren. Auch sie waren Töchter und Ehefrauen von Männern, die an den Bürgerkriegen der Jahre I93-I97 n. Chr. beteiligt waren. Es ist sehr wahrscheinlich, dass sie mit Familien verbunden waren, die sich den Interessen der severischen Dynastie verpflichtet fühlten. Der Kontext der Jahre 203-204 hätte durchaus verdient, unter dem politischen Vorzeichen der Versöhnung mit dem Senat, aber auch unter dem der Spannungen innerhalb des Kaiserhauses analysiert zu werden. Die Spannungen innerhalb des Kaiserhauses betrafen Plautianus ${ }^{183}$ und Geta, den Bruder von Septimius Severus, sowie Caracalla. Die an den Spielen teilnehmenden Kinder von 204 sind größtenteils während des Bürgerkriegs geboren.

\section{Die Familien der XVviri sacris faciundis}

Bei der Auswahl der Teilnehmer im Jahr 203 n. Chr. wurde den Familien der XVviri sacris faciundis ein besonderer Platz eingeräumt. MatrSen Nr. I ist die Frau des Magisters des Kollegiums im Jahr 203. Es ist sehr wahrscheinlich, dass andere Ehefrauen von XVviri zu den ro9 Matronen gehörten und wohl eher am Anfang der Liste der Matronen standen. Dies ist der Fall bei MatrSen Nr. 6, Ehefrau von XVvir Nr. 4*. Die Namen der MatrSen Nr. 5, 8, I 2, I9, 20 zeigen jedoch, dass die ersten Matronen der Liste noch lange nicht alle Frauen der zwanzig XVviri waren. ${ }^{184}$ Fünf der ersten sieben Pueri waren zweifelsohne Söhne von XVviri. Auch bei fünf der ersten acht Puellae war dies sicher der Fall. Mindestens ein Fünftel der Kinder, wenn nicht sogar ein Viertel oder gar ein Drittel, haben einen XVvir zum Vater, und es ist davon auszugehen, dass ihre Mütter unter den Io9 Matronen waren. ${ }^{185}$ Bei der Organisation der Zeremonie im Jahr 203 n. Chr. haben die $X$ Vviri sacris faciundis ihren Söhnen und Töchtern und in geringerem Maße auch

I 82 Iulia Domna, geboren gegen I65/I70 n. Chr., war im Jahr 204 Ende dreißig. Sie war die Mutter von Caracalla (geboren gegen i 86, also I 8 Jahre alt) und Geta (geboren I89, Is Jahre alt). Beide hatten zum Zeitpunkt der Säkularspiele bereits die toga virilis angelegt.

I 83 Es ist schwierig, die Beteiligung von nahen oder entfernten Verwandten der severischen Familie zu identifizieren. Es ist nicht ausgeschlossen, dass MatrSen Nr. 63 eine [Hort]ensia Polla Do[· $2 I \cdot]$ ist, die möglicherweise mit dem Sohn von Plautianus verwandt ist, der ein C. Fulvius Plautius Hortensianus war (PIR ${ }^{2}$ F 555 ).

I84 MatrSen Nr. Is ist die Ehefrau eines [A]vitus, der vielleicht mit XVvir Nr. I 8* identifiziert werden kann; es könnte sich bei diesem um einen [Alfius $\cdots$ Mate]rnus handeln, was jedoch alles andere als sicher ist.

I 85 So ist neben den Ehefrauen von Manilius Fuscus (XVvir Nr.6) und Calpurnius Maximus (XVvir Nr. $4^{*}$ ) auch die Anwesenheit der Frau von Salvius Tuscus (XVvir Nr. I I*), Mutter der Puella Nr. 7, außerdem der Frau von Nonius Arrius Mucianus (XVvir Nr. 3), Mutter der Puella Nr. 8, anzunehmen. Die Mütter der Pueri Nr. 2, 3 und 4 und Puella Nr. 5 könnten die Ehefrauen von Iulius Pompeius Rusonianus (XVvir Nr. 13), Cassius Pius Marcellinus (XVvir Nr. I5), Ofilius Macedo (XVvir Nr. 2*) und Gargilius Antiquus (XVvir Nr. I 2*) gewesen sein. 
ihren Frauen einen besonderen Platz eingeräumt. Dass die erste Matrone die Frau des Magisters des Kollegiums im Jahr der Vorbereitung der Feier ist, zeugt von der Bedeutung, die ihm für das Protokoll der Säkularspiele zukam. Man kann sich fragen, ob die Reihenfolge innerhalb der Gruppen bei den Prozessionen nicht so geregelt war, dass die Geschwister eine fast parallele Stellung zueinander einnahmen. Diese große Masse von Individuen (insgesamt einhundertachtzig Matronen und Kinder) sind vielleicht in zusammenhängenden, streng gegliederten Gruppen aufgetreten, in denen die Familien der XVviri eine besondere Sichtbarkeit erhielten. ${ }^{186}$ Es ist nicht ausgeschlossen, dass auch Schwestern oder Schwägerinnen, mit der Familie eines XVvir blutsverwandte oder angeheiratete Nichten ihren Platz innerhalb einer solchen Gruppe an der Prozession einnahmen. ${ }^{187}$

Außerdem stellt sich die Frage, ob bei der jährlichen Organisation mehrerer ludi und sacra in Rom die Kinder der Mitglieder des Kollegiums der XVviri sacris faciundis nicht regelmäßig eine Rolle gespielt haben, sobald Kinderlieder vorgetragen wurden, wie bei den ludi Palatini, oder ein Bedarf an jungen Assistenten während der Zeremonien bestand. Die commentarii der ludi saeculares würden somit Informationen über gewöhnliche und wiederkehrende Praktiken liefern, auch wenn dies hier im Rahmen einer außergewöhnlichen Zeremonie geschah.

\section{b. Eine Hierarchie unter den Ehemännern?}

In der Liste der ritterlichen Matronen gibt es Angaben der Ämter von tribuni oder primipilares, die von mindestens fünf Ehemännern ausgeübt werden (MaritEq Nr. Io० bis I05): Dies bedeutet, dass es in diesem Teil und wahrscheinlich in der gesamten Liste eine hierarchische Ordnung der Würde und des Aufstiegs in der ritterlichen Laufbahn gab, obwohl bei den Namen von zweien der ersten vier Ehemänner und zweien der letzten vier klar ist, dass bei ihnen keine Angabe eines Amtes folgen kann.

Es scheint, dass an die Namen der senatorischen Ehemänner keine Erwähnung eines Amtes oder Ranges angefügt war. Der sehr fragmentarische Zustand der Liste erlaubt keine Rekonstruktion der Karriereschritte jedes Mannes; es ist nicht möglich, eine absteigende Anordnung der Würde der Ehemänner zu erkennen, die derjenigen des album des Senats folgte. Aber eine solche Anordnung der einzelnen Gruppen könnte dennoch weitgehend befolgt worden sein.

I86 Vielleicht kann man sogar so weit gehen, zu spekulieren, dass die Prozession in mehrere Kolonnen eingeteilt war, die jeweils von der Frau eines XVvir angeführt wurde. Damit würde den Frauen der Mitglieder des ausrichtenden Priesterkollegiums im Ablauf der Zeremonien eine wichtige Rolle zugeteilt sein, die ihrer herausgehobenen Position im Protokoll der ludi saeculares entspricht.

I 87 Beim Stand der Bearbeitung ist es unmöglich zu wissen, ob XVvir Nr. I6, Vlpius Soter, mit MaritSen Nr. 84, Vlpius Antonin[us], der aus Prusias ad Hypium in Bithynien stammte, verwandt war oder mit MaritSen Nr. 83, Vlpius Pompeian[us]. 
Iulia Domna steht protokollarisch an erster Stelle; die Frau des Magisters der XVviri von 203 n. Chr. folgt ihr, während die Gruppe der ritterlichen Matronen von Iulia Domnas eigener Nichte, Iulia Suemias Bassiana, angeführt wird. Diese verdankt ihre Position nicht dem Rang ihres Mannes, der allerdings in der ritterlichen Hierarchie ganz oben stand und wahrscheinlich auch unter den Männern der hier erwähnten ritterlichen Matronen, sondern ihrer engen Beziehung zur Ehefrau des Kaisers. ${ }^{188}$ Bei der Erstellung der Liste können verschiedene Überlegungen eine Rolle gespielt haben: der Rang des Mannes, insbesondere seine $\mathrm{Zu}-$ gehörigkeit zum Kollegium der XVviri, Allianzen mit den Familien der XVvi$r r^{189}$ und die Verwandtschaft mit verschiedenen Zweigen der kaiserlichen Familie aus Lepcis Magna und Emesa. Jede weitere prosopografische Untersuchung muss diese Kriterien anpassen und zusammenführen.

Es ist nicht ausgeschlossen, dass verschiedene Matronen die Ehefrauen von Mitgliedern anderer Priesterkollegien sind. So ist MatrSen Nr. 20, Magia [ $\cdots$ ], zweifellos die Ehefrau eines Mauricus, den man mit dem Pontifex M. Valerius Bradua Mauricus ${ }^{190}$ von Albenga identifizieren kann. Dieser Pontifex ist mit einem anderen Pontifex, Q. Virius Egnatius Sulpicius Priscus, ${ }^{191}$ verwandt, der unter Caracalla als Konsul belegt ist; PuerLus Nr. 5 ist ein Virius. Die Zeremonie könnte so vor allem die Teilnahme von Kindern oder Ehefrauen der öffentlichen Priester Roms einbeziehen.

\section{c. Onomastische Parallelen und Endogamie innerhalb des senatorischen Standes}

Trotz des besonders schlechten Erhaltungszustands hinterlässt die Liste der senatorischen Matronen einen starken Eindruck von Beziehungen zwischen den Namen der Ehefrauen, den Namen der Ehemänner, den Namen der Pueri und Puellae, als ob diese verschiedenen Gruppen eine einzige, sehr homogene Gruppe bildeten. Eine erste Erklärung liegt darin, dass die Mütter der Kinder an der Prozession anwesend sind und dass mindestens ein Fünftel der Kinder einen $X$ Vvir zum Vater hat. Die leider weitgehend verlorenen Namen von den 9I senatorischen Ehemännern der 9r senatorischen Matronen stellten etwa ein Sechstel der Mitglieder des Senats dar. ${ }^{192}$ Diese Einbeziehung von Senatoren erhöht sich

I 88 Inlia Suemias Bassiana war mindestens fünfundzwanzig Jahre alt, also spätestens 179 n. Chr. geboren. Sie war damit deutlich älter als ihre beiden Cousins Caracalla und Geta, die I 86 bzw. I 89 geboren wurden. Es ist denkbar, dass ihre Mutter Iulia Maesa um I 59 n. Chr. und Iulia Domna um I66 n. Chr. geboren wurden.

I 89 MatrSen $\mathrm{Nr}$. I3, eine $\operatorname{Ve}\left[\cdot{ }_{16} \cdot\right]$, könnte eine Ve[ttia] sein, aber auch eine Verwandte des XVvir Nr. 17, Venidius Rufus, oder des XVvir Nr. 19*, Vetina Mamertinus.

I90 PIR $^{2} \mathrm{~V} 48$.

I9I $\mathrm{PIR}^{2} \mathrm{~V} 706$.

I92 Einige dieser Ehemänner waren auch XVviri, insofern sie weder verwitwet noch geschieden waren und Kinder hatten. 
durch die große Anzahl von anderen Angehörigen von Senatoren unter den Matronen wie zum Beispiel Schwestern, Nichten, Cousinen etc. Bei einer solchen Ballung von Mitgliedern der senatorischen Schicht wird die Endogamie, ein Charakteristikum des Senatorenstandes, sehr deutlich, besonders wenn - wie hier - die Beteiligten noch ziemlich jung sind. Eine Matrone kann eine Schwester, Nichte oder Cousine eines senatorischen Ehemannes sein; ${ }^{193}$ zwei Matronen können Schwestern oder Cousinen sein. ${ }^{194}$

Eine soziale Erklärung, die auf der Endogamie basiert, sollte von einer politischen Interpretation der Listen begleitet werden. Daneben spielte der religiöse und protokollarische Aspekt der ludi saeculares eine Rolle, wodurch den Familien der $X$ Vviri besondere Präsenz geboten wurde. Das Prestige und der außergewöhnliche Charakter der Zeremonie machten die Teilnahme zu einer Ehre für die Familien, von denen mehrere Mitglieder an den Auftritten und Prozessionen teilnehmen konnten. Diejenigen, deren Frauen und Kinder ausgewählt wurden, genossen als Verbündete oder politische Unterstützer in den Bürgerkriegen unbestreitbar die kaiserliche Gunst. Spuren dieser Auseinandersetzungen waren im Senat immer noch erkennbar. Elf und sieben Jahre zuvor musste sich jeder Senator für eine Seite entscheiden oder versuchen, eine ausgewogene Position zwischen den verschiedenen Konkurrenten um die höchste Macht zu halten. Das politische Leben sowohl innerhalb als auch außerhalb der Dynastie war weiterhin von Spannungen geprägt. Die Politik der Versöhnung mit dem Senat zwang den Kaiser weiterhin, Zugang zu Ehrungen zu verschaffen. Es besteht kein Zweifel daran, dass die Teilnehmer der Zeremonien entsprechend den engen Beziehungen ihrer Familien und denen ihrer Ehemänner ausgewählt wurden.

Das Dokument enthält die Namen der aktiven Teilnehmer sowie die beiden Vestalinnen, die an der Seite der XVviri anwesend sind. Offenbar sollten die Zeremonien die senatorische Aristokratie mobilisieren. Möglicherweise waren auch die anderen Vestalinnen öffentlich sichtbar, zweifellos aber die Mitglieder der großen Priesterkollegien (pontifices, flamines, angures, VIIviri epulonum). Auch weitere Mitglieder der kaiserlichen Familie dürften bei den Zeremonien zugegen gewesen sein: Plautianus' Tochter, Fulvia Plautilla, Augusta seit ihrer Verlobung mit Caracalla im Jahr 20I n. Chr.; die Hochzeit fand im darauffolgenden Jahr statt. Sie war unter fünfundzwanzig Jahre alt. Mit Sicherheit kann sie nicht eine der Io9 Matronen gewesen sein, die Iulia Domna begleiteten, ${ }^{195}$ war aber wahrscheinlich

193 Siehe die zwei Homonyme von MaritSen Nr. I9, [P]ontius Paulinus, und der MatrSen Nr. 32, [P]ontia Paulina.

I94 Zum Beispiel die MatrSen Nr. 79, Inlia Taria Strat[o]nice, und die MatrSen Nr. 89, Ta[ri]a Cornelia Asiana.

I95 Der Name von MatrSen Nr. I, Fl. Pollitta, ist erhalten, sie war die Ehefrau des Magisters des Kollegiums der XVviri im Jahr 203 n. Chr., Manilius Fuscus. Aus offensichtlichen protokollarischen Gründen hätte MatrSen Nr. I nicht vor der $A u$ gusta Plautilla genannt sein können. 
im Publikum anwesend. Sie dürfte nicht die einzige Frau der kaiserlichen Familie gewesen sein, die an den Feierlichkeiten teilnahm. Es ist anzunehmen, dass sich nicht weit von ihr entfernt Iulia Domnas Schwester Iulia Maesa befand, die Mutter von MatrEq Nr. I, Iulia Suemias Bassiana. ${ }^{196} \mathrm{Zu}$ deren Begleitung gehörte wahrscheinlich auch ihre andere Tochter Inlia Mamaea, die Mutter des späteren Kaisers Severus Alexander. ${ }^{197}$ Wahrscheinlich waren Mitglieder der Zweige der severischen Dynastie aus Lepcis Magna und Emesa mit ihren Ehepartnern anwesend. Ebenso ist davon auszugehen, dass die im Jahr 204 in Rom amtierenden Magistrate wie Quästoren, Volkstribune, Ädile, Prätoren, Konsuln und Konsulare etc. den Feiern beigewohnt haben. Die Listen der Matronen, Pueri und Puellae sollten nur die Namen der Personen nennen, die an den Zeremonien eine aktive Rolle spielten.

\subsection{Fazit}

Die in der severischen, vielleicht schon in der domitianischen Zeit getroffene Entscheidung, die Namen der Matronen und ihrer Ehemänner, der Pueri und Puellae in einer gut lesbaren Höhe auf den cippus zu gravieren, zeugt von dem Willen zur Erinnerung, der die Aufzeichnung des commentarium begleitete. Im Laufe des ganzen 3. Jahrhunderts konnten die Familien, deren Mitglieder an der Zeremonie der ludi saeculares teilgenommen hatten, ihre Namen lesen und eine Erinnerung an den Ruhm der Familie bewahren. ${ }^{198}$

I96 Inlia Suemias Bassiana muss im Jahr 204 n. Chr. älter als 25 Jahre alt und Mutter eines Kindes gewesen sein. Sie war somit vor $179 \mathrm{n}$. Chr. geboren und hatte einen beträchtlichen Altersunterschied zu ihren Cousins Caracalla und Geta, die i 86 und I 89 geboren wurden. Ihre Mutter muss spätestens um I 59 n. Chr. geboren sein, zweifelsohne war Iulia Domna ihre ältere Schwester.

I97 Vor ihrer Wiederverheiratung mit dem Ritter Gessius Marcianus aus Caesarea Arca, war Iulia Mamaea mit einem bisher unbekannten Senator verheiratet. Sollte sie im Jahr 204 älter als 25 und Mutter eines Kindes gewesen sein (Severus Alexander wurde erst gegen 208 n. Chr. geboren), könnte sie wie ihre Schwester eine der Matronen gewesen sein; ein Beweis dafür fehlt allerdings.

I98 Der außergewöhnliche Charakter der Feier muss Spuren in den Köpfen der Menschen hinterlassen und ihre Erinnerungen stark geprägt haben. Christol (20I4) I43I 58 konnte zeigen, dass P. Cornelius Saecularis, Präfekt der Stadt in den Jahren 258-260 n. Chr. und zum zweiten Mal Konsul im Jahr 260, ein möglicher Verwandter von Cornelia Salonina, der Ehefrau von Gallienus und Förderer der Herrschaft von Valerianus, etwa um 203-204 n. Chr. geboren sein kann, mit Sicherheit zum Zeitpunkt der ludi saeculares. Von daher erhielt er sein Cognomen. - Iulia Suemias Bassiana (MatrEq Nr. I), Ehefrau von Sex. Varius Marcellus, hat ihren Sohn Bassianus, den späteren Kaiser Elagabal, ebenfalls gegen 203-204 n. Chr. geboren. Sie hatte jedoch noch andere Kinder (wahrscheinlich Töchter), die 2 I7/2 I 8 (dazu Chausson (1997) 659-690) noch am Leben waren und vielleicht vor 204 n. Chr. geboren wurden. Es kann nicht davon ausgegangen werden, dass die Geburt ihres Sohnes Bassianus vor Juni 204 ihre Anwesenheit an den ludi saeculares als mater familias 
Dieser Kommentar wurde sicher im Kollegium der XVviri sacris faciundis, den Durchführenden der Zeremonien, verfasst. Es ist vernünftig anzunehmen, dass der Magister von 204 n. Chr., XVvir Nr. I3, der wahrscheinliche Lepcitaner Iulius Pompeius Rusonianus, die Abfassung in den Wochen oder sogar Monaten nach den ludi saeculares beaufsichtigt hat, in einem Kontext, der gegen Ende des Jahres schwieriger wurde. ${ }^{199}$ Die Ausführung der Gravur konnte mehrere Wochen in Anspruch nehmen. In allen Phasen ihrer Umsetzung spiegelt die Inschrift die religiöse und politische Atmosphäre der Jahre 203-205 n. Chr. wider.

Der hohe cippus wurde dann aufgerichtet, jedoch nicht vergraben und in zugänglichen Teilen des Heiligtums im Tarentum aufgestellt. Verschiedene Fragmente, eines mit einem claudischen Buchstaben, ein anderes mit einer Liste männlicher Namen, wurden im gleichen Gebiet gefunden wie die Fragmente der augusteischen und severischen Acta. Diese Fragmente, die zu einem späteren Zeitpunkt untersucht werden sollen, finden in den augusteischen und severischen Dokumenten keine Aufnahme. Das offensichtlich claudische Fragment könnte zu einem Kommentar über die Feierlichkeiten zum 800. Jahrestag Roms, den sfalschen ludi saeculares, gehört haben, die Claudius $47 \mathrm{n}$. Chr. veranstaltete. ${ }^{200}$ Es könnte also sein, dass die Jubiläumsfeiern von Rom (unter Claudius im Jahr 47 n. Chr., unter Antoninus Pius I 48 n. Chr., unter Philippus Arabs 248 n. Chr.) im Zusammenhang mit den Säkularfeiern zumindest teilweise in demselben Gebiet stattgefunden hätten. ${ }^{201}$ Ihre Durchführung wäre dann von ähnlichen Kommentaren dokumentiert worden, die in demselben Heiligtum aufgestellt wurden, in dem die Kalkbrenner sie später gefunden und zerschlagen hätten.

In diesem Kapitel wurde eine erste prosopografische Lesung der severischen Säkularakten durchgeführt, mit dem Ziel, die Zusammenhänge zwischen den verschiedenen Gruppen hervorzuheben. Dazu zählen die bestimmende Rolle der XVviri sacris faciundis bei der Ausübung der Riten und ihrer Familien durch die aktive Teilnahme ihrer Frauen und Kinder an der Zeremonie. ${ }^{202}$ Der nächste Schritt

garantierte und die Zeitspanne der Geburt des zukünftigen Kaisers verfeinert werden kann.

I99 P. Septimius Geta starb 204 n. Chr., nachdem er die Machenschaften von Plautianus bei seinem Bruder, dem Kaiser, angeprangert hatte. Plautianus wurde am 22. Januar 205 n. Chr. nach einer Familienkrise, die die kaiserliche Familie 204 und 205 belasten sollte, ermordet. Es ist nicht ausgeschlossen, dass die XVviri, für die eine lepcitanische Herkunft wahrscheinlich ist, XVvir Nr. I3, Iulius Pompeius Rusonianus, und $X$ Vvir Nr. 20, Fulvius Fuscus Granianus (ein naher Verwandter des Letzteren), von diesen Wechselfällen stark betroffen waren.

200 Schnegg-Köhler (2018) I $34 \mathrm{f}$.

$20 \mathrm{I}$ Es ist jedoch unwahrscheinlich, dass der unterirdische Teil des Tarentum während der ı०0-Jahr-Feiern geöffnet wurde. Seit der 900-Jahr-Feier unter Antoninus Pius spielte der Tempel der Venus und Roms, auch Templum Vrbis genannt, eine große Rolle in der Erwähnung des dies natalis der Stadt Rom.

202 Damit bietet sich auch ein Interpretationsmodell für die mögliche Beteiligung der 
ist die Veröffentlichung einer umfassenden Prosopografie der im commentarium vorhandenen Personen. Dieses Buch wird ermöglichen, die hier identifizierten Grundzüge zu verfeinern und $\mathrm{zu}$ nuancieren. Es war in diesem Kapitel nicht möglich, alle Verästelungen der Beziehungen zwischen den Teilnehmern des Senats oder des Ritterstandes zu entwickeln. Für die vorliegende Edition ist es jedoch wichtig, die neuen Lesungen und die Begründungen für neue Ergänzungen zusammenzufassen. Zukünftige Arbeiten, die bereits fortgeschritten sind, werden ein genaues Bild von den prosopografischen Problemen dieses außergewöhnlichen Dokuments vermitteln. ${ }^{203}$

Söhne der XVviri als camilli an anderen Zeremonien, die von demselben Kollegium organisiert wurden, so wie die pueri patrimi und matrimi, die die Arvalbrüder bei bestimmten Ritualen unterstützten.

203 Mein herzlicher Dank gilt John Scheid, der mir die Zusammenarbeit an diesem schönen Projekt vermittelt hat. Dabei war die Unterstützung von Thomas Späth unerlässlich, auch ihm sei an dieser Stelle gedankt. Die jahrelange Zusammenarbeit mit Bärbel Schnegg-Köhler war intellektuell, wissenschaftlich und menschlich eine nicht versiegende Quelle der Freude. Im Museo Nazionale Romano hat die Unterstützung von Rosanna Friggeri und ihrer Nachfolgerin Daniela Porro, sowie die unermüdliche Hilfsbereitschaft von Carlotta Caruso es ermöglicht, das Projekt voranzutreiben. Die Abfassung dieses Kapitels wurde wohlwollend durch den Rat von Antony Alvarez Melero, Anne-Florence Baroni, Véronique Boudon-Millot, Maria Letizia Caldelli, Michel Cristol, Werner Eck, Patrice Faure, Domenico Palombi, Marie-Thérèse Raepsaet-Charlier, Benoît Rossignol, Françoise Van Haeperen begleitet. Auch die moralische Unterstützung von Alfredo Buonopane, Francesca Cenerini, Giovanella Cresci Marone, Silvia Orlandi und Cecilia Ricci soll nicht unerwähnt bleiben. 